\title{
Dexmedetomidine as anesthetic adjuvant : cardiovascular and anesthetic effects in animals and humans
}

Citation for published version (APA):

Lawrence, C. J. (1998). Dexmedetomidine as anesthetic adjuvant : cardiovascular and anesthetic effects in animals and humans. [Doctoral Thesis, Maastricht University]. Universiteit Maastricht. https://doi.org/10.26481/dis.19980326cl

Document status and date:

Published: 01/01/1998

DOI:

10.26481/dis.19980326cl

Document Version:

Publisher's PDF, also known as Version of record

\section{Please check the document version of this publication:}

- A submitted manuscript is the version of the article upon submission and before peer-review. There can be important differences between the submitted version and the official published version of record.

People interested in the research are advised to contact the author for the final version of the publication, or visit the DOI to the publisher's website.

- The final author version and the galley proof are versions of the publication after peer review.

- The final published version features the final layout of the paper including the volume, issue and page numbers.

Link to publication

\footnotetext{
General rights rights.

- You may freely distribute the URL identifying the publication in the public portal. please follow below link for the End User Agreement:

www.umlib.nl/taverne-license

Take down policy

If you believe that this document breaches copyright please contact us at:

repository@maastrichtuniversity.nl

providing details and we will investigate your claim.
}

Copyright and moral rights for the publications made accessible in the public portal are retained by the authors and/or other copyright owners and it is a condition of accessing publications that users recognise and abide by the legal requirements associated with these

- Users may download and print one copy of any publication from the public portal for the purpose of private study or research.

- You may not further distribute the material or use it for any profit-making activity or commercial gain

If the publication is distributed under the terms of Article 25fa of the Dutch Copyright Act, indicated by the "Taverne" license above, 
Dexmedetomidine as Anesthetic Adjuvant 
(C) Christopher J. Lawrence, Maastricht 1998 ISBN $90-9011408-4$

Vormgeving: James Lawrence

Druk: Datawyse I Universitaire Pers Maastricht Omslag illustratie: Elizabeth Lawrence, "Pauw" 


\title{
Dexmedetomidine as Anesthetic Adjuvant
}

\section{Cardiovascular and anesthetic effects in animals and humans}

\author{
PROEFSCHRIFT
}

ter verkrijging van de graad van doctor aan de Universiteit Maastricht, op gezag van de Rector Magnificus,

Prof. dr. A.C. Nieuwenhuijzen Kruseman, volgens het besluit van het College van Decanen,

in het openbaar te verdedigen

op donderdag 26 maart 1998 om 16.00 uur door

Christopher J. Lawrence

geboren te Tunbridge Wells, Engeland 


\section{Promotor:}

Prof. dr. S. de Lange

\section{Co-promotor:}

Dr. F. W. Prinzen

\section{Beoordelingscommissie:}

Prof. dr. R. S. Reneman (voorzitter)

Prof. dr. W. E. Flacke (University of California, Los Angeles)

Prof. dr. P. W. de Leeuw

Prof. dr. P. B. Soeters

Prof. dr. H. A. J. Struijker Boudier

Financial support by the Department of Anesthesiology of the University Hospital of Maastricht for the publication of this thesis is gratefully acknowledged. 
For Gordana, in gratitude, love and respect 
By doubting we are led to enguire;

By enquiry we perceive the truth.

Pierre Abelard, 12 th century

Sownething unknown is doing we don't know what.

Sir Arthur Eddington

There is in us somerhing wiser than our head.

Arthur Schopenhauer 


\section{Contents}

CHAPTER 1

Introduction

1.1 Aims of the studies. . . . . . . . . . . . . . . . . . . . . . 2

\section{CHAPTER 2}

Pharmacology of the $\alpha_{2}$-adrenergic receptor - a review of the literature 5

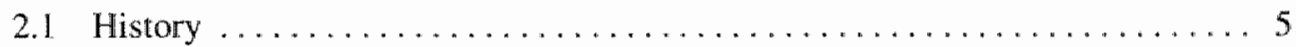

2.2 Molecular pharmacology.............................. 5

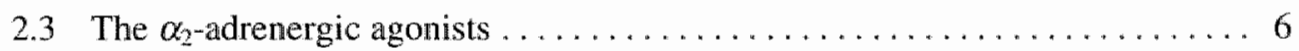

Clonidine ................................ 6

Dexmedetomidine............................. 7

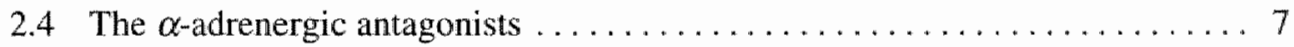

2.5 Central nervous system sites involved in the $\alpha_{2}$-adrenoceptor-mediated antihypertension and bradycardia $\ldots \ldots \ldots \ldots \ldots \ldots \ldots \ldots$

2.6 Imidazoline receptors. . . . . . . . . . . . . . . . . . . . 9

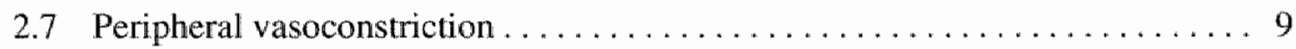

2.8 Hemodynamic effects of $\alpha_{2}$-adrenergic receptor agonists $\ldots \ldots \ldots \ldots \ldots 10$

Cardiac function. ............................... 10

2.9 Organ blood tlow $\ldots \ldots \ldots \ldots \ldots \ldots \ldots \ldots \ldots \ldots \ldots \ldots \ldots \ldots \ldots \ldots \ldots \ldots$

Myocardial blood flow..............................

Cerebral blood flow................................

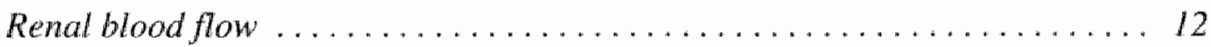

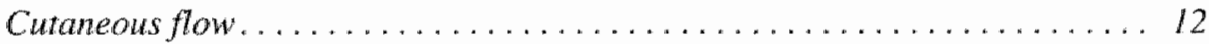

CHAPTER 3

Anesthetic effects of $\alpha_{2}$-adrenergic receptor agonists - a review of the literature $\quad 19$

3.1 Sedation and anxiolysis . . . . . . . . . . . . . . . . . . . . 19

3.2 Reduction of anesthetic requirements. . . . . . . . . . . . . . 20

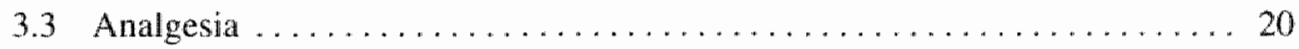

3.4 Reduction in oxygen uptake and shivering $\ldots \ldots \ldots \ldots \ldots \ldots \ldots \ldots \ldots \ldots$ 


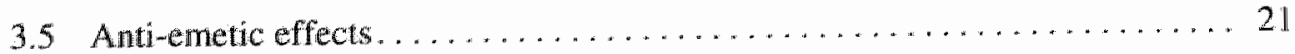

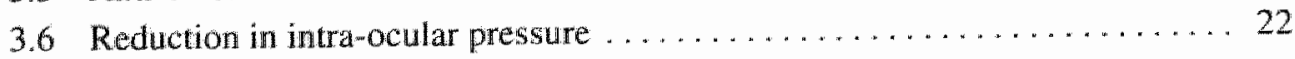

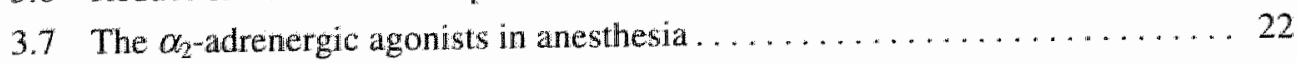

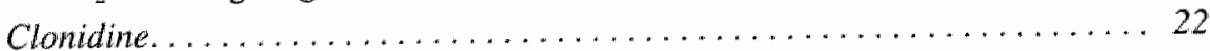

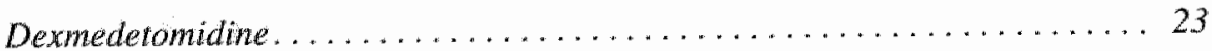

CHAPTER 4

Comparison of the hemodynamic and coronary vascular effects of

dexmedetomidine and clonidine in the anesthetized dog

\section{CHAPTER 5}

The effect of dexmedetomidine on the balance of myocardial energy requirement and oxygen supply and demand

\section{CHAPTER 6}

The effect of dexmedetomidine on nutrient organ blood flow

\section{CHAPTER 7}

Hemodynamic and coronary vascular effects of dexmedettomidine in the anesthetized goat

\section{CHAPTER 8}

Effects of a single pre-operative dexmedetomidine dose on isoflurane requirements and peri-operative hemodynamic stability

\section{CHAPTER 9}

General discussion

9.1 Cardiovascular effects . . . . . . . . . . . . . . . . . . . . . . . 89

9.2 Vascular effects ................................. 89

9.3 Coronary vasoconstriction. . . . . . . . . . . . . . . . . . . . . 90

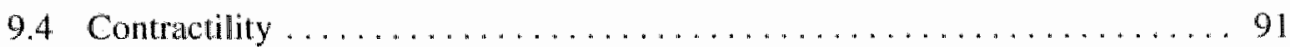

9.5 Nutrient organ flow . . . . . . . . . . . . . . . . . . . . . . 91

9.6 Advantages as an anesthetic adjuvant in humans ............... 92

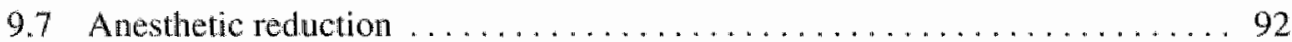

9.8 Analgesia and anti-emetic effect...................... 92

9.9 Sympatholysis . . . . . . . . . . . . . . . . . . . . . . 93

9.10 Effects on ischemic myocardium ..................... 93

9.11 Conchusions ................................ 94 
Summary

Samenvatting 101

Acknowledgments 105

Curriculum Vitae 107

List of Publications 109 


\section{CHAPTER 1}

\section{Introduction}

In the early days of anesthesia a single agent such as ether was used to provide surgical anesthesia. High doses of this single agent were often required, resulting in delayed recovery and persistent nausea and vomiting. In modern, so-called 'balanced' anesthesia the total dose of anesthetic agent is reduced by using separate agents to provide the triad of sleep, pain relief, and muscle relaxation. By balancing the agents used, side-effects can be reduced and the quality of post-operative recovery improved. In addition, sedative drugs may be used as premedicants or adjuvants to further reduce the dose of the primary anesthetics. Benzodiazepines are frequently used in this context.

To further improve the quality of anesthesia, anesthesiologists have become interested in $\alpha_{2}$-adrenergic receptor agonists since these agents have been shown to have an interesting combination of effects: sedation $[1,2]$, anxiolysis $[3,4]$, reduction of anesthetic requirements $[5,6]$, and improved hemodynamic stability in the perioperative period [7-9]. In addition, they provide analgesia which is not mediated via opiate receptors [10] and which is not associated with respiratory depression [11]. In veterinary anesthesia, $\alpha_{2}$-adrenergic receptor agonists were introduced as sedatives and anesthetic adjuvants in the $1980^{\circ}$ s and are now commonly used in this field [12-15].

Clonidine, an $\alpha_{2}$-adrenergic agonist, which was first introduced into clinical use 25 years ago as an anti-hypertensive agent, has been extensively studied as a potential anesthetic adjuvant in a variety of settings including aortic and coronary artery surgery [7-9,16-18]. Dexmedetomidine is one of the second generation of $\alpha_{2}$-adrenergic agonists, and is a full agonist with a high selectivity for the $\alpha_{2}$-adrenergic receptor (1600:1 $\alpha_{2}: \alpha_{1}$, compared to 200:1 for clonidine) [19,20]. It has been shown to possess a greater anesthetic-sparing effect than clonidine in animals [21], and to have sedative [22] and hemodynamic stabilizing effects in human volunteers [23].

While these properties suggested promising anesthetic possibilities for selective $\alpha_{2}$ agonists like dexmedetomidine, studies in animals showed cardiovascular effects which might be undesirable in a potential anesthetic adjuvant: Flacke et al. demonstrated the high vasoconstrictive potency of dexmedetomidine [24], and Heusch 
and his coworkers indicated that $\alpha_{2}$-adrenergic receptor stimulation could under certain conditions ellicit myocardial ischemia $[25-27]$.

\subsection{Aims of the studies}

In order to test the hypothesis that dexmedetomidine can be beneficially and safely used during anesthesia in healthy adults we developed two main aims:

1. Evaluation of the cardiovascular effects of dexmedetomidine in animals

2. Evaluation of dexmedetomidine as an anesthetic adjuvant in man

To the first purpose we designed the following studies:

- Comparison of the systemic and coronary hemodynamic effects of dexmedetomidine with those of clonidine in dogs (Chapter 4)

- The effects of dexmedetomidine on the balance of myocardial oxygen supply and demand (Chapter 5)

- The effect of dexmedetomidine on nutrient blood supply to the major organ systems (Chapter 6). As anesthesia may interact with the effects of dexmedetomidine, two different anesthetic techniques were used in these canine studies.

- The hemodynamic and coronary effects of dexmedetomidine in goats (Chapter 7). This study was designed to ascertain whether species is important.

To the second purpose a double-blind placebo-controlled study was designed to investigate the potential benefits of dexmedetomidine when given as a single intravenous dose prior to minor surgery in healthy patients (Chapter 8).

\section{References}

I Scheinin M, Kallio A, Koulu M, Viikari J. Scheinin H. Sedutive and cardiovascular effects of medetomidine, a novel selective alpha 2 -adrenoceptor agonist, in healthy volunteers. $\mathrm{Br}$ I Clin Pharmacol 1987; 24: 443-51.

2 Vaha VT. Clinical evaluation of medetomidine, a novel sedative and analgesic drug for dogs and cats. Acta Vet Scund 1989; 30: 267-73.

3 Redmond D. Does clonidine alter anxiety in humans? Trends Pharmacol Sci 1982; 3: 477-80.

4 Hoehw-Saric R, Merchant A, Keyser M, Smith V. Effects of clonidine on anxiety disorders. Arch Gen Psychialry 1981: 38: 1278-82.

5 Aantaa $R$. Kanto J, Scheinin $M$, Kallio A, Scheinin $H$. Dexmedetomidine, an alpha 2adrenoceptor agonist, reduces anesthetic requirements for patients undergoing minor gynecologic surgery. Anesthesiology 1990; 73: 230-5,

6 Bloor $\mathrm{BC}$. Flacke WE, Reduction in halothane anesthetic requirement by clonidine, an alphaadrenergic agonist. Anesth Analg 1982; 61:74 -5.

7 Ghignone $M$, Quintin $L$, Duke $P$, Kehler $C$, Calvillo $O$. Effects of clonidine or narcotic requinements and hemodynamic response during induction of fentanyl anesthesia and endotracheal intubation. Anesthesiology 1986: 64: 36-42. 
8 Ghignone M, Calvillo O, Quintin L. Anesthesia and hypertension the effect of clonidine on perioperative hemodynamics and isoflurane requirements. Anesthesiology 1987:67:3-10.

9 Facke $\mathrm{J}$, Bloor $\mathrm{B}$. Flacke $\mathrm{W}$, et al. Reduced narcotic requirement by clonidine with improved hemodynamic and adrenergic stability in patients undergoing coronary bypass surgery. Anesshesiology 1987; 67: 11-9.

10 Spaulding TC, Fielding S, Venafro JJ, Lal H. Antinocioceptive activity of clonidine and its potentiation of morphine analgesia. Eur I Pharmacol 1979; 58:19-25.

11 Bailey PL, Sperry RJ, Johnson GK, et al. Respiratory effects of clonidine alone and combined with morphine, in hurnans. Anesthesiology 1991; 74: 43-8.

12 Jalanka $\mathrm{H}$.. The use of medetomidine, medetomidine-ketamine combinations and atipamezole at Helsinki Zoo-a review of 240 cases. Acta Vel Scand Suppl 1989; 85: 193-7.

13 Mero M, Vainionpaa $S$, Vasenius J, Vithonen $K$, Rokkanen P. Medetomidine-ketamine-diazepam anesthesia in the rabbit. Acta Vet Scand Supp/ 1989;85:135-7.

14 Verstegen J, Fargetton X, Ectors F. Medetomidine/ketamine anaesthesia in cats. Acta Vet Scand Suppl 1989;85; 117-23.

15 Vaha VT. The clinical efficacy of medetomidine. Acta Vet Scand Suppl 1989: 85: 151-3.

16 Engelman E, Lipszyc M, Gilbart E, et al. Effects of clonidine on anesthetic drag requirements and hemodynamic response during aortic surgery. Anesthesiology 1989; 71: 178-87.

17 Quintin L, Roudot F. Roux C, et at. Effect of clonidine on the circulation and vasoactive hormones after aortic surgery. Br I Anaesth 1991; 66: 108-15.

18 Quintin L, Viale JP, Annat $\mathrm{G}$, et al. Oxygen uptake after major abdominal surgery: effect of clomidine. Anesthesiology 1991; 74: 236-41.

19 Savola JM, Ruskoaho H, Puurunen J, Salonen JS, Karki NT. Evidence for medetomidine as a selective and potent agonist at alpha 2-adrenoreceptors. J Auton Pharmacol 1986; 6:275-84.

20 Scheinin $H$, Virtanen $R$, MacDonald E, Lammintausta $R$, Scheimin M. Medetomidine-a novel alpha 2-adrenoceptor agonist: a review of its pharmacodynamic effects. Prog Nemropsychopharmacol Biol Psychiary: $1989 ; 13$ : 635-51.

21 Segal IS, Vickery RG, Walton JK, Doze VA, Maze M. Dexmedetomidine diminishes halothane anesthetic requirements in rats through a posisynaptic allpha 2 adrenergic receptor. Anesthesiology 1988; 69: 818-23.

22 Kallio A, Salonen M, Forssell H, Scheinin $H$, Scheinin M, Tuominen J. Medetomidine premedication in dental surgery-a double-blind cross-over study with a new alpha 2adrenoceptor agonist. Acta Anatesthesiol Scand 1990; 34: 171-5.

23 Kallio A, Scheinin M. Koulu M, et al. Effects of dexmedetomidine, at seleative alpha 2 adrenoceptor agonist, on hemodynamic control mechanisms. Clim pharnacol ther 1989; 46: $33-42$.

24 Flacke JW, Facke WE, Bloor BC, McIntee DF. Hemodynamic effects of dexmedetonidine, an alpha 2-adrenergic agonist, in autonomically denervated dogs. I Cardiovase Pharmacol 1990; 16: $616-23$.

25 Seitelberger $R$, Guth B, Heusch G, Lee J, Katayama K, Ross JJ. Intracoronary alpha 2-adrenergic receptor blockade attenuates ischemiat in conscious dogs during exercise. Circ Res 1988; 62: $436-42$.

26 Heusch G, Deussen A. The effects of cardiac sympathetic nerve stimulation on the perfusion of stenotic coronary arteries in the dog. Circ Res $1983 ; 53: 8-15$.

27 Heusch $G$. Alpha-adrenergic mechanisms in myocardial ischemia. Circulation 1990; 81: 1-13. 


\section{CHAPTER 2}

\section{Pharmacology of the $\alpha_{2}$-adrenergic receptor - a review of the literature}

\subsection{History}

In 1948, Alquist [1] first subdivided the adrenergic receptors into $\alpha$ and $\beta$ based on their pharmacological properties. He used five different catecholamines and found that their rank order of potency was different for two distinct physiological functions. Almost 20 years later Lands et al. [2] subdivided both the $\alpha$ and $\beta$-adrenergic receptors into $\alpha_{1}$ and $\alpha_{2}$, and $\beta_{1}$ and $\beta_{2}$ subtypes. The $\alpha$-adrenoceptors were divided into $\alpha_{1}$ and $\alpha_{2}$ largely based on function, $\alpha_{1}$ being excitatory and $\alpha_{2}$ inhibitory [3] ol location, $\alpha_{1}$ being presynaptic and $\alpha_{2}$ postsynaptic [4]. Neither of these classifications proved to be completely correct, and $\alpha_{2}$-adrenoceptors are now known to be located both pre- and post-synaptically and ellicit a complex profile of pharmacological actions.

Four $\alpha_{2}$-adrenoceptor subtypes have now been described: the $\alpha_{2 \mathrm{~A}}, \alpha_{2 \mathrm{~B}}, \alpha_{2 \mathrm{C}}$ and $\alpha_{2 \mathrm{D}}$. They have been differentiated by the relative affinities to radio-labelled antagonists $[5]$.

\subsection{Molecular pharmacology}

The $\alpha_{2}$-adrenoceptor is a member of the $\mathrm{G}$ protein-coupled family of cell membrane receptors which transduce their biological responses by activating pertussis toxinsensitive [6], guanine-nucleotide binding regulatory proteins (G-proteins) [7,8]. The $\alpha_{2}$-receptor proteins are monomeric polypeptides between 450 and 461 amino acids in length (complete amino acid sequencies are known for both human and rat receptors) $[9,10]$. The most characteristic structural feature in the suggested secondary structure of these receptor proteins is the presence of seven stretches of 20-25 hydrophobic amino acids which are thought to span the plasma membrane in an $\alpha$-helical fashion. These transmembrane domains are separated by extra- and intra-cellular loops formed of hydrophilic amino acids $[7,11]$. 
The $G$ proteins are responsible for transducing the signal to an intracellular effector system. 3,5-Cyclic adenosine monophosphate (cAMP) is an important regullator of many cellular functions. Specific CAMP-dependent kinases modify the activity of target proteins by controlling their phosphorylation status. Inhibition of adenylyl cyclase, which results in decreased formation of CAMP, is an important consequence of $\alpha_{2}$-adrenoceptor activation. This effect can be seen in virtwally every system examined so far. Increased intracellular availability of $\mathrm{Ca}^{2+}$ is indisputably inwolved in the smooth muscle contracting effect of $\alpha_{2}$-adrenergic agonists, and vasoconstriction mediated by $\alpha_{2}$-adrenoceptors can be attenuated or abolished by $\mathrm{Ca}^{2+}$-chelating agents [12].

\subsection{The $\alpha_{2}$-adrenergic agonists}

Clonidine and dexmedetomidine are both $\alpha_{2}$-adrenergic agonists (see Figure $2-1$ ).

\begin{tabular}{ll} 
Noradrenaline & alpha-1 $>$ alpha-2 \\
Adrenaline & \\
Methylnoradrenaline & \\
Dopamine & \\
Xylazine & \\
Clonidine & \\
Mivazerol & \\
Guanfacine & \\
Guanabenz & \\
Azepexole & \\
Medetomidine & alpha-2 $>$ alpha-1 \\
Dexmedetomidine & \\
\hline
\end{tabular}

Figure 2-1 $\alpha_{2}$-Adrenergic agonists from most alpha-1 to most alpha-2 (after P. Talke, personal communication).

\subsubsection{Clonidine}

Clonidine (see Figure 2-2) is the prototypical $\alpha_{2}$-adrenoceptor agonist to which all other $\alpha_{2}$-agonists are compared. Its actions are mediated mainly by $\alpha_{2}$-adrenoceptors, but it is a weak $\alpha_{1}$-agonist as well $\left(200: 1 \alpha_{2}: \alpha_{1}\right)$. The predominant effects of clonidine in human subjects include reductions in blood pressure and heart rate, sedation, decreased salivation, and a decline in plasma catecholamine concentrations indicating reduced sympathetic activity [13]. Clonidine has been used clinically for 25 years in the treatment of hypertension [14], congestive heart failure [15] and to reduce 
myocardial ischemia and infarct size [16-18]. It has also been successfully used in connection with opioid [19] and alcohol withdrawal syndromes [20].

\subsubsection{Dexmedetomidine}

Dexmedetomidine (see Figure 2-2) is the pharmacologically active $\delta$-isomer of medetomidine, a novel lipophilic imidazole derivative with a high affinity for $\alpha_{2}$ adrenoceptors $\left(1600: 1 \quad \alpha_{2}: \alpha_{1}\right) \quad[21-24]$. The pharmacological actions of dexmedetomidine closely resemble those of clonidine, but dexmedetomidine has been reported to be a complete anesthetic by itself in sufficiently high doses in experimental animals [25].

Table 2-1 Examples of $\alpha$ adrenergic antagonists

\begin{tabular}{|c|c|c|}
\hline $\begin{array}{l}\text { Non-selective } \alpha \text {-adrenoceptor } \\
\text { antagonists }\end{array}$ & $\alpha_{t}$-Adrenoceptor antagonists & or-Adrenoceptor antagonists \\
\hline Phentolamine & Prazosin & Yohimbine \\
\hline \multirow[t]{6}{*}{ Tolazoline } & Terazosin & Rauwolscine \\
\hline & Doxazosin & Idazoxan \\
\hline & Trimazosin & Alipamezole \\
\hline & Corymanthime: & \\
\hline & Phenoxybenzamine & \\
\hline & Labetolol & \\
\hline
\end{tabular}

Modified after Bloor [26].

\subsection{The $\alpha$-adrenergic antagonists}

Antagonists are used frequentlly in pharmacological studies to differentiate between different pharmacological effects of a drug. The $\alpha_{2}$-adrenoceptor antagonist atipamezole, has been shown to antagonise the hemodynamic, catecholamine and sedatory

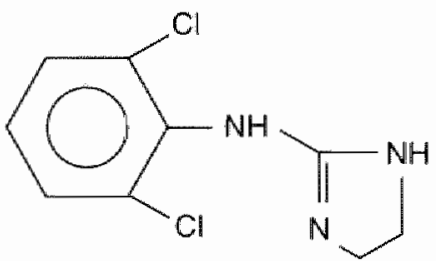

Clonidine

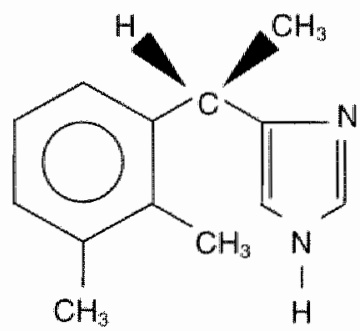

Dexmedetomidine

Figure 2-2 Structure of clonidine (2-(2,6-dichlorophenylamino)-2-imidazoline) and dexmedetomidine $(4(5)-[1-(2,3 *$ dimethylphenyl)ethyl]imidazole $)$. 
effects of dexmedetomidine in humans $[27,28]$. Atipamezole is now used routinely in veterinary practice to reverse the sedative and cardiovascular effects of medetomidine and dexmedetomidine [29-32]. Atipamezole and other $\alpha$-adrenergic antagonists are listed in Table 2-1.

\subsection{Central nervous system sites involved in the $\alpha_{2}$-adrenoceptor-mediated antihypertension and bradycardia}

Central antihypertensive and bradycardic actions of the $\alpha_{2}$ adrenergic agonists are mediated at a variety of binding sites in several brainstem visceral nuclei - especially the nucleus tractus solitarius (NTS), the rostral ventrolateral medulla (Cl area), the caudal ventrolateral medulla (AI area including the lateral reticular nucleus), the dorsal motor nucleus of the vagus (DMV), the nucleus commissuralis (NC), and the locus coeruleus (LC) $[33,34]$. Reciprocal connections exist between nearly all of these areas.

The actions of $\alpha_{2}$-adrenergic agonists on these areas are complex. Microinjection of $\alpha_{2}$-adrenergic agonists into the NTS or DMV induce bradycardia with less hypotension while microinjection into the rostral ventral lateral medulla ( $\mathrm{Cl}$ area) is associated with the induction of hypotension [33,35-37].

The bradycardic effect of $\alpha_{2}$-adrenergic agonists is complex, but is thought to be due to a combination of presynaptic inhibition of noradrenaline release at cardiac sympathetic nerve terminals and central reduction of sympathetic drive plus facilitation of the baroreceptor reflex $[38,39]$.

The $\mathrm{LC}$ is a region in the dorso-lateral pons with a high concentration of $\alpha_{2}$-adrenergic binding sites [34]. It has been shown that $\alpha_{2}$-adrenergic agonists alter cellular firing in the LC, and that electrical or chemical stimulation of the LC alters systemic arterial pressure [40,4I]. The LC has also been shown to be a major site of action for the sedative/hypnotic effect of $\alpha_{2}$-adrenergic agonists, and implicated in the anesthetic reducing and hemodynamic stabilising actions of clonidine and dexmedetomidine [42-44] (see also Chapter 3.2). It is not known whether there is an interaction between the sedative/hypnotic and cardiovascular effects of $\alpha_{2}$-adrenergic agonists on the LC.

It is probable that the effect of an $\alpha_{2}$-adrenergic agonist on sympathetic and parasympathetic tone is dependent on pre-existing endogenous tone. A high sympathetic tone may predispose to a more profound hemodynamic effect following administration of an $\alpha_{2}$-adrenergic agonist [45]. 


\subsection{Imidazoline receptors}

It has been suggested that the central hypotensive effect of clonidine-like substances could be due to their interaction with receptors distinct from the $\alpha_{2}$-adrenergic receptors specifically recognizing their imidazoline structure [46] within the rostral ventrolateral medulla $[35,36]$. Such 'imidazoline-preferring" receptors have since been identified in the brain [47] and other organs, and have been differentiated into $I_{1}$ and $I_{2}$ subtypes.

Several $\alpha_{2}$-adrenergic agonists (clonidine, rilmenidine, tizanidine and moxonidine) show high affinity for $I_{1}$ receptors $[48-52]$. A centrally-mediated sympatholytic effect can be induced by both $\alpha_{2}$-adrenergic and $\mathrm{I}_{1}$ receptor agonists [53].

It has proved difficult to dissociate imidazoline from $\alpha_{2}$-receptors both pharmacologically and functionally; all $\mathrm{I}_{1}$ receptor agonists have comparable affinity for $\alpha_{2}$-receptors and there is no selective antagonist for $I_{1}$ compared to $\alpha_{2}$-receptors. While there are subtle differences in distribution, most central nervous system nuclei contain both receptors. There appears to be a difference in the receptor involved depending on the mode of administration of the agonist. For example, clonidine induces hypotension via $I_{4}$ receptors if given directly into the rostral ventrolateral medulla (RVLM), but via $\alpha_{2}$-adrenergic receptors if given intravenously [54].

The elucidation of the imidazoline receptor is of importance since it may be possible to develop drugs with more or less affinity for the two receptors, thereby producing selectively sedation without hemodynamic effects and vice versa. The actions of rilmenidine as an antihypertensive with minimal sedation is an initial attempt at such discrimination [55].

\subsection{Peripheral vasoconstriction}

Both $\alpha_{1}$ and $\alpha_{2}$-adrenoceptors are known to be present on vascular smooth muscle [56]. The pressor effect of exogenously administered cathecholamines in the pithed rat can be blocked by $\alpha_{2}$-adrenoceptor antagonists, while the pressor response evoked by sympathetic nerve stimulation is antagonised by $\alpha_{1}$-adrenoceptor antagonists [57]. Therefore, it is likely that the sympathetic junctional receptor in systemic arterial vasculature is an $\alpha_{1}$-adrenoceptor while the extrajunctional adrenoceptor (which responds to circulating catecholamine) is of the $\alpha_{2}$ type [58].

Postjunctional $\alpha_{2}$-adrenoceptors mediate both arterial and venous vasoconstriction [56]. Alpha-adrenoceptors mediating vasoconstriction appear to differ in their utilisation of calcium ions. Although there are species differences, in general, vascular $\alpha_{1}$-adrenoceptor agonists promote vasoconstriction by utilising intracellular calcium while $\alpha_{2}$-adrenoceptor mediated vasoconstriction uses extracellular calcium. This may 
be why calcium channel blockers are effective in blocking $\alpha_{2}$-adrenoceptor induced vasoconstriction [59].

\subsection{Hemodynamic effects of $\alpha_{2}$-adrenergic receptor agonists}

The characteristic response to intravenous administration of an $\alpha_{2}$-adrenergic receptor agonist in a normotensive or hypertensive animal and man is an immediate pressor response, caused by stimulation of peripheral arterial postjunctional $\alpha_{2}$-adrenergic receptors [60-62]. This pressor response is relatively short-lived and is followed by a slow decline in arterial blood pressure to levels lower than those observed prior to drug administration. This long-lasting depressor/antihypertensive response is a result of central $\alpha_{2}$-adrenergic receptor stimulation. Heart rate declines immediately following administration and continues to be reduced for the duration of drug action. If the $\alpha_{2}$ adrenergic receptor agonist is administered directly into the central nervous system or via the vertebral artery, which allows for easy access to the central nervous system, the initial pressor resonse is not observed [60,63]. The oral administration of $\alpha_{2}$ adrenergic agonists, such as clonidine and dexmedetomidine, does not cause a pressor response prior to the centrally mediated reduction in systemic blood pressure [64]. Studies have also shown that the volatile anesthetics, halothane and isoflurane, may attenuate the vasoconstrictor responses of $\alpha_{2}$-adrenergic agonists $[65,66]$

The bradycardia associated with $\alpha_{2}$-adrenergic receptor agonists may result, in part, from a peripheral presynaptic action at prejunctional $\alpha_{2}$-adrenergic receptors on sympathetic nerves to the heart, since heart rate can be reduced in pithed rats $[67,68]$. Also, in the anesthetized rat, $\alpha_{2}$-adrenergic receptor agonist-induced bradycardia does not require penetration into the central nervous system while hypotension does [69].

\subsubsection{Cardiac function}

$a x_{2}$-Adrenoceptor agonists reduce cardiac output in dogs [59], humans [62], and in most other species studied till now. The mechanism for this decrease in pump function is still a matter for discussion $[59,70]$.

$\alpha_{2}$-Adrenergic agonists have no direct effects on myocardial cells. Housmans found that dexmedetomidine had no effects on ferret papillary muscle [71] while Flacke et $a$. demonstrated that dexmedetomidine had no direct effects on the isolated dog heart [72].

$\alpha_{2}$-Adrenoceptor stimulation can affect the contractility of the heart via the centrally mediated reduction in sympathetic tone, leading to reduced activity of cardiac sympathetic nerves and lower circulating catecholamines. In addition, stimulation of $\alpha_{2}$-adrenergic receptors on the cardiac sympathetic nerve terminals can also cause a reduction in contractility by diminishing noradrenaline release from these nerves. 
The negative inotropic effects of the selective $\alpha_{2}$-adrenergic agonists have also been attributed to harmful coronary vasoconstriction. The limitation of oxygen supply to the heart thus induced could reduce pump function [73]. The fact that cardiac output is reduced in denervated animals where no central sympatholytic effect is present has been presented as evidence for this view [70]. This question will be addressed in more detail in this thesis.

\subsection{Organ blood flow}

\subsubsection{Myocardial blood flow}

Adrenaline or noradrenaline administered directly into the coronary artery, or cardiac sympathetic nerve stimulation in the dog [74-78], rat [79], cat [78], monkey [78], and guinea-pig [80] results in a transient decrease, followed by a longer-lasting increase in coronary blood flow. The initial transient decrease is believed to be mediated by $\alpha$ adrenoceptors [77], whereas the vasodilation is believed to be mediated by $\beta$ adrenoceptors [81]. It has been suggested that $\alpha_{2}$-adrenergic receptor-mediated coronary vasoconstriction can cause myocardial ischemia [82]. The coronary circulation appears to be able to adjust to chronic adrenergic stimulation as is shown by the fact that vasoconstriction does not occur after sustained stimulation [83].

Although it is obvious that exaggerated $\alpha$-adrenergic vasoconstriction is deleterious, there is continuing debate on its relevance under (patho)physiological conditions. Coronary blood flow is strongly controlled by a metabolically driven autoregulation [84]. Coronary artery blood flow is also impeded by systolic contraction. This effect is more pronounced in the inner than the outer layers of the left ventricle [85]. Thus coronary blood flow to the endocardium occurs only during diastole which results in a reduction in the time available for flow to the endocardium during tachycardia. Feigl $e t$ al. have provided evidence that selective epicardial adrenergic vasoconstriction helps maintain a uniform transmural blood flow in the left ventricle during tachycardia and sympathetically mediated stress [81]. Whereas vasodilation "steals" blood from the endocardium, selective epicardial vasoconstriction would serve to maintain uniform perfusion (a so-called "anti-steal" effect).

\subsubsection{Cerebral blood flow}

Both clonidine and dexmedetomidine have been shown to reduce cerebral blood flow (CBF) in animals $[86,87]$ possibly due to direct stimulation of $\alpha_{2}$-adrenoceptors in the cerebral vasculature [88]. A reduction in cerebral blood flow after clonidine has also been shown in humans [89]. However, in patients with acute hypertension significant individual variation was seen, an increase where initial CBF was low, and a decrease where the initial CBF was high [90]. In studies in which a decrease in CBF has been demonstrated, the dogs were anesthetized with either halothane [86] or isoflurane [87] 
which are known to cause cerebral vasodilation. Moreover, in neither of these studies was there a significant decrease in the cerebral metabollic rate for oxygen $\left(\mathrm{CMRO}_{2}\right)$, suggesting no significant cerrebral ischemia developed. On the contrary, other studies have suggested that $\alpha_{2}$-adrenoceptor agonists may improve neurological outcome following cerebral ischaemia [91,92].

\subsubsection{Renal blood flow}

Administration of $\alpha_{2}$-adrenergic antagonists in the renal artery of hypertensive patients increased renal blood flow, yohimbine being more potent than doxazosin [93]. However, in hypertensive rats, acute reduction of blood pressure by $20 \%$ by clonidine did not reduce renal blood flow probably because of the renal sympathetic nerve blocking action of clonidine [94]. Moreover, $\alpha_{2}$-adrenergic activation has been shown to alter renal function increasing sodium and water excretion. In a human study during anesthesia for otorhinolaryngeal or orthopedic surgery, clonidine $5 \mu \mathrm{g} / \mathrm{kg}$ increased urine production 195\%. It has also been postulated that renin release is inhibited by activation of the $\alpha_{2}$-adrenoceptors in the juxtaglomerular apparatus in the rat [96].

\subsubsection{Cutaneous flow}

Finger blood flow, measured by plethysmography, decreases after administration of clonidine in human subjects [97]. This technique measures gross blood flow, including flow through arterio-venous anastomoses. It has been shown that in extremities shunt flow accounts for a considerable part of total blood flow and the role of $\alpha_{2}-$ adrenoceptors in regulation of shunt flow is well known [97,98]. The decrease in cutaneous blood flow, and (part of) the decrease in shunt flow, might be related to the role of $\alpha_{2}$-adrenoceptors in thermoregulation [99]. Observations that clonidine reduced post-operative shivering seems to agree with this idea [100,101].

\section{References}

I Alquist RP. A study of the adrenotropic receptors. Am J Physiol 1948; 1.53: 586-600.

2 Lands AM. Arnold A, McAuliff JP. Luduena FP, Brown TGJ. Differentiation of receptor systems activated by sympathomimeticamines. Nature 1967; 214: 597-8.

3 Berthelsen $S$, Petringer WA. A functional basis for classification of alpha-adrenergic receptors. Liffe: Sci $1977 ; 21: 595-606$.

4. Anden NE, Corrodi H, Fuxe K, Hokfelt B, Hokfelt T, Rydin C. Evidence for a central noradrenaline receptor stimulation by clonidine. Life Sci $1970 ; 9: 513-23$.

5 Bylund DB. Subtypes of alpha 1-and alpha 2-adrenergic receptors. FASEB / 1992; 6: 832-9.

6 Correa-Sales C, Reid K, Maze M. Pertussis toxin-mediated ribosylation of G proteins blocks the hypnotic response to an alpha 2-agonist in the locus coeruleus of the rat. Phamacol Biochem Bethon 1992; $43: 723-7$.

7 DohIman HG. Thorner J, Caron MG, Lefkowitz RJ. Model systems for the study of seventransmenbrane-segment receptors. Anmual Review of Biochemismy 1991; 60: 653-88. 
8. Bimbaumer L, Abramowitz I. Brown AM. Receptor-ffectors coupling by G proteins. Biochem Biophys Acra 1990; 1031: $163-224$.

9 Harrison JK, Pearson WR, Lynch K. Molecular characterization of $\alpha_{l}$ and $\alpha_{2}$ adrenoceptors. Thends in Pharmacological Science 1991; 12:62-7.

10 Lomasney JK, Cotechia $\mathrm{S}$, Letkowitz RJ, Caron MG. Molecular biology of a-adrenergic receptors: implications for receptor classification and for structure-function relationships. Biochem Biophys Acra 1991; 1095: 127-39.

11 Kobilka BK, Matsui $\mathrm{H}$, Kobilka TS, ef al. Cloning, sequencing, and expression of the gene coding for the human platelet $\alpha_{2}$-adrenergic receptor. Science $1987 ; 238: 650-6$.

12 Ruffolo RR, Nichols AJ, Stadel JM, Hieble JP. Structure and function of axadrenoceptors: Pharmacol Rev 1991; 43: 475-505.

13 van Zwieten PA. Drugs interacting with alpha adrenoceptors. Cardiovast Drugs Ther 1989; 3 : $121-33$.

14 Mitrovic V. Hallier E, Kuschke HJ. The haemodynamic effects of clonidine in patients with grade III to IV hypertension. J Cardiovasc Phamacol 1986; 8: S51-5.

15 Magorien RD, Hermiller JB, Unverferth DV, Leier CV. Regional hemodynamic effects of clonidine in congestive heart failure. J Cardovasc Pharmacol 1985; 7:91-6.

16 Foresti A, Massari FM, Lotto A. Hemodynamic effects of clonidine in patients with acute myocardial infarction complicated by hypertension. J Cardionasc Pharmacol 1986; 8: $\$ 30-2$.

17 Zochowski R. Intravenous clonidine in acute myocardial infarction in men. Int I Cardiol 1984; 6: 189-205.

18 Renard M, Liebens I, Waterschoot P, Bernard R. Central inhibition of sympathetic overdrive by clonidine in acute myocardial infarction with systolic bypertension. Haemodynamic study. Angiology 1986; 37: 633-41.

19 Gold MS, Pottash AC, Sweeney DR, Klever HD. Opiate withdrawal using clonidine, A safe, effective, and rapid nonopiate treatment. JAMA $1980 ; 243: 343-6$.

20 Wilkins AJ, Jenkins WJ, Steiner JA. Elficacy of clonidine in treatment of alcohol withdrawal state. Psychopharmacology 1983: 81: 78-80.

21 Savola JM, Ruskoaho $H_{*}$ Puurunen J, Salonen JS, Karki NT. Evidence for medetomidine as a selective and potent agonist at alpha 2-adrenoreceptors. J Autom Pharmacol 1986; 6: 275-84.

22 Scheinin H, Virtanen R, MacDonald E, Lammintausta $R$, Scheinin M. Medetomidine -a novel alpha 2-adrenoceptor agonist: a review of its phanmacodynamic effects. Prog Newropsychopharmacol Biol Psychatry 1989;13;635-51.

23 MacDonald E, Scheinin M, Scheinin $H$, Virtanen $R$. Comparison of the behavioral and neurochemical effects of the two optical enantiomers of medetomidine, a selective alpha-2adrenoceptor agonist. I Pharmacol Exp Ther 1991; 254: 848-54.

24 MacDonald E, Scheinin H, Scheinin M. Behavioural and neurochemical effects of medetomidine, a novel weterinary sedative. Eur J Pharmacol 1988; $158: 119-27$.

25 Vickery $\mathrm{RG}$, Sheridan BC. Segal IS, Maze M. Anesthetic and hemodynamic eflects of the stereoisomers of medetomidine, an alpha 2-adrenergic agonist, in hallothane-anesthetized dogs. Anesth Analg 1988:67:611-5.

26 Bloor B. General pharmacology of $\alpha_{2}$-adrenoceptors. Anat th Pharmaco Rev $1993 ; 1: 221-32$.

27 Karhuvara S, Kallio A, Salonen M, Tuominen J, Scheinin M. Rapid reversal of alpha 2adrenoceptor agonist effects by attipamezole in human volunteers. $\mathrm{Br}$ / Clin Pharmacol $1991 ; 31$ : $160-5$.

28 Aho M. Erkola O, Kallio A, Scheinin H, Korttila K. Comparison of dexmedetomidine and midazolam sedation and antagonism of dexmedetomidine with atipamexole. I Chin Anesth 1993; 5: 194-203.

29 Jones RS. Young LE. Medetomidine premedication in dogs and its reversal by atipamezole. Acta Ver Scand Suppl 1991; 87: 165-7. 
30 Waha VA. The clitical effectiveness of atipamezole as a medetomidine antagonist in the dog. I Ver Pharnacol Ther 1990; 13: 198-205.

31 Vainio 0 , Vaha VT. Reversal of medetomidine sedation by atipamezole in dogs. I Vef Phamacol ther 1990; 13:15-22.

32 Vainio $O$. Reversal of medetomidine-induced cardjovascular and respiratory changes with athamezole in dogs. Vet Rec 1990; 127: 447-50.

33 Unnerstall JR, Kopajtic TA, Kuhar MJ. Distribution of alpha 2 agonist binding sites in the rat and buman central nervous system: analysis of some of functionall, anatomical correlates of the. pharmacological effects of clonidine and related adrenergic agents. Brain Res 1984; 319: 69-101.

34 Unnerstall J, Kahar M. Mapping the $\alpha_{2}$-adrenergic receptor in the central nervous system: a guide to struchure and funetion., Epinephrine in the central nervous system. Edited by Stolk J. U'Prichard D, Fuxe K. New York, Oxford University Press, 1988, pp 45-59.

35 Bousquet $\mathbb{P}$, Feldman $J_{\text {, Velly }} \mathbb{J}$, Bloch $R$. Role of the ventral surface of the brain stem in the hypotensive action of clonidine. Eur J Pharmacol 1975; 34: 151-6.

36 Bousquet $\mathrm{P}$, Feldman J, Bloch $\mathrm{R}$, Schwartz J. The nucleus reticularis lateralis: a region highly sensitive to cllonidine. Eur J Pharmacol 1981; 69: 389-92.

37 Reis DJ, Morrison S, Ruggiero DA. The CI area of the brainstem in tonic and reflex control of the circulation. Hypertension $1988 ; 11 ; 18-13$.

38 Cavero 1. Roach AG. Effects of clonidine on canine cardiac neuroeffector structures controlling heart rate. $B r$ J Pharnacol 1980; 70: 269-76.

39 de Jonge $A$. Timmermans $\mathbb{P}$, vam $Z$ wieten $P$. Quantitative aspects of alpha adrenergic effects induced by clonidine-like imidazolidines. II. Central and peripheral bradycardic activities. $I$ Pharmacol Exp Ther 1982; 222: 712-9.

40 Swed A. Felsten G. Stimulation of the locus coeruleus decreases arterial pressure. Brain Res 1987; 414: 119-32.

41. Gurtu S, Pant $K$, Sinha J, Bhargava $K$. An investigation into the mechanism of cardiovascular responses elicited by electrical stimulation of locus coerulleus and subcoeruleus in the cat. Brain Res 1984; 301: 59-64.

42 Maze $M$, Tranquilli W. Alpha-2 adrenoceptor agonists: defining the role in clinical anesthesia. Anesthesiology 1991: 74: 581-605.

43 Doze VA, Chen BX. Maze M. Dexmedetomidine produces a hypnotic-anesthetic action in rats. via activation of central alpha-2 adrenoceptors. Anesthesiology 1989; 71: 75-9.

44 Correa-Sales C, Rabin BC, Maze M. A hypnotic response to dexmedetomidine, an alpha 2 agonist, is mediated in the locus coeruleus in rats [see comments]. Anesthesiology 1992; 76: 948-52.

45 Muzi M, Golf D. Kampine J, Roerig D, Ebert T. Clonidine reduces sympathetic activity but maintains baroreflex responses in normotensive humans. Anesthesiology 1992; 77:864-71.

46 Bousquet P. Feldman I, Schwartz J. Central cardiovascular effects of alpha adrenergic drugs. Difference between catecholamines and imidazolines. J Phamacol Exp Ther 1984; 230; 232-6.

47 Ernsberger P, Meeley M, Mann J, Reis D. Clonidine binds to imidazole binding sites as well as alpha 2-adrenoceptors in the ventrolateral medulla. Eur I Pharmacol 1987; 134: 1-13.

48 Ensberger $P$, Damon $T$, Graft $L$. Schafer $S$, Christian M. Moxonidine, a centrally acting amtihypertensive agent, is a selective ligend for $\mathrm{I}_{1}$-imidazoline sites. 1 Pharmacol Exp Ther 1993 ; 264: 172-82.

49 Taittonen M., Raty $H$, Kirvela $O$, Aantaa R, Kanto J. The metabolic effects of oral tizanidine in healthy volunteers. Acro Anaesthesiol Scand 1995; 39: 628-32.

50 Tibirica E, Feldman J, Mermet C, Gonon F, Bousquet P. An imidazoline-specific mechanism for the hypotensive effect of clonidine: a study with yohimbine and idazoxan. I Pharmacol Exp Ther 1991; 256: 606-13. 
51 Tibirica E, Feldman J, Mermet C, Monassier L, Gionon F, Bousquet P. Seteotivity of rilmenidine for the nucleus reticularis lateralis, a ventrolateral medullary stiucture containing imidazolinepreferring receptors. Eur I Pharnacol 1991; 209: 213-21.

52 Ernsberger $P$, Giuliano $R$, Willette $R$, Reis D. Role of imidazole receptors in the vasodepressor response to clonidine analogs in the rostral ventrolateral medulla. I Pharmecol Exp Ther 1990; 253: $408-18$.

53 Gomez R, Ensberger P, Feinland G, Reis D. Rilmenidine lowers arterial pressure via imidazol receptors in brainstem Cl area. Eur J Pharmacol 1991; 195: 181-91.

54 Hieble JP, Ruffolo RJ. Possible structural and functional relationships between imidazoline receptors and alpha 2-adrenoceptors. Ann N Y Acad Sci 1995; 763:8-21.

55 Bousquet $\mathbb{P}$. Feldman J. Tibirica $E$, et al. New concepts on the central regulation of blood pressure. Alpha2-adrenoceptors and "midazoline receptors". Am J Med 1989: 87: 105-13S.

56 Drew G, Whiting $S$. Evidence for two distinct types of postsynaptic alphatadrenoceptor in vaseular smooth muscle in vivo. BrJ Pharmacol 1979; 67: 207-15.

57 Yamaguchi I, Kopin IJ. Differential inhibition of alpha-1 and alpha-2 adrenoceptor-mediated pressor response in pithed rats. J Pharmacol Exp Ther 1980; 214:275-81.

58 Langer $\mathrm{SZ}$, Shepperson NB. Recent developments in vascular smooth muscle pharmacology: the post-synaptic alpha-2-adrenoceptor. TIPS 1982; 3:440-4.

59 Bloor BC, Frankland M, Alper G, Raybould D, Weitz. J, Shurtliff M. Hemodynamic and sedative effects of dexmedetomidine in dog. J Pharmacol Exp Ther 1992; 263:690-7.

60 Ruffolo RR, Goldberg MR, Morgan EL. Receptor interactions of imidazolines. X1. $\alpha$-adrenergic and antihypertensive effects of clonidine and its methylene-bridged analog, St $19 / 3$. Pharmacology $1982 ; 25$ : 187-201.

61 Onesti $G$, Schwartz AB, Kim KE. Antihypertensive effect of clonidine. Circ Res 1971; 28: $53-69$.

62 Bloor BC, Ward DS, Belleville JP, Maze M. Effects of intravenous dexmedetomidine in humans. II. Hemodynamic changes. Anesthesiology 1992; 77: 1134-42.

63 Timmermans PBMWM, Hoelke W, Stahle H, van Zwieten PA. Structure-activity relationships in clonidine-like imidazolines and related compounds. Prog Pharmacol 1980; 3: 1-104.

64 Proctor LT, Schmeling WT, Roerig D, Kampine JP, Warltier DC. Oral dexmedetomidine attenuates hemodymamic responses during emergence from general anesthesia in chronically instrumented dogs. Anesthesiology $1991 ; 74: 108-14$.

65 Kenny D, Pelc L, Brooks H, Kampine J, Schmeling W, Warltier D. Alterations of alpha-1 and alpha-2 adrenoceptor-mediated pressor responses by halotiane and isollturanic anesthesia. Anesthesiology 1989; $71: 224-34$.

66 Larach DR, Schuler HG, Derr JA, Larach MG, Hensley FAJ, Zelis R. Halothane selectively attenuates alpha 2-adrenoceptor mediated vasoconstriction, in vivo and in vitro. Anesthesiology 1987; 66: 781-91.

67 Misu Y, Kubo T. Central and peripheral cardiovascular responses of rats to guambenz and clonidine. Jpn I Pharmacol 1982; 32: 925-8.

68 Drew GM. Effects of alpha-adrenoceptor agonists and antagonists on pre-and postsynaptically located alpha-adrenoceptors. Eur J Pharmacol 1976; 36; 313-20.

69 de Jonge A, Timmermans $P$, van Zwieten P. Participation of cardiac presynaptic $\alpha_{2}$ adrenoceptors in the bradycardic effects of clonidine and analogues. Naumyn-Schmiedebergs Arch Pharmacol 1981; 317:8-12.

70 Flacke JW, Flacke WE, Bloor BC, McIntee DF. Hemodynamic effects of dexmedetomidine, an alpha 2-adrenergic agonist, in autonomically denervated dogs. J Cardiowasc Pharmacol 1990; 16: $616-23$.

71 Housmans PR. Effects of dexmedetomidine on contractility, relaxation, and intracellular calcium transients of isolated ventricular myocardium. Anesthesiology 1990; 73: 919-22. 
72 Flacke WE, Facke JW, Blow KD, Mclutee DF, Bloor BC. Effect of dexmedetomidine, an alpha 2-adrenergic agonist, in the isolated heart. $J$ Cardiothorac Vosc Anesth 1992; 6: 418-23.

73 Flacke WE, Flacke JW, Bloor BC. Mcintee DF. Sagan M. Effects of dexmedetomidine on systemic and coronary hemodynamics in the anesthetized dog. J Cardionorac Vasc Anesth 1993; 7: $41-9$.

74 Pitt B, Elliot EC, Gregg DE. Adrenergic receptor activity in the coronary arteries of the unanesthetized dog. Cric Res 1967: 21: 75-84.

75 Gall PG, Kattus AA, Kolin A, Ross G. Effects of adrenaline and noradrenaline on coronary blood flow before and after beta-adrenergic blockade. Br J Pharmacol 1966; 26: 713-22.

76 Lioy F. An analysis of the mechanism of catecholamine effects on coronary circulation. Am $J$ Physiol 1967; 213:487-91.

77 Malindzak GSJ, Kosinski Ed, Green HD, Yarborough GW. The effects of adrenergic stimulation on conductive and resistive segments of the coronary vascular bed. I Pharmacol Exp Ther 1978 ; 206: $248-58$.

78 Proctor $\mathrm{E}$. The effects of physiological concentrations of noradrenaline on the coronary resistance of isolated perfused hearts of the cat, dog and monkey. J Pharn Pharmacol $1968 ; 20: 36-40$.

79 Glonstein A, Hauge A, Oye I, Sinclair D. Effects of adrenaline on coronary flow in isolated perfused rat hearts. Acta Physiol Scand 1967; 69: 102-10.

80 Broadley $\mathrm{KJ}$. An analysis of the coronary vascular responses to catecholamines, using a modified Langendorff heart preparation. Br J Phamacol 1970; 40: 617-29.

81 Feigl EO. Adrenergic control of transmural coronary blood flow. Basic Res Cardiol 1990; 85: $167-76$.

82 Heusch G. Alpha-adrenergic mechanisms in myocardal ischemia. Circulation 1990; 81: $1-13$.

83 Williams DO. Most AS. Responsiveness of the coronary circulation to brief vs sustained alphaadrenergic stimulation. Circulation 1981; 63:11-6.

84 Feigl EO. Coronary physiology. Physiol Rev 1983; 63: 1-205.

85 Heineman FW, MacGregor DC, Wilson GJ, Ninomiyer J. Regional and transmural myocardial temperature distribution in cold chemicat cardioplegia: significance of critical coronary artery stenosis. I Thoracic Cardiovascular Surgery 1981; 81: 851-9.

86 Karlsson BR, Forsman M. Roald OK, Heier MS, Steen PA. Effect of dexmedetomidine, a selective and potent alpha 2-agonist, on cerebral blood flow and oxygen consumption during halothane anesthesia in dogs [see comments]. Anesth Analg 1990; 71: 125 -9.

87 Zornow MH. Fleischer JE. Scheller MS. Nakakimura K. Drummond JC. Dexmedetomidine, an alphat 2-adrenergic agonist, decreases cerebrall blood flow in the isoflurane-anesthetized dog. Anesth Analg 1990; 70:624-30.

88 Coughlan MG, Lee JG. Bosnjak ZJ, Schmeling WT, Kampine JP, Wartier DC. Direct coronary and eerebral vaseular responses to dexmedietomidine. Significance of endogenous nitric oxide synhesis. Anesthesiology 1992; 77; 998-1006.

89 Kaniwata IS, Yaksh TL, Anderson RE, Marsh RW. Elfects of clonidine on cerebral blood flow and the response to arterial $\mathrm{CO}_{2} . J$ Cerebral Blood Flow and Metabolism 1986; 6: 358-65.

90 Green CS, Gretler DD, Cervenka K, McCoy CE. Brown FD, Murphy MB. Cerebral blood flow during the acute therapy of severe hypertension with oral clonidine. Am I Emergency Medicine $1990 ; 8: 293-6$.

91 Hoffman WE, Kochs E, Wener C. Thomas C, Albrecht RF. Dexmedetomidine improwes neurologic outcome from incomplete ischemia in the rat. Reversal by the alpha 2-adrenergic antagonis atipamezole. Anesthesiology 1991; 75: 328-32.

92 Maier C. Steinberg GK. Sun GH, Zhi GT, Maze M. Neuroprotection by the alpha 2. adrenoreceptor agonist dexmedetomidine in a focal model of cerebral ischemia. Anesthesiology 1993; 79: 306-12.

93 de Leeuw PW, van Es PN, de Bos R. Birkenhager WH. Role of alpha 1-and alpha 2-adrenergic receptors in the human hypertensive kidney. Hypertension $1987 ; 9: 1210-2$. 
94 Takishita S, Muratani $H$, Kawazoe $N$, Kimura $Y$, Tozawa M, Fukiyama K. Neural effects on renal blood flow during acute hypertension vary with anthypertensive drugs. Hyperension 1994: 23: 197-101.

95 Hamaya $Y$, Nishikawa T, Dohl S. Diuretic effect of clonidine during isoflunane, nitrous oxide, and oxygen anesthesia. Anesthesiology 1994; $81: 811-9$.

96 Smyth DD, Umemura $S$, Yang E, Pettinger WA. Inhibition of renin release by alphaadrenoceptor stimulation in the isolated perfused rat kidney. Eur J Pharmocol 1987: 140: 33-8.

97 Coffman JD, Cohen RA. Role of alpha-adrenoceptor subrypes mediating sympathetic vasoconstriction in human digits. Eur J Clin Imest 1988; 18: 309-13.

98 Baker CH, Davis DL, Sutton ET. Blood flow distribution with adrenergic and histaminergic antagonists. Proc Soc Exp Biol Med 1989; 190: $260-7$.

99 Flavahan NA. The role of vascular alpha2-adrenoceptors as cutaneous themosensors. NIPS 1991: 6: $251-5$.

100 Delaunay L, Bonnet F, Duvaldestin P. Clonidine decreases postoperative oxygen consumption in patients recovering from general anaesthesia. Br J Anoesh 1991; 67:397-401.

101 Flacke J, Bloor B, Flacke W, et al. Reduced narcotic requirement by clonidine with improved hemodynamic and adrenergic stability in patients undergoing coronary bypass surgery. Anesthesiology 1987; 67: 11-9. 


\section{CHAPTER 3}

\section{Anesthetic effects of $\alpha_{2}$-adrenergic receptor agonists - a review of the literature}

During the past few years a whole range of beneficial effects of $\alpha_{2}$-adrenergic agonists have been described, many of which are potentially useful in anesthesia. Below are listed the presently known effects of these agents.

Effects of $\alpha_{2}$-adrenergic agonists:

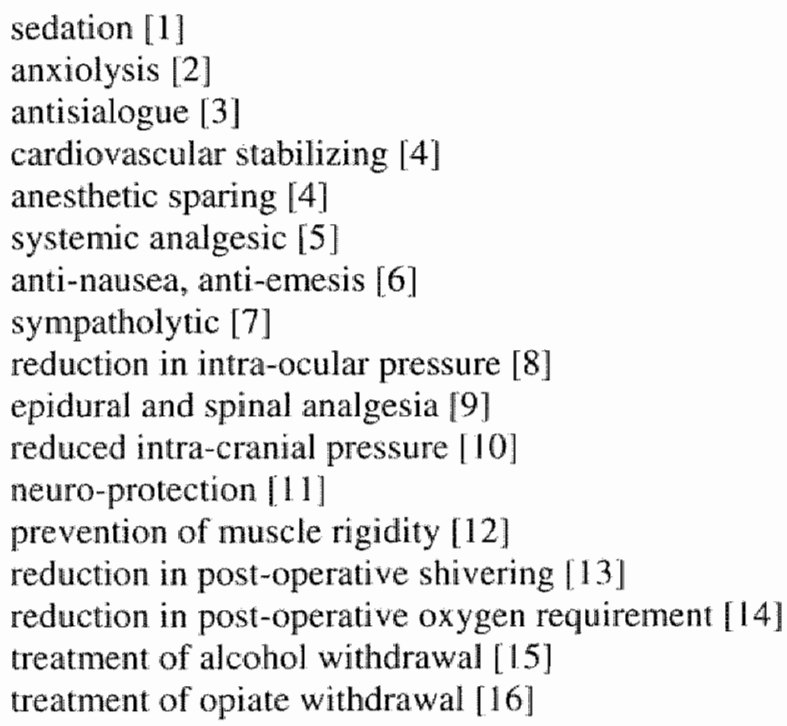

Many of these actions are of immediate interest in anesthetic practice and wil be further discussed in this chapter.

\subsection{Sedation and anxiolysis}

Sedation has always been a problem for the use of clonidine and other $\alpha_{2}$-adrenergic agonists as anti-hypertensives and the attempted seperation of sedative and antihypertensive effect has not proved entirely successful [17]. Belleville et al. studied 
dexmedetomidine $0.25,0.5,1$, and $2 \mu \mathrm{g} / \mathrm{kg}$ given intravenously to volunteers. They found that most patients who received 1 or $2 \mu \mathrm{g} / \mathrm{kg}$ dexmedetomidine were deeply sedated and unresponsive to stimuli, the sedation lasting for a mean of $195 \mathrm{~min}$ following the highest dose [1].

Low doses of $\alpha_{2}$-adrenergic agonists possess anxiolytic properties in humans $[2,18]$. This has been confirmed in animal models of anxiety $[19,20]$.

\subsection{Reduction of anesthetic requirements}

The central noradrenergic system has been shown to be an important mediator of the hypnotic actions of volatile anesthetics, anesthetic requirements being related to central noradrenaline levels [21]. Prior administration of central noradrenaline depletors ( $\alpha$-methyldopa and reserpine), reduced the minimal alveolar concentration (MAC) for halothane in dogs, while administration of central noradrenaline elevators (iproniazid) was associated with an increase in cyclopropane anesthetic requirements. Pretreatment with guanethidine, an agent which depletes peripheral, but not central, noradrenaline levels, was not associated with a change in anesthetic requirement [21]. Roizen $e t$ al. showed that halothane and cyclopropane both consistently and selectively altered neurotransmitter content in a small fraction of brain nuclei, the locus coeruleus, central grey catecholamine area and nucleus raphe dorsalis [22]. They further showed that destruction of these discrete areas caused reductions in anesthetic requirements in rats. Localized lesions of the locus coeruleus produced a similar change in halothane MAC as did the pharmacological destruction of the entire noradrenergic system [23]. Clonidine was shown to reduce halothane MAC in rats [24], and the more selective $\alpha_{2}$ adrenergic agonist, azepexole, reduced halothane MAC by more than 85\% [25], whereas disruption of noradrenergic pathways never caused a reduction of more than $40 \%$ in anesthetic requirements $[21,23]$. Rats, in which the central noradrenaline stores were almost totally depleted, have a lower basal. MAC than normal rats, but dexmedetomidine could further reduce MAC for halothane [26]. Therefore, other mechanisms beside synaptic depletion of noradrenaline must be involved. The most likely site of this action is a postsynaptic $\alpha_{2}$-adrenoceptor [27]. The sedative/hypnotic effects of $\alpha_{2}$-agonists are currently believed to be mediated primarily by $\alpha_{2}$ adrenoceptors in the locus coeruleus in the brain by reducing the firing rate of noradrenergic coerulocontical neurons $[28-30]$.

\subsection{Analgesia}

$\alpha_{2}$-Adrenergic agonists have been shown to produce analgesia by action at $\alpha_{2}$ adrenergic receptors independent of the opiate receptors [31]. Their analgesic effects have been demonstrated in animals [32,33] and in man [5]. In contrast to opioids, the analgesia produced by $\alpha_{2}$-agonists is not associated with respiratory depression $[34,35]$. The mechanisms of this analgetic action have not been fully ellucidated. In the 
locus coeruleus, common effector mechanisms have been found for both $\alpha_{2}$-adnenergic and opioid systems [36].

Also, there is a spinal component of $\alpha_{2}$-adrenoceptor-mediated analgesia which is independent of opioid receptor mechanisms [37,38], but which may react synergistically with the opioid receptors $[39,40]$. In a double-blind study in patients using self-administered epidural or intravenous clonidine, Bernard ef al. showed that post-operative analgesia can be achieved by both routes. The epidural route was associated with significant reductions in self-administered clonidine dose, in plasma clonidine concentration, and in the level of sedation, indicating a climically useful effect at the spinal level [41].

Eisenach et al. have shown that analgesia can spread upwards from the spinal segment where clonidine is injected when a continuous lumbar epidural infusion is given [42]. In this volunteer study he showed that it was possible to maintain a steady concentration of clonidine in the lumbar cerebro-spinal fluid (CSF) when a pharmacokinetically-designed, computer-controlled infusion of clonidine is given via the Jumbar epidural space. Clonidine caused similar dose-related analgesia in both the foot and the hand, suggesting that continuous addition of clonidine to the lumbar CSF occurs allowing cephalad spread of the drug in the CSF.

In addition, oral clonidine has been shown to prolong sensory and motor block from lidocaine spinal anesthesia [43]. Thus, various mechanisms at several levels within the central nervous system seem to be involved in the analgesic actions of $\alpha_{2}$-adrenergic agonists.

Epidural clonidine has also been studied in the management of patients with chronic cancer pain. In a randomized, double-blind study, clonidine has been shown to be effective for the treatment of intractable cancer pain, especially in patients with neuropathic pain [44].

\subsection{Reduction in oxygen uptake and shivering}

Clonidine has been shown to reduce oxygen uptake and carbon dioxide production in the post-operative period $[13,14]$. Some studies showed a decrease in the incidence of shivering after clonidine $[13,45]$ while other studies could detect no difference between clonidine and placebo [14]. Reduction in post-operative shivering has also been reported for dexmedetomidine [46].

\subsection{Anti-emetic effects}

Clonidine premedication has been shown to reduce postoperative vomiting in children [47], although the mechanism is unknown. $\alpha_{2}$-Adrenergic agonists are known to diminish salivary flow [48] and reduce gastro-intestinal motility [49], which may, in part, explain this effect. 


\subsection{Reduction in intra-ocular pressure}

Both clonidine and dexmedetomidine have been shown to reduce intra-ocular pressure (IOP) 18,50$]$. Intravenous dexmedetomidine almost entirely prevented the increase in IOP after laryngoscopy and tracheal intubation [50]. In another ophthalmological study, intramuscular dexmedetomidine was given as premedication for outpatient cataract surgery under peri ocular anesthesia [51]; dexmedetomidine $1 \mu \mathrm{g} / \mathrm{kg}$ given intramuscularly $60 \mathrm{~min}$ prior to surgery lowered IOP when compared to midazolam or placebo and provided a light sedative effect without compromising the cooperation of the patient.

\subsection{The $\alpha_{2}$-adrenergic agonists in anesthesia}

$\alpha_{2}$-Adrenergic agonists are commonly used as anesthetics in veterinary practice. Xylazine "the first $\alpha_{2}$-adrenergic agonist to be used as veterinary sedative and analgesic, is widely used either alone or as an adjunct to ketamine anesthesia $[52,53]$. Detomidine shows a dose-dependent analgesia and sedative effect in horses and cattle. Medetomidine is used for sedation in dogs and non-domestic animals [54].

$\alpha_{2}$-adrenergic agonists have been advocated for some time as adjuncts to general anesthesia in humans. Originally, clonidine was investigated in a variety of clinical settings, but was limited by the absence of an intravenous formulation in the U.S.A. Moreover, while clonidine can decrease volatile anesthetic requirements up to a maximum of $48 \%[55]$, the more $\alpha_{2}$-selective adrenergic agonist, dexmedetomidine has been shown to reduce halothane anesthetic requirements by more than $90 \%$ in rats [26]. Therefore, we chose to study the safety and efficacy of dexmedetomidine in this thesis.

\subsubsection{Clonidine}

Clonidine has been investigated for its anesthetic-sparing and hemodynamicstabilising effects in a number of clinical studies.

Flacke et al. gave patients undergoing coronary artery bypass grafting either placebo or clonidine ( 200 or $300 \mu \mathrm{g}$ orally, based on patient weight) $90 \mathrm{~min}$ prior to arrival in the operating room, and a second dose via nasogastric tube while the patient was on cardiopulmonary bypass. Clonidine patients were more sedated on arrival in the operating room and required $40 \%$ less sufentanil during operation (as assessed by hemodynamic criteria). At all times the heart rate and blood pressure were significantly lower in the clonidine group; cardiac output was higher and systemic vascular resistance (SVR) lower following cardiopulmonary bypass. Plasma catecholamines were consistently lower in the treated group [45]. 
Ghignone et al. using electro-encephalogram (EEG) measurement of anesthedic depth (shift to $0.5-3 \mathrm{~Hz}$ frequency range) demonstrated a $45 \%$ reduction in fentanyl requirements following $5 \mu \mathrm{g} / \mathrm{kg}$ clonidine orally $90 \mathrm{~min}$ before arrival in the operating room [56]. In a further study, the hemodynamic response to endotracheal intubation in mildly hypertensive patients receiving either clonidime alone or a combination of diazepam and lidocaine was investigated. Preoperative blood pressure was better controlled and there was no tachycardic response to intubation in the clonidine group [57]. Using EEG as index of anesthetic depth Ghignone ot al demonstrated a reduction in volatile anesthetic requirement by $40 \%$ and in fentanyl requirement by $74 \%$, while hemodynamic stability was better maintained. In a study of patients undergoing aortic surgery, clonidine $5 \mu \mathrm{g} / \mathrm{kg} 90$ min prion to surgery reduced the requirements for alfentanyl and droperidol when compared to placebo. The clonidinetreated patients had fewer episodes of tachycardia and hypertension than the placebo group [58]. Clonidine has been shown to reduce the endocrine response to surgery and stabilise the cardiovascular response following aortic surgery [59].

\subsubsection{Dexmedetomidine}

In a single blind study, dexmedetomidine in four different doses $(0.167,0.33,0.67$, and $1.0 \mu \mathrm{g} / \mathrm{kg}$ ) was given intravenously $15 \mathrm{~min}$ prior to induction of anesthesia for uterine dilatation and curettage. Thiopental was used for induction, and maintenance of anesthesia was with nitrous oxide/oxygen (70\%/30\%) supplemented with thiopental. The total amount of thiopental was reduced from $400 \pm 166 \mathrm{mg}$ (mean \pm SD) after $0.167 \mu \mathrm{g} / \mathrm{kg}$ to $1.80 \pm 65 \mathrm{mg}$ after $1.0 \mu \mathrm{g} / \mathrm{kg}$. Blood pressure, heart rate and noradrenaline leve]s were reduced after dexmedetomidine [60]. In a double blind study comparing dexmedletomidine $(0.5,1.0$, and $1.5 \mu \mathrm{g} / \mathrm{kg})$ with placebo given intramuscularly $60 \mathrm{~min}$ prior to induction, no difference was found in anesthetic requirements, but hemodynamic and sedative effects of dexmedetomidine were still apparent four hours after administration of the drug |61|. In a double-blind, randomised study of patients undergoing abdominal hysterectomy, a single intravenous dose of dexmedetomidine $0.6 \mu \mathrm{g} / \mathrm{kg}$, given before the induction of anesthesia, reduced the increase in heart rate in response to tracheal intubation and diminished isoflurane requirements, when compared to that required by patients receiving fentany $2 \mu \mathrm{g} / \mathrm{kg} \mathbb{4} 4$. In a further study of patients undergoing abdominal hysterectomy, these authors investigated the effect of a two step infusion to rapidly achicve a steady state plasma concentration on anesthetic requirement. Dexmedetomidine infusion did not completely abolish the need for isoflurane but diminished its requirement by $>90 \%$, while the heart rate response to tracheal intubation was considerably blunted [62].

\section{References}

1 Belleville JP, Ward DS, Bloor BC, Maze M. Effects of intravenous dexmedetomidine in humans. 1. Sedation, ventilation, and melabolic rate. Anesthesiology $1992 ; 77 ; 1125-33$. 
2 Redmond D. Does clonidine alter anxiety in humans? Trerds Phamacol Sici 1982; 3: 477-80.

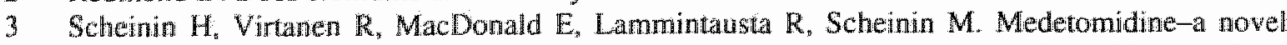
alphia 2-adremoceptor agonist: a review of its pharmacodynamic effects. Prog Neuropsychopharnacol Biol Pychiatry 1989; 13: 635-51.

4. Aho M, Lehtinen AM, Erkola $O$, Kallio A, Kortila K. The effect of intravenously administered dexmedetomidine on perioperative hemodynamics and isoflurane requirements in patients undergoing abdominal hysterectony. Anesthesiology 1991; 74: 997-1002.

5 Aho MS, Erkola OA, Scheinin H, Lehtinen AM, Korttila KT. Effect of intravenously administered dexunedetomidine on pain after laparoscopic wbal ligation. Anesth Analg 1991; 73: $112-8$.

6 Aantaa R, Kanto I, Scheinin M, Kallio A, Scheinin H. Dexmedetomidine, an alpha 2adrenoceptor agonist, reduces anesthetic requirements for patients undergoing minor gynecologic surgery. Anewhesiology $1990 ; 73: 230-5$.

7 Kallio $A$, Scheinin $M$, Koulu $M$, et al. Effects of dexmedetomidine, a selective alpha 2adrenoceptor agonist, on hemodynamic control mechanisms. Cin Pharmacol Ther 1989; 46: $33-42$.

8 Ghignone $M_{\text {"Noe }}$, Calwillo O, Quintin L. Anesthesila for ophthalmic surgery in elderly: the effects of clonidine on intra-ocular pressure "perioperative hemodynamics, and anesthetic requirement. Anesthesiology $1988 ; 68: 707-16$.

9 Kalso EA, Poyhia $\mathbb{R}$, Rosenberg PH. Spinal antinociception by diexmedetomidine, a highly selective alpha 2-adrenergic agonist. Pharmacol Toxicol 1991; 68: $1.40-3$.

10 Zomow MH, Scheller MS, Sheehan PB, Strnat MA, Matsumoto M. Intracranial pressure effects of dexmedetomidine in rabbits. Anesth Analg 1992; 75:232-7.

11 Hoffman WE, Kochs E, Werner C. Thomas C, Albrecht RF. Dexmedetomidine improves neurologic outcome from incomplete ischemia in the rat. Reversal by the alpha 2-adrenergic antagonist atipamezole. Anesthesiology 1991; 75:328-32.

12 Weinger MB, Segal IS, Maze M. Dexmedetomidine, acting through central alpha-2 adrenoceptors, prevents opiate-induced muscle rigidity in the rat. Anesthesiology $1989 ; \mathbf{7 1}$ : 242-9.

13 Delatuay L, Bonnet F, Duvaldestin P. Clonidine decreases postoperative oxygen consumption in patients recovering from general anaesthesia. Br J Anaesth 1991; 67: 397-401.

14 Quintin L, Viale JP, Annat G, et al. Oxygen uptake after major abdominal surgery: effect of clonidine. Anesthesiology 1991; 74: 236-41.

15 Wilkins AJ, Jenkins WJ, Steiner JA. Efficacy of clonidine in treatment of alcoholl withdrawal state. Psychopharmacology $1983 ; 81: 78-80$.

16 Gold MS. Pottash AC, Sweeney DR, Klever HD. Opiate withdrawal using clonidine. A safe, effective, and fapid nonopiate treatment. JAMA 1980; 243: 343-6.

17 van Zwieten PA. Drugs interacting with alpha adrenoceptors. Cardiowasc Drugs Ther 1989: 3: $121-33$.

18 Hoelhn-Saric R, Merchant A, Keyser M. Smith V. Effects of clonidine on anxiety disorders. Arch Gen Psycthatry 1981; 38: 1278-82.

19 Lammintausta $R$, Uyeno $E_{*}$ Hollister $L$, Csermansky J. A selective alpha-2-agonist, medetomidine, shows anxiolytic effects in the rat approach/awoidance conflict test. ACNP Abstracts. Washimton DC, 1986, pp 205.

20 Handley $S$, Mithani $S$. Effects of alpha-adrenoceptor agonists and antagonists in a mazeexploration model of "fear"-motivated behaviour. Namny-Sckmiedebergs Arch Pharmacol 1984; 327: $1-5$.

21 Miller RD, Way WL, Eger EI. The efects of alpha-methyldopa, reserpine, guanethidine and iproniazid on minimum alveolar anesthetic requirement (MAC). Anesthesiology: 1968; 29: 1153-8. 
22 Roizen M, Kopin. I. Thoa N, et al. The effect of two anesthetic agents on nonepinephrine and dopamine in discrete brain nuclei, fiber tracts and terminal regions of the rat. Broin Res 1976 ; 110: $515-22$.

23 Roizen MF, White PF, Eger El, Brownstein M. Effects of ablation of serotonin or norepinephrine brain-stem areas on halothene and cyclopropane MACs in rats. Anestheshology 1978 ; 49: $252-5$.

24 Maze M, Birch B, Vickery R. Clonidine reduces halothane MAC in rats. Anesthesiology 1987; 67: 868-9.

25 Maze M. Vickery R, Merlone S, Gaba D. Anesthetic and hemodynamic effects of the alpha2" adrenergic agonist, azepexole, in isoflurane anesthetized dogs. Anesthesiology 1988: 68: 689-94.

26 Segal IS, Vickery RG, Walton JK, Doze VA, Maze M. Dexmedetomidine diminishes hallothane anesthetic requirements in rats through a postsynaptic alpha 2 adrenergic receptor. Anesthesiology 1988; 69:818-23.

27 Doze VA, Chen BX, Maze M. Dexmedetomidine produces a hyprotic-anesthetic action in rats via activation of central alpha-2 adrenoceptors. Anesthexiology $1989 ; 71 ; 75-9$.

28 Cedarbaum JM, Aghajanian GK. Catecholamine receptors on locus coeruleus neurons: pharmacological characterization. Eur I Pharmacol 1977; 44: 375-85.

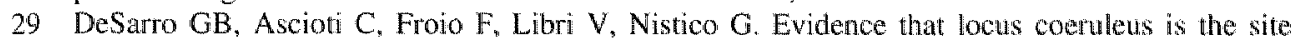
where clonidine and drugs acting at $\alpha_{1}$ - and $\alpha_{2}$ adrenoceptors affect sleep and arousal mechanisms. Br J Pharmacal 1987; 90: 675-85.

30 Correa-Sales C, Rabin BC, Maze M. A hypnotic response 10 dexmedetomidine, an alpha 2 agonist, is mediated in the locus coeruleus in rats [see comments]. Anesthesiology 1992; 76: $948-52$.

31 Spaulding TC, Fielding S, Venafro JJ, Lal H. Antinocioceptive activity of clonidine and its potentiation of morphine analgesia. Eur I Pharnacol 1979; 58: 19-25.

32 Puke $M J$, Wiesenfeld $H Z$. The differential effects of morphine and the alpha 2-adrenoceptor agonists clonidine and dexmedetomidine on the prevention and treatment of experimental neuropathic pain. Anesth Analg 1993; 77: 104-9.

33 Ylisela $\mathrm{E}$, Vainio $\mathrm{O}$. Effects of medetomidine on the experimental auricular pain in dogs. Acta Vet Scand Supp! 1989; 85: 187-91.

34 Furst SR, Weinger MB. Dexmedetomidine, a selective alpha 2-agonist, does not potentiate the cardiorespiratory depression of alfentanil in the rat. Anesthesiology 1990; 72: 882-8.

35 Bailey PL. Sperry RJ, Johnson GK, et al. Respiratory effects of clonidine allone and combined with morphine, in humans. Anesthesiology 1991; 74: 43-8.

36 Aghajanian $G_{n}$ Wang $Y$. Common $\alpha_{2}$-opiate and effector mechanisms in the locus coeruleatus: intracellular studies in brain slices. Neurophamacology 1987, 26: 793-9.

37 Solomon RE, Brody MJ, Gebhart GF. Pharmacological characterization of alpha adrenoceptors involved in the antinociceptive and cardiovascular effects of intrathecally administered clonidine. I Pharmacol Exp Ther 1989; 251: 27-38.

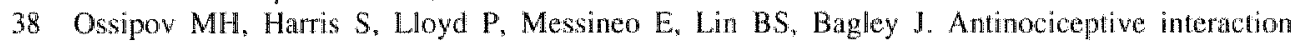
between opioids and medetomidine: systemic additivity and spinal synergy. Aneshesiotogy 1990; 73: $1227-35$.

39 Sullivan AF, Kalso EA, McQuay HJ, Dickenson AH. Evidence for the involvement of the mu but not delta opioid receptor subtype in the synergistic interaction between opioid and allpha 2 adrenergic antinociception in the rat spinal cord. Neurosci Lett 1992: 139:65-8.

40 Sullivan AF, Kalso EA. McQuay HJ, Dickenson AH. The antinociceptive anctions of dexmedetomidine on dorsal horn neuronal responses in the anaesthetized rat. Eur I Pharnacol $1992 ; 215: 127-33$.

41 Bernard IM, Kick O. Bonnet F. Comparison of intravenous and epidural clonidine for postoperative patient-controlled analgesia. Anesh Amalg 1995; 81: 706-12. 
42 Eisenach JC, Hood DD, Tuttle R. Shafer \$. Smith T, Tong CH. Computor-cortrolled epidural infusion to targeted cerebrospinal fluid concentrations in humans. Clonidine. Anesthesiology $1995: 83: 33-47$.

43 Liu $S$, Chíu A, Neall J, Carpenter $R$, Bainton $B G$, Gerancher JC. Oral clonidine prolongs lidocaine spinal anesthesia in human volunteers. Anesthesiology 1995; 82: 1353-9.

44. Eisenach JC, Du Pen S, Duboif M, Migue] R, Allin D. Epidural clonidine for intractable cancer pain. Pain 1995; $61: 391-9$.

45 Flacke J, Bloor B. Flacke W, ef al. Reduced narcotic requirement by clonidine with improved hemodynamic and adremergic stability in patients undergoing coronary bypass surgery. Anesthesiology $1987 ; 67: 11-9$.

46 Erkola $O$, Kortila $K$, Aho $M$. Halasio J, Aantaa $R$, Kallio A. Comparison of intramuscular dexmedelomidine and midacolam premedication for elective abdominal hysterectomy. Anesth Afralg 1994; 79:646-53.

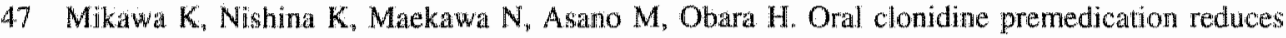
vomiting in children after strabismus surgery. Can J Amaesth 1995; 42: 977-81.

48 Karhuvaara $S_{2}$ Kallio $A_{\text {n }}$ Sallonen M, Tuominen J, Scheinin M. Rapid reversall of alpha 2adrenoceptor agonist effects by atipamezole in human wolunteers. Br J Clin Pharnacol 1991; 31 : $160-5$

49 Wikberg $J$. Localization of adrenergic receptors in guinea pig ileum and rabbit jejunum to cholinergic neurons and to smooth muscle cells. Acta Physiol Scand 1977; 99: 190-207.

50 Jaakola $M L$, Ali MT, Kanto J, Kallio A, Scheinin $H$, Scheinin M. Dexmedetomidine reduces intraocular pressure, intubation responses and anaesthetic requirements in patients undergoing ophthalmic surgery. Br J Ancesth 1992; 68: 570-5.

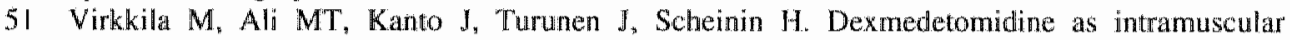
premedication for day-case cataract surgery. A comparative study of dexmedetonidine, midazolam and placebo. Anaesthesia 1994; 49: 853-8.

52 Moens $Y$, Fargetton $X$. A comparative study of medetomidine/ketamine and xylazine/ketamine anaesthesia in dogs [see comments]. Ver Rec 1990; 127: 567-71.

53 Verstegen J, Fargetton X. Domay I, Ectors F. Comparison of the clinical utility of medetomidine/ketamine and xylazine/ketamine combinations for the ovariectomy of cats. Vet Rec 1990; 127: 424-6.

54 MacDonald E, Scheinin H, Scheinin M. Behavioural and newrochemical effects of medetomidine, a novel veterinary sedative. Eur J Pharmacol 1988; 158: 119-27.

55 Kaukinen $S$, Pyykko $K$. The potentiation of halothane anaesthesia by clonidine. Acta Anaesthesiol Scand 1979; 23: 107-11.

56 Ghignone $M$, Quintin L, Duke P, Kehler C, Calvillo O. Effects of clonidine on narcotic requirements and hemodynamic response during induction of fentanyl anesthesia and endotracheal intubation. Anesthestology 1986; 64:36-42.

57 Ghignone M. Calvillo $O$, Quintin L. Anesthesia and hypertension: the effect of clonidine on perioperative hemodynamics and isoflurane requirements. Anesthesiology 1987; 67:3-10.

58 Engelman E, Lipsyyc M, Gilbart E, et al. Effects of clonidine on anesthetic drug requirements and hemodynamic response during aortic surgery. Anesthesiology 1989; 71: 178-87.

59 Quintin L, Roudot F, Roux C, et al. Effect of clonidine on the circulation and vasoactive homones after aortic surgery. $B r J$ Ancesth 1991; 66: 108-15.

60 Aanvaa RE, Kanto JH, Scheinin M* Kallio AM, Scheinin H. Dexmedetomidine premedication for minor gynecologic surgery. Anesth Analg 1990; 70: 407-13.

61 Aantaa $R$, Kanto J, Scheinin M. Intramuscular dexmedetomidine, a novel alpha 2-adrenoceptor "ngonist, as premedication for minor gynaecological surgery. Acta Anaesthesiof Scand 1991; 35: $28,3-8$

62 Aho M. Erkola O. Kallio A, Scheinin H, Korttila K. Dexmedetomidine infusion for maintenance of anesthesia in patients undergoing abolominal hysterectomy. Anesth Analg 1992; 75: 940-6. 


\title{
Comparison of the hemodynamic and coronary vascular effects of dexmedetomidine and clonidine in the anesthetized dog ${ }^{\dagger}$
}

\author{
C. J. Lawrence, F. W. Prinzen, and S. de Lange
}

\begin{abstract}
The hemodynamic and coronary vascular effects of the new selective $\alpha_{2}$-udrenergic agonist dexmedetomidine and the established but less $\alpha_{2}$-selective agonist clonidine have not yer been compared in the same protocol in vivo. To this purpose we studied is anesthetized open-chest dogs. After baseline measurements, seven dogs received dexmedetomidine in doses of $0.1,0.3,1,3$, and $10 \mu \mathrm{g} / \mathrm{kg}$ and eight dogs were given clonidine $1,3,10$, and $30 \mu \mathrm{g} / \mathrm{kg}$ as $2-\mathrm{min}$ intravenous injections at $20 \mathrm{~min}$ intervals. Two minutes after arug administration dexmedetomidine was $3-10$ times more potent than clonidine in increasing blood pressure and systemic and coronary vascular resistance and decreasing heart rate, cardiac output, and mixed venous and cotonary venous oxygen saturation. Within $15 \mathrm{~min}$ the pressor effect faded and both venous oxygen saturations recovered for dexmedetomidine and clonidine. High dose clonidine $(10$ and $30 \mu \mathrm{g} / \mathrm{kg})$ induced prolonged coronary vasoconstriction and reduction in $\mathrm{dP} / \mathrm{dt} \mathrm{t}_{\text {inax. }}$. We conclude that slow administration is more important for the potent and selective $\alpha_{2}$-adrenergic agonisi dexmedetomidine than for clonidine. Dexmedetomidine lacks the untoward, probably $\alpha_{1}$ adrenergic effects, occurring at high doses of clonidine.
\end{abstract}

\section{Introduction}

$\alpha_{2}$-Adrenergic agonists have a number of central nervous system actions which may be beneficially applied in clinical anesthesia; those reported include sedation, anxiolysis, analgesia, reduction of anesthesia requirement, and a reduction of the hemodynamic and metabolic stress response to anesthesia and surgery [1]. Clonidine, one of the first $\alpha_{2}$-adrenergic agonists used clinically, reduced the minimal alveolar

\footnotetext{
"Submitted for publication (presented in part at the European Association of Cardiolhoracic Anaesthesiologists" seventh Anmul Meeting Maastricht, The Netherlands, June 9-12, 1992, and published in abstract form in d Cardiothorac Vasc Anesth 1994: 8 (Suppl 2): 32)
} 
concentration (MAC) for halothane by $40 \%-50 \%$, in dogs [2] and rats [3] but a ceiling effect was noted so that increasing the dose tenfold did not further reduce anesthetic requirements. This is thought to be due to $\alpha_{1}$-adrenergic receptor activation by high doses of clonidine antagonizing the $\alpha_{2}$-adrenergic receptor mediated hypnotic response. Dexmedetomidine is one of the newer generation of $\alpha_{2}$-adrenergic agonist with a greater selectivity for the $\alpha_{2}$-adrenergic receptor [4] and a greater anestheticsparing effect than clonidine 15,6$]$. Dexmedetomidine is the dextro enantiomer of medetomidine, the laevo enantiomer being inactive 17,8]. Medetomidine is routinely used in veterinary anesthesia. Volunteer and clinical studies have shown dexmedetomidine's sedative, anxiolytic, analgesic and anesthetic agent sparing actions in nan $[9,10]$.

Besides these sedative effects, $\alpha_{2}$ adrenergic agonist have also considerable hemodynamic effects. They are known to give rise to a rapid pressor effect followed by a long lasting reduction in heart rate and blood pressure. This has been demonstrated for both drugs $[1-16]$, but never compared in the same experimental setting. Of special interest is the effect on the coronary circulation, since some reports suggest that $\alpha_{2}$-adrenergic mediated coronary vasoconstriction may occur [17].

Therefore we studied dexmedetomidine and clonidine in a dog model, which allowed extensive measurements of hemodynamic and coronary vasculat variables. Since the dog is more prone to $\alpha_{2}$-adrenergic vasoconstriction than man [13], possibly harmful vasoconstrictive effects can be determined more sensitively in this species.

\section{Methods}

These experiments conformed to the Dutch law for animal experimentation and were approved by the local animal ethical committee. Fifteen adult, healthy, mongrel dogs of either sex weighing between 20 and $40 \mathrm{~kg}$ were fasted overnight then premedicated with fentanyl $250 \mu \mathrm{g}$ intramuscularly $30 \mathrm{~min}$ prior to anesthesic induction. Anesthesia was induced with thiopental $20 \mathrm{mg} / \mathrm{kg}$ intravenously given via a vein in the hind leg. After intubation, the dogs were ventilated with a mixture of oxygen $40 \%$ and nitrous oxide $60 \%$ using a Drager Pulmomat mechanical ventilator. Tidal volume (initially 15 $\mathrm{mL} / \mathrm{kg}$ ) and respiratory rate (12-18 per $\mathrm{min}$ ) were adjusted to maintain end-expired carbon dioxide concentration (Datex capnograph Oscar, Datex Instrumentation Corp., Helsinki, Finland) between 3.5 and $4.5 \mathrm{kPa}$. Halothane $1.0 \%$ was added to the inspired gases. Fentanyl $1-2 \mu \mathrm{g} / \mathrm{kg}$ intravenously was given as necessary to maintain heart rate between 90 and $110 \mathrm{bpm}$. Oxygen saturation was monitored by tongue pulse oximetry (Datex Oscar) and arterial blood gases were analyzed every half hour during the study (ABL 3, Radiometer). Arterial desaturation was treated by increasing the inspiratory oxygen concentration and metabolic acidosis by infusing sodium bicarbonate $4.2 \%$. The temperature was recorded and maintained as close as possible to $38^{\circ} \mathrm{C}$ by means of a heating pad under the dog. A venous cannula was inserted in a leg vein for infusion of fluids and medication. Crystalloid ( $0.9 \%$ sodium chloride solution) was 
infused to maintain hydration and replace losses. Colloid (Haemaceel, Bahring Pharma) was infused to replace blood loss. A femoral artery was surgically exposed and a long catheter for arterial blood sampling and measurement of arterial pressure (Millar micro-manometer catheter tip) introduced into the aorta. The thorax was opened via the fifth lateral intercostal space and the pericardium opened to expose the heart. The left interventricular coronary artery was prepared and a flow probe (Skalar, Delft, The Netherlands) placed around it near its origin. A small polyethelene cathetei (PE 60) was inserted into the coronary vein accompanying the artery in order to obtain regional venous blood samples. A micro-manometer cathetertip transducer (Millar, Housten, TX, U.S.A.) was inserted into the left ventricle via the left common carotid artery or the right femoral artery. The first positive derivative of left ventricular pressure ( $\mathrm{LVdP} / \mathrm{dt}_{\text {max }}$ ) and heart rate were derived from the left ventricular pressure signal. A thermodilution pulmonary artery catheter was introduced via the left external jugular vein and floated into the pulmonary artery using the continuously displayed pressure tracing as a guide. This catheter was used to obtain mixed venous blood samples from the pulmonary artery and to measure cardiac output by the thermodilution technique using a cardiac output computer (Edwards SAT 1). Cardiac output was measured in triplicate using cold injectate and the average taken. Left ventricular pressure, aortic pressure, coronary flow and electrocardiogram (lead II) were displayed contimuously (Knott). All pressures and flows were recorded continuously using a Schwarzer pen-recorder at $0.25 \mathrm{~cm} / \mathrm{s}$, increased to $5 \mathrm{~cm} / \mathrm{s}$ during data acquisition.

Dexmedetomidine was supplied by Orion Corp., Farmos, Turku, Finland as a crystalline powder. This was disolved in saline to produce a solution containing 100 $\mu \mathrm{g} / \mathrm{kg}$. The calculated dose was taken from this solution and diluted to $20 \mathrm{~mL}$ in saline before injection. Clonidine (Sigma Chemical Corp., St Louis, MO, U.S.A.) was supplied as a crystalline powder. This was dissolved in saline to produce a solution containing $100 \mu \mathrm{g} / \mathrm{kg}$. The calculated dose was taken from this solution and diluted to $20 \mathrm{~mL}$ in saline before injection. All test medications were given over two minutes into the right atrium through the right atrial port of the pulmonary artery catheter.

After a stabilization period of $30 \mathrm{~min}$ baseline measurements were taken. Following this, increasing doses of clonidine or dexmedetomidine were given as stated above and measurements recorded at peak blood pressure effect (within $1-2 \mathrm{~min}$ ), and $15 \mathrm{~min}$ later. Eight dogs received clonidine in the doses $1,3,10$, and $30 \mu \mathrm{gg} / \mathrm{kg}$ and seven dogs dexmedetomidine in the doses $0.1,0.3,1,3$, and $10 \mu \mathrm{g} / \mathrm{kg}$ at 20 -min intervals.

At each measurement point the following data were obtained: heart rate, mean arterial pressure, left ventricular end-diastolic pressure, coronary flow, LVdP/dt max, thermodilution cardiac output; arterial, mixed venous (pulmonary artery) and coronary venous blood was collected for measurement of hemoglobin and blood gases. (ABL 3 , Radiometer blood gas analyzer, OSM 2 hemoximeter (Radiometer) saluration analyzer (calibrated for dog blood)). 
Systemic vascular resistance (SVR), and coronary vascular resistance (CVR) were calculated using the formulae below:

$$
S V R=M A P \times 80 / C O\left(\text { dynes } \cdot \mathrm{s} \cdot \mathrm{cm}^{-5}\right)
$$

where

$$
\begin{aligned}
\text { MAP } & =\text { mean arterial pressure }(\mathrm{mm} \mathrm{Hg}) \\
C O & =\text { cardiac output }(\mathrm{L} / \mathrm{min})
\end{aligned}
$$

$$
C V R=M A P / C F\left(m m H g \cdot m L^{-1} \cdot \min ^{-3}\right)
$$

where $C F=$ coronary blood flow $(\mathrm{mL} / \mathrm{min})$.

\section{Statistical analysis}

Two-way analysis of variance for repeated measures was used for intergroup comparisons. Intragroup comparisons were evaluated using one-way analysis of variance for repeated measures. When significance was found, Fisher's protected least significant difference test was used as a post-hoc multiple comparison procedure. Baseline values between the two groups were compared using Student's t-test. A $P$ value of less than 0.05 was considered significant.

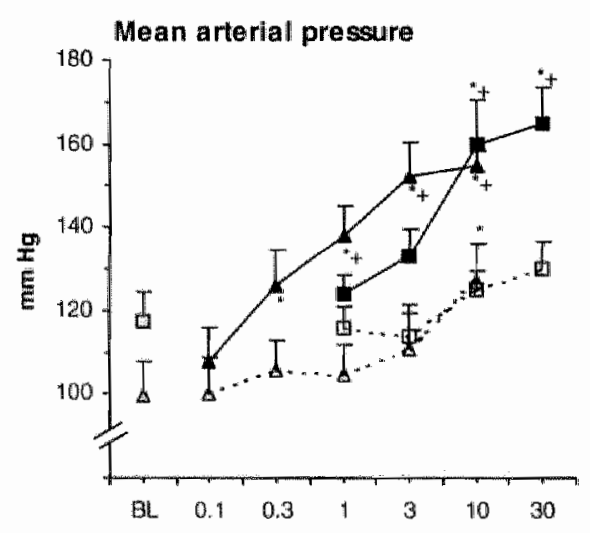

Dexmedetomidine / Clonidine ( $\mu \mathrm{g} / \mathrm{kg})$

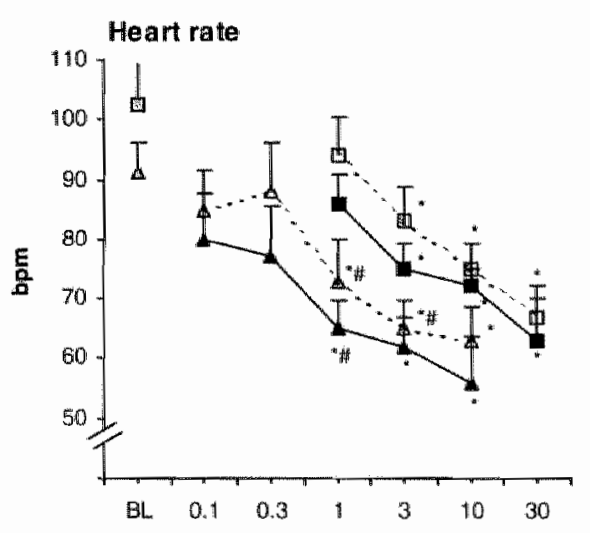

Daxm ede tomidime / Clonidine $(\mu \mathrm{g} / \mathrm{kg})$
A. DMBL

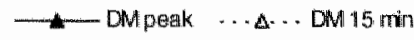
G ClBL
$\longrightarrow$ CL peak …… OL 15 min

Algure 4-1 Eflects of dexmedetomidine (DM) and clonidine (CL) oth mean arterial pressure (left) and heart rato (righlu. Measarements at batine (BL), peak mean arterial blood pressure (peak), and 15 min after administation (15 min). All values are mean \pm sEM. * Significantly different from baseline. \# Significant diference between the two groups. + Significant difference between peak and 15 -min walue. 


\section{Results}

Figure 4-1 depicts the effect of the two drugs on mean arterial pressure. Increasing doses of the drugs caused increasingly high peaks in mean arterial pressure. Fifteen minutes after 'peak' effect, MAP was only increased after $10 \mu \mathrm{g} / \mathrm{kg}$ dexmedetomidine. Two minutes after administration of dexmedetomidine blood pressure increased more than after the same dose of clonidine. However, 15 min later there was no significant difference in the change in blood pressure (Figure 4-1). Heart rate decreased significantly after dexmedetomidine $\geq 1 \mu \mathrm{g} / \mathrm{kg}$ and after clonidine $\geq 3 \mu \mathrm{g} / \mathrm{kg}$. The effect was dose-dependent both for peak and 15 -min values and there was no significant difference between peak and 15-min values (Figure 4-1).

Both drugs decreased cardiac output dose-dependently (Figure 4-2). This reduction was significant for dexmedetomidine $\geq 1 \mu \mathrm{g} / \mathrm{kg}$ and clonidine $\geq 10 \mu \mathrm{g} / \mathrm{kg}$. No significant recovery of cardiac output occurred within 15 min with either drug (Figure 4-2). Both $\alpha_{2}$-agonists dose-dependently increased systemic vascular resistance. Two minutes after drug administration this increase was significant for dexmedetomidine $\geq 1 \mu \mathrm{g} / \mathrm{kg}$ and for clonidine $\geq 10 \mu \mathrm{g} / \mathrm{kg}$ (Figure 4-2). Systemic vascular resistance recovered to baseline values after dexmedetomidine $1 \mu \mathrm{g} / \mathrm{kg}$ but not after clonidine 10 $\mu \mathrm{g} / \mathrm{kg}$ (Figure 4-2).
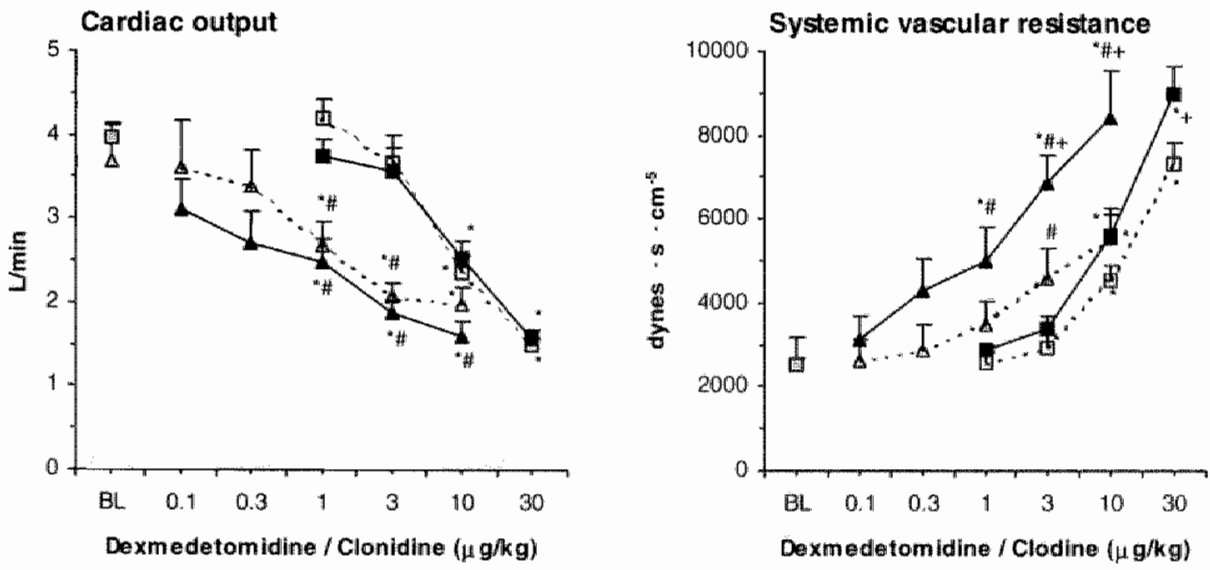

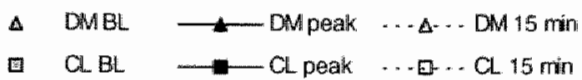

Figure 4-2 Effects of dexmedetomidine (DM) and clonidine (CL) on cardiac output (left) and systemic vascular resistance (right). Measurements at baseline (BL), peak mean arterial blood pressure (peak), and $15 \mathrm{~min}$ after administration (15 min). All values are mean 1 sem. "Significantly different from baseline. Significant difference between the two groups. Significant difference between peak and 15 -min walue. 

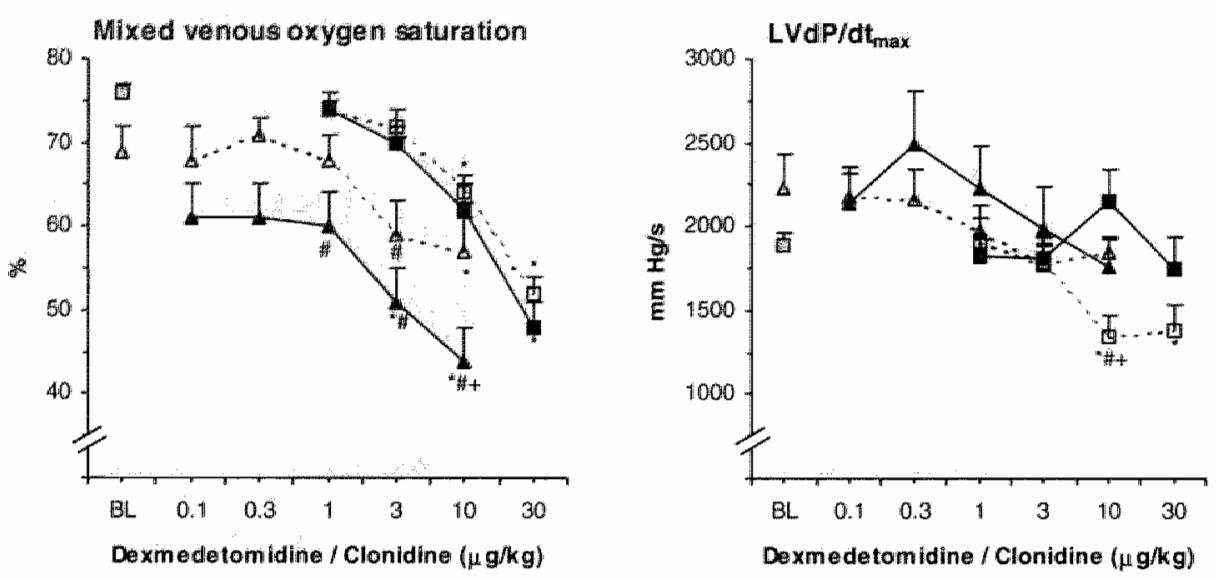

$\triangle \quad$ DMBL $\longrightarrow$ DMpaak $\cdots \Delta . .$. DM 15 min

- C.BL $\rightarrow$ CL peak ...

Dexmedetomidine / Clonidine $(\mu \mathrm{g} / \mathrm{kg})$

Figure 4-3 Effects of dexmedetomidine (DM) and clonidine (CL) on mixed venous oxygen saturation (left) and $\mathrm{LVdP}_{\mathrm{d}} \mathrm{I}_{\max }$ (right). Measurements at baseline (BL), peak mean arterial blood pressure (peak), and $15 \mathrm{~min}$ after administration (15 min). All values are mean \pm SEM. * Significantly different from baseline. \# Significant difference between the two groups. \# Significant difference between peak and 15 -min value.

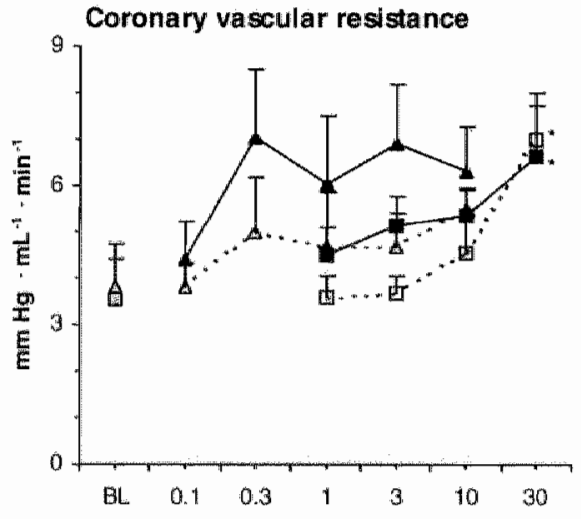

Dexmedletomidine / Clonidine $(\mu \mathrm{g} / \mathrm{kg})$

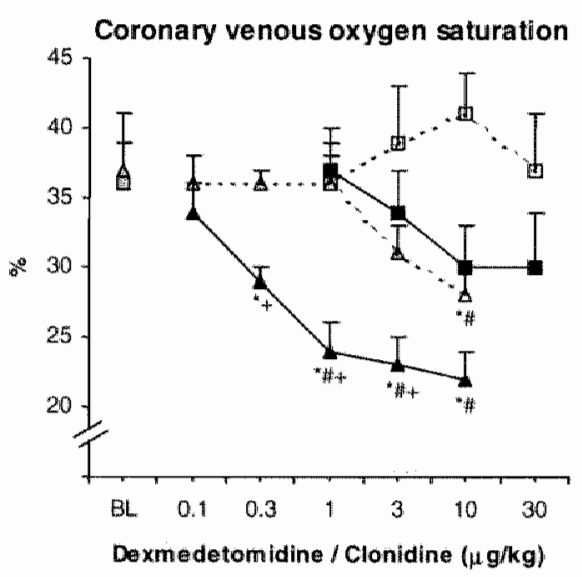
$\triangle$ DABL

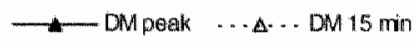
a. BL.
$\longrightarrow$ C. peak …… C. 15 min

Figure 4-4 Effects of dexmedetomidine (DM) and clonidine (CL) on coronary vascular resistance (left) and coronary venous oxygen saturation (right). Measurements at baseline (BL), peak mean arterial blood pressure (peak), and 15 min after administration (15 min). All vallues are mean I SEM. * Significantly different from baseline. Significant difference between the two groups. + Significant difference between peak and 15 -min walue. 
Table 4-1 Effects of increasing doses of dexmedetomidine ar clonidine

\begin{tabular}{|c|c|c|c|c|c|c|c|c|}
\hline \multirow[b]{2}{*}{ Variable } & \multirow[b]{2}{*}{ Dose } & \multirow[b]{2}{*}{ Basellne } & \multicolumn{2}{|c|}{$0.1 \mu \mathrm{g} / \mathrm{kg}$} & \multicolumn{2}{|c|}{$0.3 \mathrm{Hg} / \mathrm{kg}$} & \multicolumn{2}{|c|}{$1.0 / \mathrm{gg} / \mathrm{kg}$} \\
\hline & & & peak & $15 \mathrm{~min}$ & peak & 15 min & peallk & 15 nin \\
\hline & DM & $40.7 \pm 4.6$ & $38.3 \pm 2.5$ & $42.8 \pm 5.5$ & $35.4 \pm 4.0$ & $38.7 \pm 3.9$ & $41.4 \pm 7.7$ & $37.6 \pm 40$ \\
\hline$(m L)$ & $\mathrm{CL}$ & $38.0 \pm 1.9$ & & & & & $41.4 \pm 2.6$ & $41.7 \pm 3.2$ \\
\hline LVEDP & DM & $8.2 \pm 2.6$ & $7.9 \pm 0.1$ & $7.4 \pm 0.1$ & $9.9 \pm 0.1$ & $7.6 \pm 0.1$ & $45.9 \pm 2.8^{*}$ & $84 \pm 29$ \\
\hline$(\mathrm{mm} \mathrm{Hg})$ & $C L$ & $10.6 \pm 1.0$ & & & & & $19.5 \pm 1.2$ & $11.8 \pm 1.0$ \\
\hline \multirow{4}{*}{$\begin{array}{l}\mathrm{CF} \\
\text { (m)L/min) }\end{array}$} & $\mathrm{DM}$ & $33.3 \pm 5.6$ & $29.6 \pm 4.5$ & $28.4 \pm 3.1$ & $22.8 \pm 3.9$ & $26.7 \pm 4.1$ & $28.3 \pm 3.8$ & $27.2 \pm 3.1$ \\
\hline & $\mathrm{Cl}$ & $36.4 \pm 3.9$ & & & & & $31.4 \pm 42$ & 36.314 .3 \\
\hline & & & \multicolumn{2}{|c|}{$3.0 \mu \mathrm{g} / \mathrm{kg}$} & \multicolumn{2}{|c|}{$10 \mu \mathrm{g} / \mathrm{kg}$} & \multicolumn{2}{|c|}{$30 \mu \mathrm{g} / \mathrm{kg}$} \\
\hline & & & peak & $15 \mathrm{~min}$ & peak & $15 \mathrm{~min}$ & pealk & $15 \mathrm{~min}$ \\
\hline SV & $D M$ & & $31.3 \pm 4.1 \dagger$ & $32.7 \pm 2.9$ & $30.4 \pm 4.9$ & $32.8 \pm 4.0$ & & \\
\hline$(m L)$ & $\mathrm{CL}$ & & $44.8 \pm 4.2 \dagger$ & $41.6 \pm 4.5$ & $33.5 \pm 2.8$ & $31.5 \pm 2.4$ & $25.7+2.5^{*}$ & $22.8 \pm 22^{\circ}$ \\
\hline LWEDP & DM & & $16.7 \pm 3.1^{*}$ & $9.9 \pm 3.0$ & $18.6 \pm 2.3^{*}$ & $11.0 \pm 22$ & & \\
\hline$(\mathrm{mm} \mathrm{Hig})$ & $\mathrm{CL}$ & & $14.8 \pm 1.5$ & $12.1 \pm 1.3$ & $19.0 \pm 2.6^{*}$ & $12.1 \pm 1.6$ & $19.0 \pm 2.0^{*}$ & $11.5 \pm 2.0$ \\
\hline CF & $\mathrm{DM}$ & & $29.0 \pm 6.3$ & $27.6 \pm 4.0$ & $29.6 \pm 5.2$ & $23.6 \pm 1.7$ & & \\
\hline$(\mathrm{mL} / \mathrm{min})$ & $\mathrm{Cl}$ & & $30.1 \pm 4.6$ & $34.4 \pm 4.2$ & $31.9 \pm 3.4$ & $33.6 \pm 5.0$ & $30.8 \pm 5.6$ & $22.1 \pm 3.5^{*}$ \\
\hline
\end{tabular}

Values are expressed as mean \pm SEM. peak = peak blood pressure effect: 15 min = elfect 15 min after peak effect $S V=$ stroke volume; LVEDP = left ventricular end-diastolic pressure; $\mathrm{CF}=$ coronary blood flow: DM = dexmedetomidine; $\mathrm{CL}=$ clonidine; $\mathrm{SEM}=$ standard error of the mexn. "Significanily different from baseline. $\downarrow$ Significant difference betwen DM and CL.

In both groups the immediate changes in mixed venous oxygen saturation followed the changes in cardiac output. (Figure 4-3). After dexmedetomidine $10 \mu \mathrm{g} / \mathrm{kg}$ mixed venous saturation recovered significantly while after clonidine 10 and $30 \mu \mathrm{g} / \mathrm{kg}$ there was no significant recovery. $\mathrm{LVdP} / \mathrm{dt}_{\max }$ was not significantly altered by even the highest doses of dexmedetomidine (Figure 4-3). In contrast, clonidine (10 and $30 \mu \mathrm{g} / \mathrm{kg}$ ) decreased $\mathrm{LVdP} / \mathrm{dt}_{\max } 15 \mathrm{~min}$ after administration, although not at peak effect.

Dexmedetomidine did not significantly affect stroke volume, but $30 \mu \mathrm{g} / \mathrm{kg}$ clonidine caused a significant decrease in stroke volume (Table 4-1). Left ventricular enddiastolic pressure increased significantly after dexmedetomidine $\geq \mathrm{l} \mu \mathrm{g} / \mathrm{kg}$ and clonidine $\geq 10 \mu \mathrm{g} / \mathrm{kg}$ but recovered after $15 \mathrm{~min}$ with all doses (Table 4-1). No significant changes occured in coronary blood flow after either drug except 15 min after clonidine $30 \mu \mathrm{g} / \mathrm{kg}$ (Table $4-1$ ).

At low doses clonidine affected coronary vascular resistance less than dexmedetomidine, but after $30 \mu \mathrm{g} / \mathrm{kg}$ a pronounced, significant increase in coronary vascular resistance occurred which did not decrease within 15 min (Figure 4-4). Coronary venous oxygen saturation decreased with increasing doses of dexmedetomidine above $0.3 \mu \mathrm{g} / \mathrm{kg}$ with significant recovery within $15 \mathrm{~min}$ after all doses except $10 \mu \mathrm{g} / \mathrm{kg}$ (Figure 4-4). No significant reduction in coronary venous oxygen saturation was seen after clonidine. 
Table 42 Lowest dose wh a statistically sionificant change from baseline

\begin{tabular}{|c|c|c|c|c|}
\hline \multirow[b]{2}{*}{ Variable } & \multicolumn{2}{|c|}{ Dexmedetomidime (ug/kg) } & \multicolumn{2}{|c|}{ Clonidine $(\mu \mathrm{g} / \mathrm{kg})$} \\
\hline & peak & $15 \mathrm{~min}$ & peak & $15 \mathrm{~min}$ \\
\hline Heant rate & 9 & 1 & 3 & 3 \\
\hline MAP & 03 & 10 & 10 & None \\
\hline SVR & 1 & 10 & 10 & 10 \\
\hline CVR & Mone & None & 30 & 30 \\
\hline $\mathrm{MixwO}_{2}$ & 3 & 10 & 10 & 10 \\
\hline Corvon: & 0.3 & 10 & None: & None \\
\hline LVEDP & 1 & None & 10 & None \\
\hline $\mathrm{CO}$ & 1 & 1 & 10 & 10 \\
\hline
\end{tabular}

peak $=$ at peak effect: 15 min $=15$ min after maximum effect; $M A P=$ mean arterial pressure; $S V R=$ systemic vascular resistance; $\mathrm{CVR}=$ coronary vascular resistance; $\mathrm{MixwO}_{2}=$ mixed venous oxygen saturation; $\mathrm{COrVO}_{2}=$ coronary venousi oxygen saturation; $\mathrm{LVEDP}=$ left ventricular end diastolic pressure; $C O=$ cardiac output.

Table 4-2 summarizes the lowest doses at which a significant change from baseline occurred for the variables shown.

\section{Discussion}

This study is the first to compare the systemic and coronary hemodynamic effects of clonidine and dexmedetomidine under the same conditions in vivo.

\section{Peripheral vascular effects}

The observation that changes in mean arterial pressure and cardiac output after dexmedetomidune $1 \mu \mathrm{g} / \mathrm{kg}$ were comparable to those after clonidine at doses between 3 and $10 \mu \mathrm{g} / \mathrm{kg}$ indicate clexmedetomidine's higher potency. These findings are in agreement with those of Kallio ef al. in human volunteers, who showed a similar reduction in cardiac output and blood pressure for $100 \mu \mathrm{g}$ medetomidine (the racemic mixture of dexmedetomidine and the biologically inactive L-medelomidine) and 200 $\mu \mathrm{g}$ clonidine [18]. The higher potency of dexmedetomidine is probably related to its higher selectivity for $\alpha_{2}$-adrenergic receptors than clonidine, and the fact that dexmedetomidine is a full agonist at the $\alpha_{2}$-adrenergic receptor whereas clonidine is a partial agonist [19].

A transient increase in blood pressure has also been reported after intravenous administration of clonidine and dexmedetomidine in man [20] and in dogs [15, 16]. Such a transient pressure effect was not found after slower intravenous infusion in human volunteers [18] or oral administration in dogs [21].

The reason for the shorter lived vasoconstrictive effect of dexmedetomidine compared to clonidine may be related to its increased lipophilicity [22]. As a consequence, this drug is more rapidly distributed in a large volume and has easy access to the central 
nervous system. The subsequent more powerful stimulation of central $\alpha_{2}$-adrenergic receptors could cause sympatholysis and thus decrease of vasoconstriction.

Although dexmedetomidine has a shorter elimination half-life than clonidine [23] this is unlikely to be a contributing factor since the reduction in cardiac output and heart rate have been shown to persist for at least one hour after intravenous administration of $5 \mu \mathrm{g} / \mathrm{kg}$ in dogs [7], and for four hours following $20 \mu \mathrm{g} / \mathrm{kg}$ intravenously in dogs [11].

The more persistent vasoconstrictive effects of clonidine 10 and $30 \mu \mathrm{g} / \mathrm{kg}$ may be due to the fact that at these doses $\alpha_{1}$-adrenergic effects are more apparent. Thus direct stimulation of $\alpha_{1}$-adrenergic receptors in vascular smooth muscle may sustain vasoconstriction at high doses [24]. It is important to note that these effects occurred at doses of clonidine 2-6 times higher than used in clinical anesthesia.

\section{Coronary vascular effects}

The coronary vascular effects of clonidine and dexmedetomidine were less pronounced than the effects on the peripheral circulation. As for the peripherall vascular effects, dexmedetomidine was more potent than clonidine, but the coronary vascular effects were also short-lived except after the highest dose $(10 \mu \mathrm{g} / \mathrm{kg})$. It is well known that a considerable species difference exists in the sensitivity of the coronary vascular bed for $\alpha$-adrenergic vasoconstriction, the dog being a species very prone to it [13]; a direct effect on isolated coronary artery strips has been demonstrated [25]. Recently, it has been shown by Indolfi et al. that $\alpha_{2}$-adrenergic mediated increase in coronary vascular resistance in humans is $28 \%$ at most [26], a value less than half the maximum observed in the present study.

After a dose of $30 \mu \mathrm{g} / \mathrm{kg}$ clonidine a pronounced and prolonged coronary vasoconstriction was observed. As for the peripheral circulation, this might be due to the prevailing $\alpha_{f}$-adrenergic effects.

\section{Cardiac effects}

A similar dosedependent, cumulative and persistent bradycardia was found for clonidine $\left(\geq 3 \mu \mathrm{g} / \mathrm{kg}\right.$ ) and dexmedetomidine $\left(\geq 1 \mu \mathrm{g} / \mathrm{kg}\right.$ ). This bradycardic effect of $\alpha_{2}$ adrenergic receptors is well known $[27,28]$ and thought to be due to a combination of presynaptic inhibition of norepinephrine release at cardiac sympathetic nerve terminals and central reduction of sympathetic drive plus vagal facilitation of the baroreceptor reflex. A reduction in heart rate at constant venous return would result in an increase in end-diastolic volume and, due to the Frank-Starling mechanism, in a larger stroke volume. The absence of an increase in stroke volume ais well as the tendency to a decrease in $\mathrm{LVdP} / \mathrm{dt}_{\text {max }}$ indicate a decrease in contractility. 
Such a negative inotropic effect has been previously demonstrated for dexmedetomidine $[11,12]$ and clonidine [16], and may be related to a reduction in central sympathetic outflow by stimulation of central $a_{2}$-adrenergic receptors [29]. Other studies have shown a reduction in plasma noradrenaline, supporting such sympatholylic effects $[21,30,3]]$.

\section{Possible clinical relevance}

Clonidine has been used clinically for 25 years in the treatment of hypertension [32], congestive heart failure [33] and to reduce myocardial ischemia and infarct size [34-36]. Moreover, clonidine in doses between 5 and $7 \mu \mathrm{g} / \mathrm{kg}$ reduced the hemodynamic response to tracheal intubation [37], stabilized hemodynamics during coronary artery bypass grafting \38\, major vascular [39] and general surgery [40] without any obvious deleterious effects on myocardial function and reduced the metabolic response to anesthesia and surgery [41].

Dexmedetomidine has greater anesthetic-sparing effects then clonidine in animals [5] and humans [42], and in clinical studies has significant sedative [43] and analgesic [44] activity at doses of 0.5 to $1.5 \mu \mathrm{g} / \mathrm{kg}$. It may, therefore, have advantages over clonidine when used as an anesthetic adjuvant.

In the present study performed in a species which is prone to $\alpha_{2}$-adrenergic vasoconstriction [13] we found no evidence of prolonged vasoconstrictive effects after dexmedetomidine at a dose $(0.5-2 \mu \mathrm{g} / \mathrm{kg})$ likely to be used in humans.

\section{Conclusion}

In an animal model prone to $\alpha_{2}$-adrenergic vasoconstriction, the hemodynamic effects of clonidine and dexmedetomidine are qualitatively similar, dexmedetomidine being 3-10 times more potent for the transient systemic and coronary vasoconstrictive effects. Fifteen minutes after administration the vasoconstrictive effects of dexmedetomidine are not greater than those of clonidine. At supraclinical doses clonidine has a more pronounced vasoconstrictive effect. These data indicate that slow intravenous administration is more important for a selective $\alpha_{2}$-adrenergic agonist like dexmedetomidine than for the less selective clonidine and that dexmedetomidine lacks the possibly untoward $\alpha_{1}$-adrenergic effects which occur at high doses of clonidine.

\section{Acknowledgments}

This work was supported in part by Orion Corporation, Farmos, Turku, Finland who also supplied the dexmedetomidine used in the study. The technical assistance of Mr. R. Kruger, Mr. T. vd Nagel, and Mr. J. Habets is gratefully acknowledged. 


\section{References}

1 Maze M, Tranquill W. Alpha-2 Adrenoceptor Agonists: Detining the Role in Climical Anesthesia Anesthesiology 1991; 74:581-605.

2 Bloor BC, Flacke WE. Reduction in halothane anesthetic requirement by clonidine, an alphaadrenergic agonist. Anesth Analg 1982;61: $741-5$.

3 Maze M, Birch B, Vickery R. Clonidine reduces halothane MAC in rats. Anesihesiology 1987: 67: 868-9

4 Virtanen R, Savola JM, Saano V. Nyman L. Characterization of the selectivity, specificify and potency of medetomidine as an alpha 2-adrenoceptor agonist. Eur J Pharmacol 1988; 150: $2-14$.

5 Segal IS, Vickery RG, Walton JK, Doze VA, Maze M. Dexmedetomidine diminishes halothane anesthetic requirements in rats through a postsynaptic alpha 2 adrenergic receptor. Anesthesiology 1988; 69:818-23.

6 Vickery RG, Sheridan BC, Segal IS, Maze M. Anesthetic and hemodynamic effects of the stereoisomers of medetomidine, an alpha 2-adrenergic agonist, in halothane-anesthetized dogs. Anesth Analg 1988; 67: 611-5.

7 Schmeling WT, Kampine JP, Roerig DL, Warltier DC. The effects of the stereoisomers of the alpha 2-adrenergic agonist medetomidine on systemic and coronary henodynamics in conscious dogs. Anesthesiology 1991; 75; 499-511.

8 Savola JM. Virtanen R. Central alpha 2-adrenoceptors are highly stereoselective for dexmedetomidine, the dextro enantioner of medetomidine. Eur J Pharmacol 1991: 195: 193 9 .

9 Aantaa $\mathbb{R}$, Kanto J, Scheinin M, Kallio A, Scheinin H. Dexmedetomidine, an alpha 2addrenoceptor agonist, reduces anesthetic requirements for patients undergoing minor gynecologic surgery. Anesthesiology 1990; 73:230-5.

10 Aho M, Lehtinen AM, Erkola O, Kallio A, Korttia K. The effect of intravenously administered dexmedetomidine on perioperative hemodynamics and isoflurane requirements in patients undergoing abdominal hysterectomy. Aneshesiology 1991; 74: 997-1002.

11 Bloor BC, Frankland M, Alper G, Raybould D, Weitz J, Shurtliff M. Hemodynamic and sedative effects of dexmedetomidine in dog. I Pharnacol Exp Ther 1992; 263:690-7.

12 Flacke WE, Flacke JW, Bloor BC, Mclntee DF, Sagan M. Effects of dexmedetomidine on systemic and coronary hemodynamics in the anesthetized dog. ICardiothorac Vasc Anesth 1993; 7: $41-9$.

13 Heusch $G$. Alpha-adrenergic mechanisms in myocardial ischemia. Circulation 1990; 81: 1-13.

14 Holtz J. Saeed $M$, Sommer O. Norepinephrine constricts the canine coronary bed via postsynaptic alphaz-adrenoceptors. Ear J Pharmacol 1982; 82: 199-202.

15 Jarvensivu P. Timisjarvi J, Ketunen R. The responses of the systemic and pulmonary circulations to intravenously administered clonidine in anaesthetized dogs. Acta Physiol Scand Suppl 1984; 537: 23-30.

16 Timisjarvi $\mathfrak{J}$, Jarvensiva $P$, Kettunen $R$. Left ventricular responses to intravenous administration of clonidine in anaesthetized dogs. Acta Physiol Sand Suppl 1984; 537: $31-7$.

17 Deussen $A$, Heusch $G$. Thämer V. $\alpha_{2}$-Adrenoceptor-mediatted coronary vasoconstriction persists after exhaustion of coronary vasodilator reserve. Ear J Pharmacol 1985; 115" 147-53.

18 Kallio A, Saraste M, Scheinin M, Hartiala J, Schemin H. Acute hemodymamic effects of medetomidine and clonidine in healthy volunteers: a moninvasive echocardiographic study. $J$ Cardiovasc Pharmacol 1990; 16: 28-33.

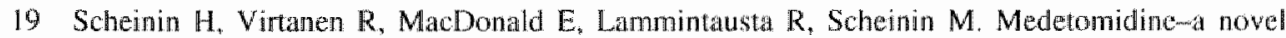
alpha 2-adrenoceptor agonist: a review of its pharmacodynamic effects. Prog Neuropsychopharmacol Biol Psychiary 1989; 13:635-51.

20 Bloor BC. Ward DS, Belleville JP, Maze M. Effects of intravenous dex mederomidine in humans. II. Hemodynamic changes. Anesthesiology 1992; 77: 1134-42. 
21 Proctor LT, Scthmeling WT, Roerig D, Kampine JP, Warlier DC. Oral dexmedetomidine athenuates hemodynamic responses during emergence from general anesthesia in chronically instrumented dogs. Anesthes tology 1991; 74: 108-14.

22 Savola JM, Ruskoaho $H_{3}$ Puurunen $J$, Salonen JS, Karki NT. Evidence for medetomidine as a selective and potent agonist at alpha 2-adrenoreceptors. I Aaton Pharmacol 1986; 6: 275-84.

23 Salonen JS. Pharmacokinetics of medetomidine. Acta Vet Scond Suppl 1989; 85: 49-54.

24 Docherty JR, MeCrath JC. The factors influencing the time course of drug action at $\alpha$ adrenoceptors: an investigation of the effects of clonidine in the pithed rat. Br J Pharmac 1980, 68: $225-34$.

25 Coughlan MGi Lee JG, Bosnjak ZJ, Schmeling WT, Kampine JP, Wartier DC. Direct coronary and cerebral vascular responses to dexmedetomidine. Significance of endogenous mitric oxide synthesis. Anesthesiology 1992; 77; 998-1006.

26 Indolfi C, Piscioni F, Villari B, et al. Role of alphaz-adrenoceptors in normal and atherosclerotic human cononary circulation. Circalation 1992; 86: 1116-24.

27 Cavero I, Roach AG. Effects of clonidine on canine cardiac neurceffector structures controlling heart rate. Br J Pharmacol 1980; 70: 269-76.

28. de Jonge A, Timmermans P, van Zwieten P. Quantitative aspects of alpha adrenergic effects

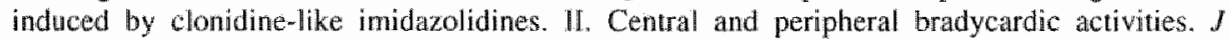
Pharmacol Exp Ther 1982; 222: 712-9.

29 Kobinger W. Centrall $\alpha$-adrenergic systems as targets for hypotensive drugs. Rev Physiol Biochem Pharwacol 1978; 81: 39-100.

30 Hokfelt B, Hederland H, Hansson B. The effect of clonidine and penbutolol respectively on catecholamine in blood and urine, plasma renin activity and urinary aldosterome in hypertensive patients. Arch In Pharmacodyn 1975; 213: 307-21.

31 Flacke JW, Flacke WE, Bloor BC, McIntee DF. Hemodynamic effects of dexmedetomidine, an alpha 2-adrenergic agonist, in antonomically denervated dogs. J Cardiovasc Pharnacol 1990; 16: $616-23$.

32 Mitrovic $\mathrm{V}$, Hallier $\mathbb{E}$, Kuschke HI. The haemodynamic effects of clonidine in patients with grade III to IV hypertension. I Cardiovasc Pharmacol 1986; 8 (Supp. 3): S51-5.

33 Magorien RD, Hermiller JB, Unverferth DV, Leier CV. Regional hemodynamic effects of clonidine in congestive hear failure. J Cardionasc Pharmacol 1985; 7: 91-6.

34 Foresti A, Massari FM. Lotto A. Hemodynamic effects of clonidine in patients with acute

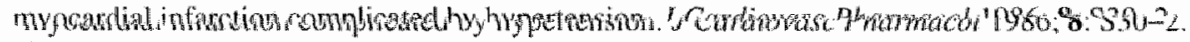

35 Zochowski R. Intravenous clonidine in acute myocandial infarction in men. In 7 Cardiol 1984; 6 $189-205$.

36 Renard M, Liebens 1, Waterschoot P, Bernard R. Central inhibition of sympathetic overdrive by clonidine in acute myocardial infarction with systolic hypertension. Haemodynamic study. Angiology $1986 ; 37: 633-41$.

37 Ghignone $M_{4}$ Quintin L, Duke P. Kehler C, Calvillo $O$. Effects of clonidine on rarcotic requirements and hemodynamic response during induction of fentanyl anesthesia and endotracheal intubation. Anesthesiology 1986; 64: 36-42.

38 Flacke J, Bloor B, Flacke W, et al. Reduced narcotic requirement by elonidine with improved hemodynamic and adrenergic stability in patients undergoing coronary bypass surgery. Auneshesiology $1987 ; 67: 11-9$.

39 Engelman E, Lipszyc M, Gilbart E, et al. Effects of clonidine on anesthetic drug requirements and hemodynamic response during aortic surgery. Anesthesiology 1989; 71 : 178-87.

40 Ghignone $\mathrm{M}$, Calvillo $\mathrm{O}$, Quintin $\mathrm{L}$. Amesthesia and hypertension: the effect of clonidine on perioperative hemodynamics and isoflurane requirements. Anesthesiology 1987; 67:3-10.

41 Quntin L. Roudot $\mathbb{K}^{-3}$, Roux $\mathrm{C}$, ef al. Effect of clonidine on the circulation and vasoactive hormones after aortic surgery. BrJ Anaesth 1991; 66: 108-15. 
42 Aho M, Erkola O, Kallio A, Scheinin $\mathrm{H}$, Korttila $\mathbb{K}$. Dexmedetomidine infusion for maintenance of anesthesia in patients undergoing abdominal hysterectony. Anesith Amolg 1992; 75: 940-6.

43 Aantaa $R$. Assessment of the sedative effects of dexmedetomidine, an alpha 2 -adrenoceptor agonist, with analysis of saccadic eye movements. Phannacol Toxicol 1991; 68: 394-8.

44 Aho MS, Erkola OA, Scheinin H, Lehtinen AM, Kortila KT. Effect of intravenously administered dexmedetomidine on pain after laparoscopic tubal ligation. Anesth Analg 1991; 73: $112-8$. 


\title{
CHAPTER 5
}

\section{The effect of dexmedetomidine on the balance of myocardial energy requirement and oxygen supply and demand ${ }^{\dagger}$}

\author{
C. J. Lawrence, F. W. Prinzen, and S. de Lange
}

\begin{abstract}
The effect of the $\alpha_{2}$-adrenergic agonist dexmedetomidine on the balance between myocardial energy requirement and oxygen supply and demand was investigated in 16 open-chest dogs anesthetized with either chloralose/urethane (CU) or fentany/halothane (FH). Myocardial energy requirement (estimated from the pressure work index), blood flow and its transmural distribution (radioactive microspheres), as well as myocardial oxygen and lactate extraction were measured before and after administration of dexmedetomidine in doses ranging from 0.1 to $10 \mu \mathrm{g} / \mathrm{kg}$ intravenously. Under CU anesthesia clexmedetomidine decreased heart rate, blood pressure and cardiac output During FH anesthesia, dexmedetomidine reduced heart rate and cardiac output whereas arterial blood pressure increased. Dexmedetomidine decreased myocardial energy requirement only during $\mathrm{CU}$ anesthesia; myocardial oxygen supply and demand decreased in parallel. At the (large) dose of $10 \mu \mathrm{g} / \mathrm{kg}$. myocardial oxygen extraction increased during both types of anesthesia. Dexmedetomidine $\geq 1 \mu \mathrm{g} / \mathrm{kg}$ increased endocardial/epicardial blood flow ratio during $\mathrm{FH}$ anesthesta. These data indicate that dexmedetomidine $\geq 1 \mu \mathrm{g} / \mathrm{kg}$ reduces myocardial energy requirements, especially when baseline heart rate and blood pressure are increased. Dexmedetomidine preserves endocardial perfusion and reduces oxygen demand in paratlel with oxygen supply and energy requirements.
\end{abstract}

\footnotetext{
Published in Anesh Analg 1996; 82: 544-50. Reproduced with permission of the publisher (presented in part at the European Association of Cardiothoracic Anaesthesiologists"seventh Annual Meeting. Maastrictht. The Netherlands, June 9-12. 1992, and published in abstract form in J Cardiofiorac Vasc Anesth 1994:8 (Suppl 2): 84
} 


\section{Introduction}

$\alpha_{2}$-Adrenergic agonists are of interest to anesthesiologists because they produce sedation, anxiolysis, analgesia, reduction of anesthetic requirement and hemodynamic stabilization through an action on $\alpha_{2}$-adrenergic receptors in the central nervous system [1], $\alpha_{2}$-Adrenergic agonists are being introduced into clinical anesthesia especially for their hemodynamic stabilizing effect [2]. Part of the central action of $\alpha_{2}$ agonists can be characterized as sympatholytic [1]. As a consequence, these drugs decrease heart rate and contractility $[1,3]$ leading to a decrease of myocardial energy requirements. Since the heart possesses a powerful autoregulation [4], this decrease in energy requirements could lead to a decrease in coronary blood flow. In this case coronary vascular resistance would increase while the balance between myocardial oxygen supply and oxygen demand is maintained.

A decrease in coronary blood flow could, however, also be due to $\alpha$-adrenergic vasoconstriction resulting from stimulation of postsynaptic vascular $\alpha_{2}$ receptors [5-7]. In this case a reduction in oxygen supply would coincide with increased afterload and increased demand $[6,7]$ and thus cause imbalance between requirements and supply. It is important to understand the interaction of sympatholytic and vasoconstrictive effects of $\alpha_{2}$ agonists on the heart since these drugs may be used more often in patients with cardiovascular disease. Therefore we investigated the effect of dexmedetomidine on myocardial oxygen supply, oxygen demand, and energy requirement in two groups of dogs which differed as to type of anesthesia used as well as hemodynamic status. One group, anesthetized with chloralose and urethane (CU), was relatively hyperdynamic compared to the second group, which received fentanyl/halothane anesthesia (FH). In addition, the dog was chosen as the experimental animal because this species is prone to $\alpha$-adrenergic vasoconstriction [5] so that less desirable effects of dexmedetomidine on the heart, if any, could be elicited more readily.

\section{Methods}

These experiments conformed to the Dutch law for animal experimentation, and were approved by the local animal ethical committee. Sixteen adult, healthy, mongrel dogs of either sex weighing between 22 and $39 \mathrm{~kg}$ were used for the study. Anasthesia was induced with thiopental ( $30 \mathrm{mg} / \mathrm{kg}$ ) and, after endotracheal intubation, the dogs were ventilated with oxygen/nitrous oxide $(40 \% / 60 \%)$. Subsequently, two different anesthetic regimes were followed. Six animals were anesthetized with $60 \mathrm{mg}$ chloralose and $300 \mathrm{mg}$ urethane intravenously (IV) per kilogram of body weight ( $\mathrm{CU}$ group). In the other 10 animals, halothane $(0.5 \%-1 \%)$ was added to the inspired gases to maintain adequate anesthesia throughout the study. Fentanyl $(\mathbb{l}-5 \mu \mathrm{g} / \mathrm{kg})$ was administered IV in the FH group during surgical preparation to keep heart rate (HR) at approximately $100 \mathrm{bpm}$ until baseline measurements were taken. 
A venous cannula was inserted in a leg vein for infusion of fluids and medication.

The experimental preparation has been described previously in detail [8]. Catheters were introduced for measurement of aortic and left ventricular pressure (Millai catheter tip). After opening the thorax, a flow probe (Skalar, Delf, The Netherlands) was placed around the lleft anterior descending coronary artery (LAD). A small polyethelene catheter (PE 60) was inserted into the coronary vein accompanying the $\mathrm{LAD}$ in order to obtain regional venous blood samples. The first positive derivative of left ventricular pressure ( $\mathrm{LVdP} / \mathrm{dt}_{\text {max }}$ ) and $\mathrm{HR}$ were derived from the left ventricular pressure signal. A thermodilution pulmonary artery catheter introduced via the left external jugular vein was used to obtain mixed venous blood samples from the pulmonary artery and to measure cardiac output by the thermodilution technique. Left ventricular pressure, aortic pressure, coronary flow and electrocardiogram (lead II) were displayed continuously. All pressures and flows were recorded continuously using a pen recorder at $0.25 \mathrm{~cm} / \mathrm{s}$, increased to $5 \mathrm{~cm} / \mathrm{s}$ during data acquisition.

Radioactive microspheres (New England Nuclear, Boston, MA) 15 m in diameter and labeled with ${ }^{141} \mathrm{Ce},{ }^{113} \mathrm{Sn},{ }^{103} \mathrm{Ru},{ }^{95} \mathrm{Nb}$, or ${ }^{46} \mathrm{Sc}$ were used to determine regional myocardial blood flow (MBF) by the reference withdrawal method [9] as previously described in detail [8]. Approximately $2.5 \times 10^{6}$ microspheres were injected into the left atrium and a reference sample taken from the brachial artery at a rate of 20.7 $\mathrm{mL} / \mathrm{min}$. After killing the dogs with an overdose of pentobarbital, the heart was excised, rinsed, and stored in formaldehyde $5 \%$. Transmural samples were taken from the perfusion area of the LAD (anterior wall) and from the posterior wall and interventricular septum and were divided into subendocardial, mid-wall and subepicardial layers. The myocardial pieces were weighed and counted in a $\gamma$ counter together with the reference blood samples. From these data MBF $\left(\mathrm{mL} \cdot \mathrm{min}^{-1} \cdot \mathrm{g}^{* 1}\right.$ ) was calculated with the MIC II program [8].

After completion of instrumentation and a stabilization period of 15 min, baseline measurements were taken and repeated after 10 min. After this, successively increasing doses $(0.1,0.3,1,3$, and $10 \mu \mathrm{g} / \mathrm{kg})$ af dexmedetomidine were giwen IV by slow infusion over 2 min at 20 -min intervals and measurements recorded 15 min after administration.

At each sample time the hemodynamic measurements were performed and arterial, mixed venous, and coronary venous blood samples obtained. Radioactive microspheres were injected only at baseline and at doses of $0.1,1.0$, and $10 \mu \mathrm{g} / \mathrm{kg}$ in all animals of the $\mathrm{CU}$ group and in eight animals of the FH group.

Endocardial, epicardial, and total coronary wascular resistance (CVR, mm $\mathrm{Hg} \cdot \mathrm{min} \cdot \mathrm{g}$ - $\left.\mathrm{mL}^{-1}\right)$ were calculated as the ratio of the specific $\mathrm{MBF}\left(\mathrm{mL} \cdot \mathrm{min}^{-1} \cdot \mathrm{g}^{-1}\right)$ and mean arterial blood pressure. The endocardial/epicardial blood flow ratio was also calculated. Myocardial oxygen consumption $\left(\mathrm{MVO}_{2}, \mu \mathrm{mol} \cdot \mathrm{min}{ }^{-1} \cdot \mathrm{g}^{-1}\right)$ was calculated as the product of arterio-local coronary venous difference of oxygen saturation, arterial 
hemoglobin concentration (mmol/L) and total MBF $\left(\mathrm{mL} \cdot \mathrm{min}^{-1} \cdot \mathrm{g}^{-1}\right.$, being the average of all the samples from the various myocardial layers). Myocardial oxygen supply was calculated as the product of total MBF and arterial oxygen content.

Energy requirement of the left ventricle was estimated from the pressure work index (PWI; arbitrary units, equivalent to $\mu \mathrm{mol} \cdot \mathrm{min}^{-1} \cdot \mathrm{g}^{-1}$ ), as described by Rooke and Feigl [10]:

$$
P W I=c l(S B P \times H R)+c 2(0.8 S B P+0.2 D B P) \times H R \times S V / B W+c 3
$$

where

$$
\begin{aligned}
S V & =\text { stroke volume }(\mathrm{mL}) \\
S B P & =\text { systolic blood pressure }(\mathrm{mm} \mathrm{Hg}) \\
D B P & =\text { diastolic blood pressure }(\mathrm{mm} \mathrm{Hg}) \\
B W & =\text { body weight }(\mathrm{kg}) \\
c 1 & =1.63 \times 10^{-4} \\
c 2 & =1.30 \times 10^{-4} \\
c 3 & =0.57
\end{aligned}
$$

A two-way analysis of variance for repeated measures was used for intergroup comparisons. Intragroup comparisons were evaluated using one-way analysis of variance for repeated measures. When significance was found, Fisher's protected least significant difference test was used as a post-hoc multiple comparison procedure. Baseline values between the two groups were compared using Student's $t$-test. A $P$ value of less than 0.05 was considered significant.
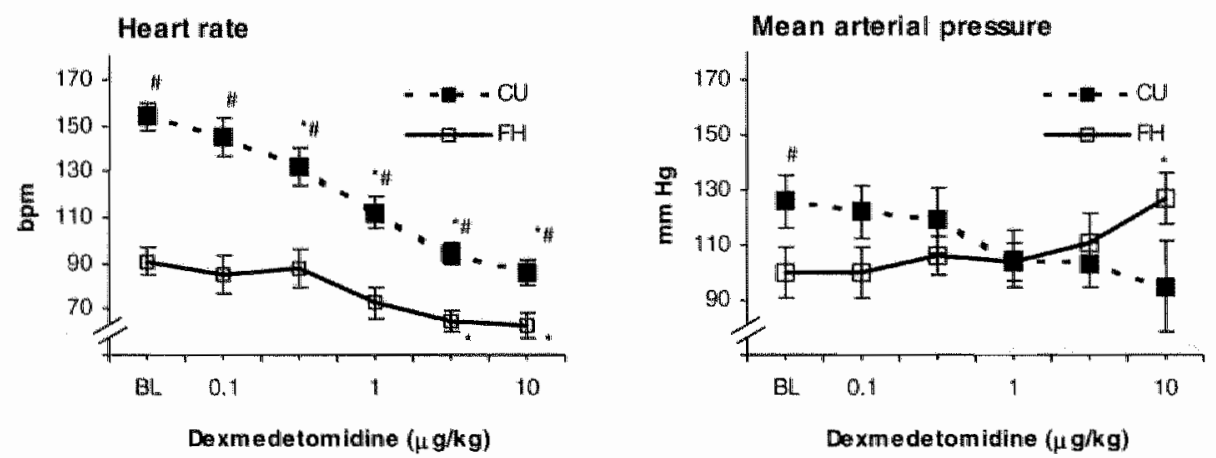

Figure 5-1 Heart rate and mean arterial pressure at baseline (BL) and 15 min after dexmedetomidine $0.1,0.3,1,3$, and $10 \mu \mathrm{g} / \mathrm{kg}$ given intravenously over 2 min. Values are mean \pm SEM. $\mathrm{CU}=$ chloralose/urethane-anesthetized dogs; $\mathrm{FH}=$ fentanyl/halothane-anesthetized dogs. * $P<0.05$ compared to baseline. \# $P<0.05 \mathrm{FH}$ dogs compared to $\mathrm{CU}$ dogs. 
Table 5-1 Systemic vascular and cardlac effects of increasing doses of dexmedelomidine

\begin{tabular}{|c|c|c|c|c|c|c|c|}
\hline \multirow[b]{2}{*}{ Variable ${ }^{\mathrm{a}}$} & \multirow[b]{2}{*}{ Group } & \multicolumn{6}{|c|}{ Dexmedetomidine (aglkg) } \\
\hline & & Baseline & 0.1 & 0.3 & 1.0 & 3.0 & 10.0 \\
\hline Gardiac output & $\mathrm{FH}$ & $3.7 \pm 0.4$ & $3.6 \pm 0.6$ & $3.4 \pm 0.4$ & $2.7 \pm 0.3^{*}$ & $2.1 \pm 0.2^{*}$ & $20 \pm 0.2^{*}$ \\
\hline (Lmin) & $\mathrm{Cll}$ & $3.7 \pm 0.2$ & $3.5 \pm 0.3$ & $3.2 \pm 0.3^{*}$ & $2.3 \pm 0.2^{2}$ & $1.8 \pm 0.3$ & $1.6+0.2^{*}$ \\
\hline SVR Idymes - s & $\mathrm{FH}$ & $2568 \pm 617$ & $2636 \pm 517$ & $2900 \pm 581$ & $3481+579$ & $4584 \pm 701^{\circ}$ & $5576+692^{12}$ \\
\hline $\mathrm{cm}^{5}$ & $\mathrm{Cu}$ & $2751 \geq 256$ & $2898 \pm 267$ & $3087 \pm 380$ & $3777 \pm 402$ & $5227 \pm 764$ & $5016 \pm 801^{*}$ \\
\hline Stroke volume & $\mathrm{FH}$ & $40.7 \pm 4.6 \dagger$ & $42.8 \pm 5.5$ & $38.7 \pm 4.0$ & $37.6 \pm 4.0$ & $327 \pm 2.9$ & $32.9 \pm 40$ \\
\hline$(m L)$ & $\mathrm{Cu}$ & $25.0 \pm 2.4$ & $24.7 \pm 2.8$ & $25.1 \pm 2.9$ & $21.6 \pm 3.1$ & $19.4 \pm 2.9^{*}$ & $18.9 \pm 2.8^{\prime \prime}$ \\
\hline LWdPIdTex & $\mathrm{FH}$ & $2229 \pm 206$ & $2181 \pm 179$ & $2169 \pm 173$ & $1979 \pm 154$ & $1789 \pm 103^{*}+$ & $1852 \pm 93^{4}$ \\
\hline$(\mathrm{mm} \mathrm{Hg} / \mathrm{s})$ & $\mathrm{CU}$ & $2217 \pm 253$ & $1967 \pm 187$ & $1617 \pm 159^{*}$ & $1350 \pm 126^{*}$ & 1267 내 $8 \|^{*}$ & $1117 \pm 162^{10}$ \\
\hline LVEDP & $\mathrm{FHH}$ & $82+1.0$ & $7.4 \pm 0.7$ & $7.6 \pm 1.1$ & $84 \pm 13$ & $9.9 \pm 23$ & $11.0 \pm 2.8$ \\
\hline$(\mathrm{mm} \mathrm{Hg})$ & $\mathrm{CU}$ & $8.3 \pm 0.7$ & $8.2 \pm 1.4$ & $7.7 \pm 1.5$ & $7.0 \pm 1.0$ & $9.0 \pm 1: 4$ & $9.7 \pm 2.0$ \\
\hline Coronary flow & $\mathrm{FH}$ & $33.3 \pm 5.6$ & $28.4 \pm 3.1$ & $26.7 \pm 4.1$ & $27.2 \pm 3.1$ & $27.6 \pm 4.0$ & $23.6 \pm 1.7$ \\
\hline (mL/min) & $\mathrm{CU}$ & $35.7 \pm 5.0$ & $32.3 \pm 3.4$ & $29.7 \pm 3.3$ & $22.9 \pm 2.8$ & $24.8 \pm 3.8$ & $24.7+3.8$ \\
\hline CVR $(\mathrm{mm} H \mathrm{H}$ & $\mathrm{FH}$ & $3.8 \pm 0.9$ & $3.8 \pm 0.5$ & $5.0 \pm 1.2$ & $4.7 \pm 1.2$ & $4.7 \pm 0.7$ & $5.5 \pm 0.4$ \\
\hline$\left.m L^{-1} \cdot m^{n} n^{-1}\right)$ & $\mathrm{CU}$ & $3.9 \pm 0.5$ & $4.0 \pm 0.5$ & $4.3 \pm 0.7$ & $5.6 \pm 1.5$ & $5.6 \pm 1.7$ & $5.3 \pm 1.6$ \\
\hline PWl (umol & $\mathrm{FH}$ & $3.98 \pm 0.4+$ & $3.91+0.4 \uparrow$ & $4.42 \pm 0.6$ & $3.92 \pm 0.5$ & $2.97 \pm 0.2$ & $3.30 \pm 0.2$ \\
\hline$\left.\cdot g^{-1} \cdot \min ^{-1}\right)$ & $\mathrm{CU}$ & $6.36 \pm 0.6$ & $5.81 \pm 0.5$ & $5.44 \pm 0.5^{*}$ & $3.82 \pm 0.3^{3}$ & $3.12 \pm 0.2^{2}$ & $2.73+0.4^{\mathrm{tt}}$ \\
\hline Stroke work & $\mathbb{F H}$ & $3974 \pm 486 \uparrow$ & $4254 \pm 551$ & $4059 \pm 404$ & $3866 \pm 374$ & $3572 \pm 384$ & $4123 \pm 505$ \\
\hline$(\mathrm{mL} \cdot \mathrm{mm} H \mathrm{Hg})$ & $\mathrm{CU}$ & $3134 \pm 361$ & $3080 \pm 477$ & $3031+485$ & $2371 \pm 460^{*}$ & $2017 \pm 366^{*}$ & $1945 \pm 545^{\circ}$ \\
\hline
\end{tabular}

Values ane expressed as mean \pm SEM. FH $=$ dogs anesthetized with fentanyl and halothane; CU $=$ dogs anesthetized with chloralose/urethane; $S V R=$ systemic vascular resistance; $L V d P / d t_{\text {nux }}=$ first positive derivative of left vertricular pressure; LVEDP = left ventricular end-diastolic pressure; CVR = coronary vascular resistance; PWI = pressure work index. ${ }^{2}$ For each variable, the measurements are: baseline and effect 15 mint after dexmedetonidine in the doses shown. "P<0.05 compared to baseline $\dagger P<0.05$ FH wompared to CU $\operatorname{dog} s$.

\section{Results}

\section{Hemodynamics}

Baseline hemodynamics of the two groups differed significantly (Table 5-1). HR and mean arterial pressure (MAP) values were higher in the CU than in the FH dogs (Figure 5-1). Differences in $\mathrm{LVdP} / \mathrm{dt}_{\max }$ and left ventricular end-diastolic pressure were not statistically significant. SV and stroke work were significantly greater in the FH group, but PWI was significantly higher in the CU group. In both groups dexmedetomidine administration caused a dose-dependent decrease of $\mathrm{HR}$, significant at doses $\geq 0.3$ and $1 \mu \mathrm{g} / \mathrm{kg}$ in CU and FH dogs, respectively. MAP increased in the FH group but tended to decrease in the CU group. The decrease in $\mathrm{CO}$ and increase in systemic vascular resistance was similar in both groups. SV decreased significantly in the $\mathrm{CU}$ but not in the $\mathrm{FH}$ group. $\mathrm{LVdP} / \mathrm{dt}_{\max }$ decreased significantly at doses $\geq 0.3$ and $3 \mu \mathrm{g} / \mathrm{kg}$ in the $\mathrm{CU}$ and $\mathrm{FH}$ groups, respectively (Table 5-1). PWI, an index of myocardial energy requirement, decreased. In the $\mathrm{CU}$ group this decrease became significant at $0.3 \mu \mathrm{g} / \mathrm{kg}$ and was as large as $57 \%$ at $10 \mu \mathrm{g} / \mathrm{kg}$. No significant change was seen in the FH group (Table 5-1). 

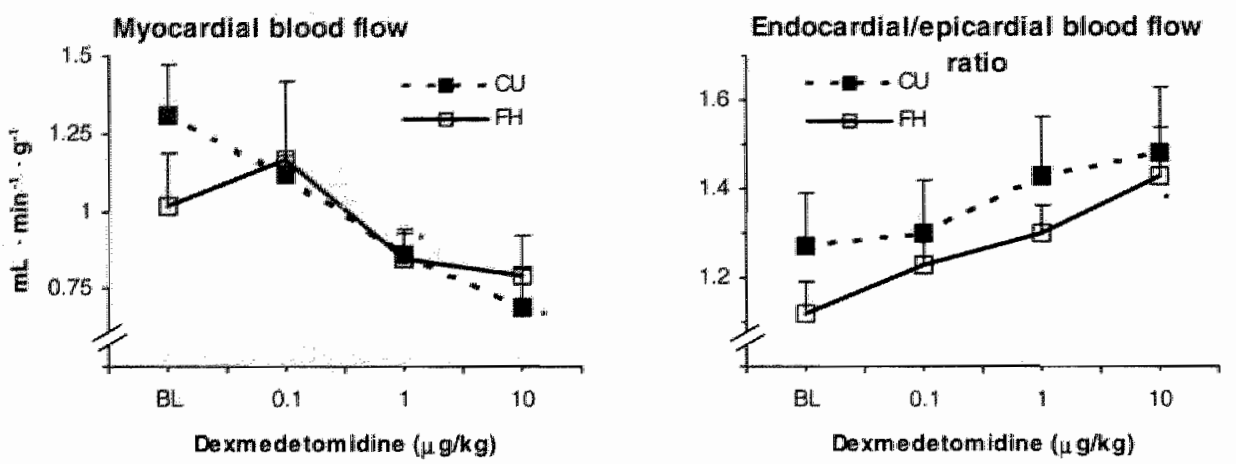

Figure 5-2 Effect of dexmedetomidine on total transmural myocardial blood flow and endocardial/epicardial blood flow ratio. Measurements at baseline $(\mathrm{BL})$ and $15 \mathrm{~min}$ after $2 \mathrm{~min}$ intravenous infusion of dexmedetomidine $0.1,1$, and $10 \mu \mathrm{g} / \mathrm{kg}$. Values are mean $\pm \mathrm{SEM}$. CU $=$ chloralose/urethane-anesthetized dogs; $\mathrm{FH}=$ tentanylhalothane-anesthetized dogs. " $P<0.05$ compared to baseline.
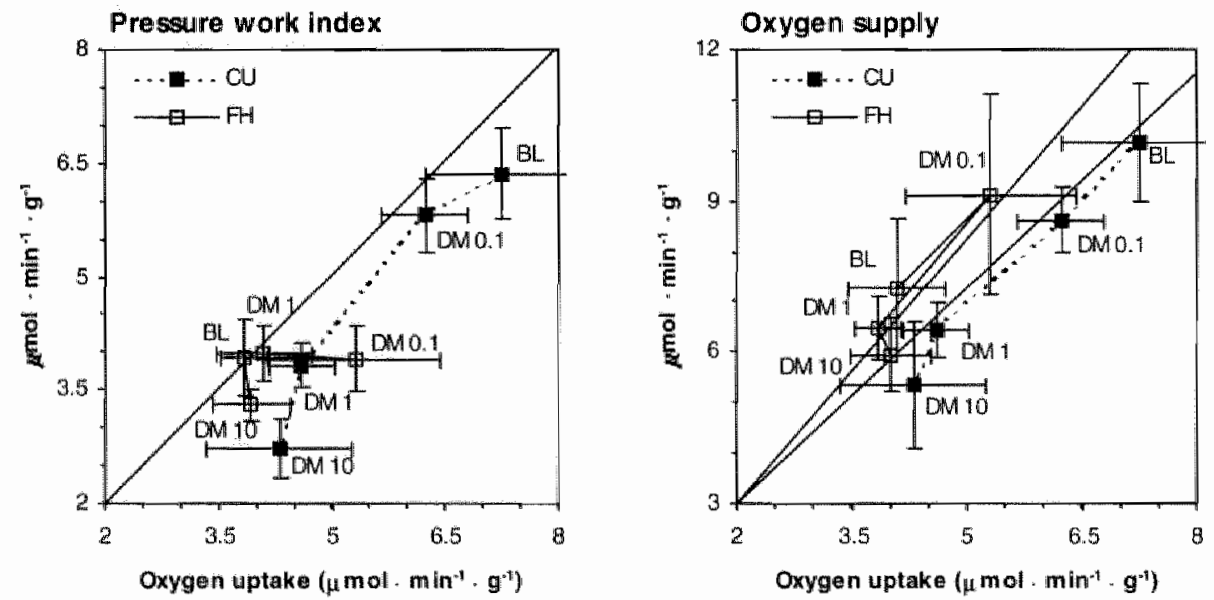

Figure 5-3 Plelationship between oxygen uptake and pressure work index (left panel) and oxygen supply (right panel). Values are mean \pm SEM. $\mathrm{CU}=$ chloralose/urethane-anesthetized dogs. $\mathrm{FH}=$ fentanyl/halothane-anesthetized dogs. Baseline (BL) and 15 min after slow (2 min) intravenous infusion of dexmedetomidine (DM) $0.1,1$, and $10 \mu \mathrm{g} / \mathrm{kg}$. The lines represent the line of unity (left panell) and line of $57 \%$ (right panel, upper) and $69 \%$ oxygen extraction (right panel, lower). Data in the left panel indicate that pressure work index (estimate of myocardial energy requirement) changes proportional to oxygen uptake. The right panel demostrates that at DM $\leq 1$ $\mu \mathrm{g} / \mathrm{kg}$ changes in oxygen uptake and supply are proportional, indicating metabolic regulation of myocardial blood flow. 
Table 5-2 Effect of increasing doses of dexmedetomidine on myrocandial biood flow coronay vascular resistance and MVo

\begin{tabular}{|c|c|c|c|c|c|}
\hline \multirow[b]{2}{*}{ Variablles } & \multirow[b]{2}{*}{ Group } & \multicolumn{4}{|c|}{ Dexmedetomiline $(\mu \mathrm{rg} / \mathrm{kg})$} \\
\hline & & Baseline & 0.1 & 1.0 & 10.0 \\
\hline \multicolumn{6}{|l|}{$\begin{array}{l}\text { Blood flow } \\
\left(\mathrm{mL} \cdot \text { min-1 }^{-1} \cdot \mathrm{g}^{-1}\right)\end{array}$} \\
\hline \multirow[t]{2}{*}{ Epicardial } & $\mathrm{FH}$ & $0.97 \pm 0.16$ & $1.05 \pm 0.21$ & $0.73 \pm 0.08$ & $0.65 \pm 0.09^{\prime \prime}$ \\
\hline & $\mathrm{Cu}$ & $1.16 \pm 0.15$ & $0.97 \pm 0.05$ & $0.70 \pm 0.06^{\circ}$ & $0.55: 0.09$ \\
\hline \multirow[t]{2}{*}{ Endocardial } & $\mathrm{FH}$ & $1.10 \pm 0.20$ & $1.32 \pm 0.28$ & $0.93 \pm 0.11$ & $0.93 \pm 0.17$ \\
\hline & $\mathrm{CU}$ & $1.44 \pm 0.18$ & $1.26 \pm 0.12$ & $0.99 \pm 0.09^{\circ}$ & $0.79 \pm 0.15$ \\
\hline \multicolumn{6}{|l|}{$\begin{array}{l}\text { Vascular resistance } \\
\left(\mathrm{mm} H \mathrm{Hg} \cdot \min \cdot \mathrm{g} \cdot \mathrm{mL}^{-1}\right)\end{array}$} \\
\hline \multirow[t]{2}{*}{ Epicardial } & $\mathrm{FH}$ & $121.8 \pm 29.6$ & $109.5 \pm 220$ & $166.5 \pm 24.5$ & $227.3 \pm 32.1$ \\
\hline & $\mathrm{cu}$ & $117.4 \pm 17.3$ & $128.6 \pm 12.9$ & $179.2 \pm 32.0$ & $208.9=37.4$ \\
\hline \multirow[t]{2}{*}{ Endocardial } & $\mathrm{FH}$ & $110.9 \pm 25.0$ & $90.3 \pm 17.6$ & $128.4 \pm 16.2$ & $163.6 \pm 22.2$ \\
\hline & $\mathrm{CU}$ & $91.8 \pm 12.1$ & $99.4 \pm 6.2$ & $122.4 \pm 18.0$ & $136.0 \pm 17.8$ \\
\hline Total MVO2 & $\mathrm{FH}$ & $4.10 \pm 0.63 t$ & $5.31 \pm 1.12$ & $3.84 \pm 0.31$ & $3.93 \pm 0.52$ \\
\hline$\left(\right.$ umol $\left.\cdot \min ^{-1} \cdot g^{-1}\right)$ & $\mathrm{Cu}$ & $7.26 \pm 0.60$ & $6.23 \pm 0.58$ & $4.60 \pm 0.43^{\mathrm{k}}$ & $4.31 \pm 0.96$ \\
\hline
\end{tabular}

Values are expressed as mean \pm SEM. $F H=$ dogs anesthetized with tentanyl and halohane: $\mathrm{CU}=$ dogs anesthetized with chloralose/urethane; MVor = myocardial oxygen consumpion. "For each vartable, the mensurements are: baseline and effect 15 min after dexmedetomidine in the doses shown. * $P<0.05$ compared to baseline. $+P<0.05$ FIT dogs compared with CU dogs.

\section{Myocardial blood flow and vascular resistance}

The effect of dexmedetomidine on MBF was different between the two experimental groups as well as between the various layers of the left ventricular wall (Table 5-2). At doses $\geq 1 \mu \mathrm{g} / \mathrm{kg}$ total transmurall (Figure 5-2) as well as epi- and endocardial blood flow decreased dose dependently in the $\mathrm{CU}$ group. In the FH group the only significant change was in the epicardial blood flow after $10 \mu \mathrm{g} / \mathrm{kg}$ (Table 5-2). However, dexmedetomidine altered the distribution of blood flow between the varrious layers of the ventricular wall, especially in the FH group as evidenced by a significant increase in the endocardial/epicardial blood flow ratio (Figure 5-2). Dexmedetomidine 10 $\mu \mathrm{g} / \mathrm{kg}$ significantly increased epi- and endocardial CVR compared to baseline.

\section{Myocardial lactate and oxygen uptake}

At all sample times in all experiments the aortocoronary lactate difference was positive and dexmedetomidine did not influence this variable (Table 5-3).

At baseline aortocoronary oxygen saturation difference was approximately 0.12 higher in the $\mathrm{CU}$ than in the $\mathrm{FH}$ group $(P<0.05)$. In both groups aortocoronary oxygen saturation difference tended to increase with increasing doses of dexmedetomidine, but this increase (by approximately 0.10 ) was only significant at the highest dose in both groups (Table 5-3). 
Table 53 Effect of increasing doses of dexmedelonidime on oxygen saturation and lactatse extraction

\begin{tabular}{|c|c|c|c|c|c|c|c|}
\hline \multirow[b]{2}{*}{ Variable: } & \multirow[b]{2}{*}{ Group } & \multicolumn{6}{|c|}{ Dexmiedetomidine (wg/kg) } \\
\hline & & Baseline & 0.1 & 0.3 & 1.0 & 3.0 & 10.0 \\
\hline \multirow[t]{2}{*}{$O x \operatorname{sat}(A-V)(\%)$} & $\mathrm{FH}$ & $0.31 \pm 0.03$ & $0.32 \pm 0.04$ & $0.29=0.02 t$ & $0.32+0.03 \dagger$ & $0.414^{4} 0.04^{*}+$ & $0.43 \pm 0.04^{*}$ \\
\hline & $\mathrm{CU}$ & $0.33 \pm 0.03$ & $0.34 \pm 0.03$ & $0.37=0.05$ & $0.45 \pm 0.04$ & $0.60 \pm 0.08^{2}$ & $0.61 \pm 0.04^{*}$ \\
\hline \multirow[t]{2}{*}{$O_{2} s a t(A-C)(\%)$} & $\mathrm{FH}$ & $0.57 \pm 0.05 t$ & $0.59 \pm 0.03$ & $0.61 \pm 0.02$ & $0.61 \pm 0.03$ & $0.64+0.02$ & $0.67 \pm 0.03^{ \pm}$ \\
\hline & $\mathrm{CU}$ & $0.69 \pm 0.04$ & $0.70+0.03$ & $0.68+0.04$ & $0.70 \pm 0.02$ & $0.74 \pm 0.03$ & $0.80 \pm 0.02$ \\
\hline \multirow{2}{*}{$\begin{array}{l}\text { Lactate }(A-C) \\
\text { (minoll) }\end{array}$} & $\mathrm{FH}$ & $0.82 \pm 0.27$ & $0.72 \pm 0.23$ & $0.46+0.36$ & $0.73 \pm 0.25$ & $0.45 \frac{15}{10} 0.30$ & $0.91 \pm 0.40$ \\
\hline & $\mathrm{CU}$ & $0.61 \pm 0.30$ & $0.57 \pm 0.23$ & $0.54 \pm 0.22$ & $0.62 \pm 0.23$ & $0.60 \pm 0.22$ & $0.62 \div 0.17$ \\
\hline
\end{tabular}

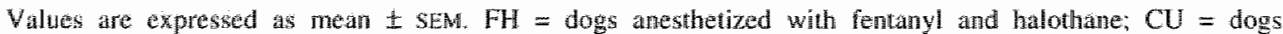
anesthetized with chloralose/urethane; $O_{2}$ kat $(A-V)=$ arterio-mixed venous saturation difference; $O_{2}$ sat $(A-C)=$ arteriocoronary venous saturation difference: Lactate $(A-C)=$ arteriocoronary vellous lactalte diference. ${ }^{\text {B For }}$ each warable, the measurements are: baseline and effec 15 min after dexmedetomidine in the doses shown. * $p$ $<0.05$ compared to baseline. $+P<0.05$ FH dogs compared to CU dogs.

The decrease of $\mathrm{MVO}_{2}$ in the $\mathrm{CU}$ group (approximately 40\%, $P<0.05$ at 1 and 10 $\mu \mathrm{g} / \mathrm{kg}$ dexmedetomidine) was less pronounced than the decrease in total MBF (approximately $48 \%$ ). In the $\mathrm{FH}$ group $\mathrm{MVO}_{2}$, like $\mathrm{MBF}$, remained essentially unchanged (Table 5-2).

\section{Relation between myocardial energy requirement and oxygen supply and demand}

To illustrate the relation of the changes in $\mathrm{MVO}_{2}$ to those of myocardial energy requirements, PWI was plotted as a function of $\mathrm{MVO}_{2}$ (Figure 5-3, left panel). In the $\mathrm{CU}$ group, dexmedetomidine shifted the PWI- $\mathrm{MVO}_{2}$ relation parallel to the line of identity (diagonal line). Only at a dose of $10 \mu \mathrm{g} / \mathrm{kg}$ dexmedetomidine was a deflection away from the identity line observed, indicating that $\mathrm{MVO}_{2}$ decreased less than PWI. To analyze the influence of dexmedetomidine on the regulation of myocardial blood flow we plotted myocardial arterial oxygen supply as a function of myocardial oxygen demand, as introduced by Mohrman and Feigl [11] (Figure 5-3, right panel). In the CU group dexmedetomidine up to a dose of $1 \mu \mathrm{g} / \mathrm{kg}$ caused a shift from upper right to lower left, parallel to a line representing $69 \%$ extraction. At the highest dose (10 $\mu \mathrm{g} / \mathrm{kg}$ ) the supply-demand relation shifted more downwards, due to the increased oxygen extraction. The supply-demand relationship of the FH group was shifted upwards and leftwards compared to that of the $\mathrm{CU}$ group, due to the lower oxygen extraction. In the FH group, the supply-demand relationship also shifted downwards at a dose of $10 \mu \mathrm{g} / \mathrm{kg}$ of dexmedetomidine.

\section{Discussion}

The results from the present study demonstrate that the hemodynamic effects of dexmedetomidine may be influenced by the type of anesthesia as has been demonstrated for the cerebrovascular circulation [12]. Dexmedetomidine decreases myocardial energy requirement and $\mathrm{MVO}_{2}$, especially when baseline HR and MAP are 
high, as seen in the CU group. Most of the changes in MBF and oxygen supply after dexmedetomidine are due to changes in energy requirement. The increased myocardial oxygen extraction at $10 \mu \mathrm{g} / \mathrm{kg}$ suggests some $\alpha$-adrenergic vasoconstriction at this high dose. Dexmedetomidine also increases the endocardial/epicardial blood flow ratio. This seems to be the result of predominant epicardial vasoconstriction, bradycardia, and (for the FH group) increase in blood pressure.

Chloralose and urethane (ethyl carbamate) are used as anesthetics for acute animal experiments, especially because they have few effects on cardiac function [13] and cardiovascular reflexes [14]. It has been suggested that urethane may activate the sympathetic outflow from the central nervous system [15]. Halothane depresses baroreflex activity [16] and reduces contractility [17], $\mathrm{HR}$, blood pressure, and $\mathrm{MVO}_{2}$ [18]. Fentanyl increases vagal tone [19] and reduces sympathetic tone [20]. Therefore, it is likely that baseline sympathetic tone was higher in the CU dogs and parasympathetic tone higher in the FH dogs. This is supported by the higher baseline HR and MAP, and consequently PWI, in the CU group. It was in this group that the hemodynamic response to dexmedetomidine was most similar to that reported in concious dogs [21] and in humans [22].

During both types of anesthesia, dexmedetomidine caused a similar decrease of HR and increase of systemic vascular resistance and CVR. However, the reduction in contractility was greater in the CU than in the FH dogs (as indicated by the larger decreases in cardiac output, stroke work and $\left.L V d P / d t_{\text {max }}\right)$. Moreover, MAP decreased during $\mathrm{CU}$ anesthesia while it increased during $\mathrm{FH}$ anesthesia. These data suggest that the vasoconstrictive effect is directly related to stimulation of peripheral vascular $\alpha_{2}$ receptors, whereas changes in contractility and blood pressure are dependent on the state of activity of the autonomic nervous system.

A primary question in the present study was how dexmedetomidine interferes with the balance between myocardial oxygen supply and demand. It was observed that at doses up to $1 \mu \mathrm{g} / \mathrm{kg}$ dexmedetomidine's sympatholytic effects exceeded its vasoconstrictive effects. At these doses dexmedetomidine caused an equivalent decrease in PWI and oxygen uptake during CU anesthesia, whereas clexmedetomidine did not change these variables in the FH group. Thus changes in $\mathrm{MVO}_{2}$ were related to changes in energy requirements. Moreover, changes in $\mathrm{MVO}_{2}$ occurred almost exclusively due to changes in $\mathrm{MBF}$, as indicated by the absence of significant changes in myocardial oxygen extraction. This is a behaviour similar to that observed when HR is varied by atrial pacing [23] but different from the effect of a noradrenaline infusion or bicarotid artery occlusion [1]]. Both these interventions increase MBF as well as oxygen extraction [11]. Representing their results as a graph of oxygen supply versus oxygen demand (similar to Figure 5-3), Mohrman and Feigl [11] concluded that $\alpha$-adrenergic stimulation impaired $30 \%$ of the increase of $\mathrm{MBF}$. In our study the unaltered oxygen extraction at doses up to $3 \mu \mathrm{g} / \mathrm{kg}$ indicates that dexmedetomidine does not significantly limit MBF by adrenergic vasoconstriction at this dosage. The increase of myocardial oxygen extraction at a dose of $10 \mu \mathrm{g} / \mathrm{kg}$ in both groups indicales that, 
under these conditions, dexmedetomidine limits MBF through $\alpha$-adrenergic vasoconstriction by about $10 \%-15 \%$. Because dexmedetomidine has complex hemodynamic effects, changes in myocardial energy requirements could not be estimated from a single variable. We used the PWI for this purpose because it accurately predicts changes in $\mathrm{MVO}_{2}$ due to changes in afterload and adrenergic stimulation $[10,24]$.

The finding in the $\mathrm{CU}$ group that $\mathrm{MVO}_{2}$ decreased in proportion to $\mathrm{PWI}$, in combination with the unaltered lactate arteriowenous difference, indicates that the balance between myocardial energy requirement and $\mathrm{MVO}_{2}$ is maintained at increasing doses of dexmedetomidine. Halothane decreases $\mathrm{MVO}_{2}[18]$ as reflected in the lower baseline value of the FH group. The increased MAP after dexmedetomidine should increase in $\mathrm{MVO}_{2}$ but, because of the reduction in $\mathrm{HR}$, the product of MAP and HR remains constant and is correlated to $\mathrm{MVO}_{2}$ in halothane-anesthetized dogs [18].

The results from the microsphere measurements demonstrate that $\alpha_{2}$ stimulation by dexmedetomidine increases endocardial/epicardial blood flow ratio, especially in the FH group. These results seem in agreement with the finding that $\alpha$-adrenergic blockade decreases endocardial/epicardial blood flow ratios in normally perfused as well as underperfused myocardium [25]. Both results indicate that predominantly epicardiall vasoconstriction occurs by an $\alpha$-adrenergic mechanism.

Since there is no evidence for a transmural gradient in the density of coronary $\alpha$ adrenergic receptors or of sympathetic nerves [26], these findings are possibly explained by a stronger metabolic vasodilatory regulation in the endocardium as compared to the epicardium [4], so that adrenergic vasoconstriction can be obtunded in the endocardium but not in the epicardium. This possibility is supported by evidence that hypoxia and acidosis can impair adrenergic coronary vasoconstriction $[27,28]$. In the present study, the changes in endocardial/epicardial blood flow ratio may also be due, in part, to the hemodynanic effects of dexmedetomidine. A decrease in HR, observed in both groups, is known to be beneficial for blood flow to the endocardial layers. Such a redistribution has been observed during variation of heart rate with atrial pacing $[23,29]$ as well as after administration of $\beta$-blockers $[30,31]$.

These data seem in conflict with the opinion that $\alpha_{2}$-receptor stimulation plays an important role in the origination of myocardial ischemia [5]. However, that concept was derived primarily from experiments with maximal sympathetic stimulation and $\alpha$ adrenergic blockade, conditions quite different from that in the present study.

The present results demonstrate that myocardial energy requirement decreases at 1 $\mu \mathrm{g} / \mathrm{kg}$ dexmedetomidine, whereas moderate coronary vasoconstriction (as shown by the increased oxygen extraction) occurs after $10 \mu \mathrm{g} / \mathrm{kg}$. Because the dose currently used for premedication in anesthesia is between 0.5 and $2 \mu \mathrm{g} / \mathrm{kg}$ [32], the myocardial energy sparing effect of dexmedetomidine most likely prevails. This comparison between human and canine dexmedetomidine doses seems justified, since a 2-min IV 
infusion of $1 \mu \mathrm{g} / \mathrm{kg}$ in dogs gave a plasma level after 15 min of $0.61 \pm 0.19 \mathrm{ng} / \mathrm{mL}$ (mean $\pm \mathrm{SD}$ ) [33]. The same infusion in humans resulted in plasma levels of $0.94 \pm$ 0.18 after $10 \mathrm{~min}$ and $0.29 \pm 0.04 \mathrm{ng} / \mathrm{mL}$ after $60 \mathrm{~min}[22]$.

Indolfi ef al. [34] showed that the human CVR may increase by a maximum of $28 \%$ after intracoronary administration of an $\alpha_{2}$-adrenergic agonist, a value less than half the maximum observed in the present study. Therefore, at comparable doses, coronary $\alpha_{2}$-adrenergic vasoconstriction may be the less pronounced in humans than in dogs. Since the sympathetic tone is generally higher in conscious humans than in anesthetized dogs, the myocardial energy-saving effect most likely prevails in clinical use.

\section{Acknowledgments}

We thank Mr. R. Kruger, Mr. T. vd Nagel, and Mr. J. Habets for their expert technical assistance, and Mr. C. van Leeuwen for his help in data analysis. We also thank Orion Corporation, Farmos, Turku, Finland for supplying dexmedetomidine.

\section{References}

1 Maze M, Tranquilli W. Alpha-2 adrenoceptor agonists: defining the role in clinical anesthesia. Anesthesiology 1991; 74: 581-605.

2 Flacke J, Bloor B, Flacke $W$, et al. Reduced narcotic requirement by clonidine with improved hemodynamic and adrenergic stability in patients undergoing coronary bypass strgery. Anesthesiology: 1987; 67: 11- -19 .

3 Vickery RG, Sheridan BC, Segal IS, Maze M. Anesthetic and hemodyamic effects of the stereoisomers of medetomidine, an $\alpha_{2}$-adrenergic agonist, in halothane-anesthetized dogs. Anesh Analg 1988; 67: 611-15.

4 Feigl EO. Coronary physiology. Physiol Rev 1983; 63: 1-205.

5 Heusch G. Alpha-adrenergic mechanisms in myocardial ischemia. Circulosion 1990; 81:1-13.

6 Bloor BC. Frankland M, Alper $\mathrm{G}_{\text {n }}$ et al. Hemodynamic and sedative effects of dexmedetomidine in dog. J Pharmacol Exp Ther 1992; 263(2):690-7.

7 Flacke WE, Flacke JW, Bloor BC, ef al. Effects of dexmedecomidine on systemic and coronary hemody namics in the anesthetized dog $J$ Cardiothorac Vase Anesth 1993; 7(1):41-6).

8 Prinzen FW, Van der Vusse GJ, Reneman RS. Blood flow distribution in the lef wentricular free wall in open-chest dogs. Basic Re.i Cardion 1981: 76:431-7.

9 Heymann MA, Payne BD, Hofman IIE, Rudolph AM. Blood flow metsurements witli radionuclide-labeled microspheres. Prog Cardionasc Dis $1977,20: 55-79$.

10 Rooke GA, Feigl EO. Work as a correlate of canine left ventricular oxygen consumption, and the problem of catecholamine oxygen wasting. Cir Res 1982; 50: 273-86.

11 Mohrman DE, Feigl EO. Competition between sympathetic vasoconstriction and metabolic vasodilation in the canine coronary circulation. Circ Res 1978; 42: 79m.8.

12 Fale A, Kirsch JR, McPherson RW. Alpha 2-adrenergic agonist effects on normocapnic and hypercapnic cerebral blood flow in the dog are anesthetic dependent. Amesth Andig 1994: 79(5): $892-8$. 
13 Lang RM, Marcus RH. Neunan A, et al. A time-course study of the effects of pentobarbital, fentanyl, and morphine chloralose on myocardial mechanies, I Appl Physiol 1992; 73(1): $143-50$.

14 Maggi CA. Meli A. Suitability of urethane anesthesia for physiopharmacological investigations in various systems. Part 2. Cádiowascular system. Experientia 1986; 42(3): 292-7.

15 Magg CA. Mell A. Suitability of arethane anesthesia for physiopharmacological investigations in varous systervis. Pant 1: Generall considerations. Experientia 1986; 42(2): 109-14.

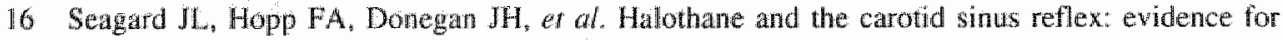
multiple sites of action. Anestheriology $1982 ; 57: 191-202$.

17 Trigr $\mathrm{P}$. Christan CC, Fagraeus $\mathbb{L}$, of al. Myocardial depression by anesthetic agents (halothane, enfurine and nitrous oxide): quantiation based on end-systolic pressure-dimension relations. Am J Cardiol 1984; 53(1): 243-7.

18 Wilkinson PL, Tyberg JV, Moyers JR, White AE. Correlates of myocardial oxygen consumption when afterload changes during halothane anesthesia in dogs. Anesth Analg 1980; 59: 233-9.

19 Inoue K. Samodelor LF. Arndt JO. Fentanyl activates a particular population of vagal efferentes which are cardioinhibitory. Nawny-Schmiedebergs Arch Pharmacol 1980; 312(1): 57-61.

20 Latubie M, Schmitt H. Drouillat M. Central sites and mechanisms of the hypotensive and bradycardic effects of the narcotic anaigesic agent fentanyl. Naunyn-Schmiedebergs Arch Phamacol 1977; 296: 255-61.

21 Schmeling WT, Kampine IP, Roerig DL., Warltier DC. The effects of the stereoisomers of the alpha 2-adrenergic agonist medetomidine on systemic and coronary hemodynamics in conschous dogs. Anesthesiology 1991; 75(3): 499-511.

22 Bloor BC. Ward DS, Belleville JP, Maze M. Effects of intravenous dexmedetomidine in humans. II. Hemodynamic changes. Anesthesiology 1992; 77(6): I 134-42.

23 Weiss HR. Regional oxygen consumption and supply in the heart: effect of atrial pacing. An $J$ Physiol 1979; 236: H23:-7.

24 Schipke JD, Burkhoff D, Kass DA, et al. Hemodynamic dependence of myocardial oxygen consumption indexes. Am J Physiol 1990; 258: H1281-91.

25 Nathan HJ, Feigl EO. Adrenergic vasoconstriction lessens transmural steal during coronary hypoperfusion. Am J Physiol 1986; 250: 14645-53.

26 Chilian WM. Harrison DG, Haws CW, ef al. Adrenergic coronary tone during submaximal exercise in the dog is produced by circulating catecholamines. Evidence for adrenergic denervation supersensitivity in the myocandium but not in cononary vessels. Cinc Res 1986; $58(1): 68-82$

27 Heistad DD, Abboud FM. Mark AL. Schmid. Elfect of hypoxemian on responses to noradrenaline and angiotensin in coronary and muscular vessels. I Phamacol Exp Ther 1975; 193: 941-50.

28. Curro FA. Greenberg S. Characteristics of postsynaptic alphal and alpha2 adrenergic receptors in canine vascular smooth muscle. Can If Physo Pharmacol 1983; 61: 893-904.

29 Becker L. Elfect of tachyeardia on left ventricular blood flow distribution during coronary occlusion. Am J Physiol 1976; 230: 1072-7.

30 Becker LC. Fortuin NN, Pitt B. Effect of ischemia and antianginal drugs on the distribution of radioactive microspheres in the canine left ventricle. Circ Res 1970; $28: 263-9$.

31 Gross GJ. Winbury MM. Beta adrenergic blockade on intramyocardial distribution of coronary blood llow. I Phamaco $1973 ; 187 ; 45 \rrbracket-64$.

32 Aantan R. Scheinin M. Alphany-adrenergie agents in anaesthesia. Acta Anatsthesiol Scand 1993; 37: $433 \rightarrow 48$.

33 Rockaerts PM, Prinzen FW, Lange Sd. Coronary wascular effects of dexmedetomidine during reactive hyperemia in the anesthetized dog. J Cardiothorac Vasc Anesh 1996; 10: 619-26.

34 Indolfi $C$. Piscioni $F$, Villari $B$, et at. Role of alphaz-adrenoceptors in normal and atherosclerotic human coronary circulation. Circulation 1992; 86: 1116-24. 


\title{
CHAPTER 6
}

\section{The effect of dexmedetomidine on nutrient organ blood flow'}

\author{
C. J. Lawrence, F. W. Prinzen, and S. de Lange
}

The adrenergic agonist dexmedetomidine decreases not only heart rate, myocardial contractility, and oxygen demand, but also cardiac output (CO). To investigate whether this reduction in $\mathrm{CO}$ could critically impan perfusion of individual organs, we studied the effect of dexmedetomidine on nutrient blood flow to heart, brain, kidney, spleen, skin, intestine, liver, and arteriovenous anastomoses using the radioactive microsphere technique. Studies were conducted in 14 dogs with an open chest and anesthetized with either chloralose/urethane (CU) or fentanyl/halothane (FH), to create different baseline conditions. Hemodynamic wariables, organ blood flow, arterial and mixed venous oxygen, and lactate content were measured before and after administration of $0.1,1$, and $10 \mu \mathrm{g} / \mathrm{kg}$ dexmedetomidine intravenously (IV). After $10 \mu \mathrm{g} / \mathrm{kg}$ dexmedetomidine $\mathrm{CO}$ decreased in both groups by $50 \%$. The decrease in blood flow varied greatly between the organs. While flow through anteriovenous anastomoses and skin decreased by $70 \%$ to $90 \%$, renal blood flow decreased by $30 \%$, cerebral blood flow only when baseline blood flow was high (FH dogs), and left ventricular blood flow only in the CU group, where the largest decrease in hemodynamic variables occurred. Oxygen consumpion decreased only in $\mathrm{CU}$ dogs, but so did arterial bactate levels. These data indicate that dexmedetomidine causes considerable redistribution of $\mathrm{CO}$, predominanty reducing blood flow to less vital organs and shum flow.

\footnotetext{
"Published in Anesth Analg 1996; 83: 1 160-5. Reproduced will permission of the publishor (presented in part at the European Association of Cardiothoracic Anaesthesiologists" seventh Amual Meeting. Malastricht, The Neiherlands, June 9-12, 1992, and published in abstract form in J Cardionhoriac Vasc Anesh 1994: 8 (Suppl 2): $82 h$
} 


\section{Introduction}

$\alpha_{2}$-Adrenergic agonists, like clonidine, mivazerol, and dexmedetomidine, alter systemic hemodynamics by stimulation of central $\alpha_{2}$-adrenoceptors, thereby decreasing sympathetic outflow, heart rate, and myocardial contractility [1]. Previous studies from our laboratory showed that acute administration of dexmedetomidine and mivazerol reduces oxygen requirements of the ventricle due to the reductions in theart rate and contractility $[2,3]$. In combination with the redistribution of blood flow from epicardial to endocardial layers of the ventricular wall [2], this reduced workload of the heart had favorable effects during myocardial ischemia [3,4]. However, these beneficial effects for the heart were accompanied by decreases in cardiac output (CO) of up to $50 \%$ in anesthetized [2,5] and conscious dogs [6], while in humans a decrease of $41 \%$ has been reported [7].

No study has indicated whether a reduction in $\mathrm{CO}$ by dexmedetomidine critically impairs perfusion and oxygen supply of vital organs. Because the number of $\alpha_{2}$ receptors varies considerably from organ to organ, some organs might be affected more than others.

To investigate this question, dexmedetomidine was administered to anesthetized dogs and blood flow in various organs was measured by the radioactive microsphere technique [8]. Systemic oxygen consumption and plasma lactate concentration were also measured. To evaluate the effect of differences in baseline condition on the various actions of dexmedetomidine, two groups of dogs were compared. One group was anesthetized with chloralose and urethane (CU group), the other with fentanyl and halothane (FH group). These two anesthetic techniques are known to affect the autonomic system in different ways [2].

\section{Methods}

All animal experiments were performed after approval of the animal experimental committee of the University of Limburg, Maastricht, The Netherlands. Fourteen thealthy, mongrel dogs of either sex weighing $22-39 \mathrm{~kg}$ were studied. Anesthesia was induced with the short-acting barbiturate thiopental $(30 \mathrm{mg} / \mathrm{kg})$ and, after endotracheal intubation, the dogs were ventilated with oxygen/nitrous oxide $(40 \% / 60 \%)$. Subsequently two different anesthetic regimes were followed. Six animals were anesthetized with $60 \mathrm{mg}$ chloralose and $300 \mathrm{mg}$ urethane intravenously (IV) per kilogram of body weight (CU group). In the other eight animals halothane $(0.5 \%-1 \%)$ was added to the inspired gases to maintain adequate anesthesia throughout the study. Fentanyl $(1-5 \mu \mathrm{g} / \mathrm{kg})$ was administered IV in the FH group during surgical preparation. A venous cannula was inserted in a leg vein for infusion of fluids and medication.

The experimental preparation has been described previously in detail [2,9]. Catheters were introduced in brachial and femoral arteries for measurement of aortic and left 
ventricular (LV) pressure. A thermodilution pulmonary artery catheter introduced via the left external jugular vein was used to obtain mixed venous blood samples from the pulmonary artery and to measure $\mathrm{CO}$ by the thermodilution technique. $\mathrm{LV}$ pressure, aortic pressure, coronary flow, and electrocardiogram (lead II) were displayed continuously. All pressures and flows were recorded continuously using a pen recorder at $0.25 \mathrm{~cm} / \mathrm{s}$, increased to $5 \mathrm{~cm} / \mathrm{s}$ during data acquisition.

Radioactive microspheres (New England Nuclear, Boston, MA) 15 am in diameter and labeled with ${ }^{141} \mathrm{Ce},{ }^{113} \mathrm{Sn},{ }^{103} \mathrm{Ru},{ }^{95} \mathrm{Nb}$, or ${ }^{46} \mathrm{Sc}$ were used to determine nutrient organ blood flow. Approximately $2.5 \times 10^{6}$ microspheres were injected into the left atrium and an arterial reference sample was taken from the brachial artery at a rate of $20.7 \mathrm{~mL} / \mathrm{min}$. At each dose of dexmedetomidine one of the isotopes was injected. Since the 15 - $\mu \mathrm{m}$ spheres are distributed through the body relative to the volume flow to each organ and lodge in the microcirculation, the number of microspheres measured after the experiments represents the flow to that organ at the time of injection. After the dogs were killed with an overdose of pentobarbital, their organs were excised, rinsed, and stored in formaldehyde 5\%. For blood flow determination multiple, representative samples of $1-3 \mathrm{~g}$ were taken randomly from each organ (cerebral cortex samples, containing mainly gray matter, left ventricle, both lungs, thoracic skin, kidneys, spleen, intestine, and liver). Use of this calculation for the lung samples yields a measure of the absolute amount of shunt flow, since all microspheres passing through arteriovenous shunts larger than $15 \mu \mathrm{m}$ lodge in the lungs. The pieces were weighed to the nearest milligram and counted in a $\gamma$ counter (Packard Multichannel Analyzer, Brussels, Belgium or LKB Compugamma 1282, Turku, Finland), together with the reference blood samples. Using the gammaspectra the contribution from each of the injected isotopes could be determined and nutrient organ blood flow in $\mathrm{mL}$. $\min ^{-1} \cdot 100 \mathrm{~g}^{-1}$ calculated with the MIC II program [9]. Absolute blood flow values were calculated using the equation [8]:

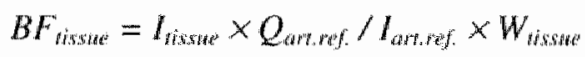

where $\mathrm{BF}_{\text {tissue }}$ is blood llow to the tissue $\left(\mathrm{mL} \cdot \mathrm{min}^{-1} \cdot 100 \mathrm{~g}^{-1}\right), \mathrm{I}_{\text {tigsae }}$ and $\mathrm{I}_{\text {ar }}$ rer are the radioactivity of the tissue and arterial reference sample, respectively, and $W_{\text {tissue }}$ is the weight of the tissue.

Fifteen minutes after completion of instrumentation, baseline measurements were taken and repeated after $10 \mathrm{~min}$. After the baseline measurements, successively increasing doses $(0.1,1$, and $10 \mu \mathrm{g} / \mathrm{kg}$ ) of dexmedetomidine were given IV by slow infusion over $2 \mathrm{~min}$ at 40 min intervals. Fifteen minutes after each administration, the hemodynamic measurements were performed, arterial and mixed venous samples obtained and radioactive microspheres injected.

Arterial and mixed venous blood gases, blood $\mathrm{pH}$, hemoglobin (Hb) concentration, and oxygen saturation were determined. Oxygen content was calculated from the latter variables. 
Table 1 Hendynamic effects of dexmedetomidine

\begin{tabular}{|c|c|c|c|c|c|}
\hline \multirow[b]{2}{*}{ Variable } & \multirow[b]{2}{*}{ Group } & \multicolumn{4}{|c|}{ Dexmedetomitine ( $\mu \mathrm{g} / \mathrm{kg})$} \\
\hline & & Baseline & 0.1 & 1.0 & 40.0 \\
\hline \multirow[t]{2}{*}{ Cardiac oufput (Liminj) } & $\mathrm{CU}$ & $3.7+2$ & 3.5 .40 .3 & $2.3 \pm 0.2^{*}$ & $1.6 \pm 0.2^{ \pm}$ \\
\hline & $\mathrm{FH}$ & $3.7 \pm 0.4$ & $3.6 \pm 0.6$ & $2.7 \pm 0.3$ & $2.0 \pm 0.2^{*}$ \\
\hline Marn arterial blood & $\mathrm{CU}$ & $126 \pm 9.5$ & $123 \pm 9.7$ & $105 \pm 10.2$ & $95 \pm 16.8$ \\
\hline presstire (mm Hg) & $\mathrm{FH}$ & $100 \pm 9.6$ & $100 \pm 8.9$ & $104 \pm 7.0$ & $127 \pm 90^{*}$ \\
\hline \multirow[t]{2}{*}{ Heant rate (pom } & $\mathrm{CU}$ & $154.84+$ & $145 \pm 7.7 \pm$ & $112 \pm 9.7$ & $86 \pm 8.4$ \\
\hline & $\mathrm{FH}$ & $91 \pm 5.9$ & $85 \pm 8.7$ & $73 \pm 6.9$ & $63+57^{2}$ \\
\hline \multirow[t]{2}{*}{ SWR (dyress - $\left.+\mathrm{cm}^{5}\right)$} & $\mathrm{CU}$ & $2751+256$ & $2898 \pm 267$ & $3777 \pm 402$ & $5016 \pm 8011^{t}$ \\
\hline & $\mathrm{FH}$ & $2568 \pm 617$ & $2636 \pm 517$ & $348 \pm 579$ & $5.576 \pm 692^{1}$ \\
\hline \multirow[t]{2}{*}{ Stroks volume (mL) } & $\mathrm{CU}$ & $25.0 \pm 2.4 \uparrow$ & $24.7 \pm 2.8$ & $21.6 \pm 3.1$ & $18.9 \pm 2.8 *$ \\
\hline & $\mathrm{FH}$ & $40.7 \pm 4.6$ & $42.8 \pm 5.5$ & $37.6 \pm 4.0$ & $32.9 \pm 40$ \\
\hline
\end{tabular}

Values are expressed as mean \pm SEM.CU $=$ dogs anesthetised with chloralose/urethane; FH $=$ dogs anesthetsed with fentumylhatohane; $\mathrm{SVR}=$ systemic vascular nesutance. "Significantly different from baseline $(P<0.05) . \dagger$ Significant difference between $\mathrm{CU}$ and FH at this dose:

Systemic vascular resistance (SVR) was calculated as mean arterial pressure (MAP) $\times$ $80 / \mathrm{CO}$ (dynes $\cdot \mathrm{s} \cdot \mathrm{cm}^{-5}$ ). Mixed venous oxygen extraction ( $\mathrm{mL} / \mathrm{dL}$ blood) was calculated as" $\mathrm{Hb} \times 1.34 \times\left(\mathrm{SaO}_{2}-\mathrm{Svo}_{2}\right)$ where $\mathrm{Hb}$ is in grams per deciliter, $\mathrm{SaO}_{2}$ is arterial oxygen saturation, and $\mathrm{SvO}_{2}$ is mixed venous oxygen saturation (the small contribution of dissolved oxygen was not taken into account). Total body oxygen uptake was calculated as the product of oxygen extraction and $\mathrm{CO}$. Two-way analysis of variance

Renal and splenic blood flow

....... kidney OU

....... kidney FH $\mathrm{FH}-\mathrm{spleखn} \mathrm{FH}$

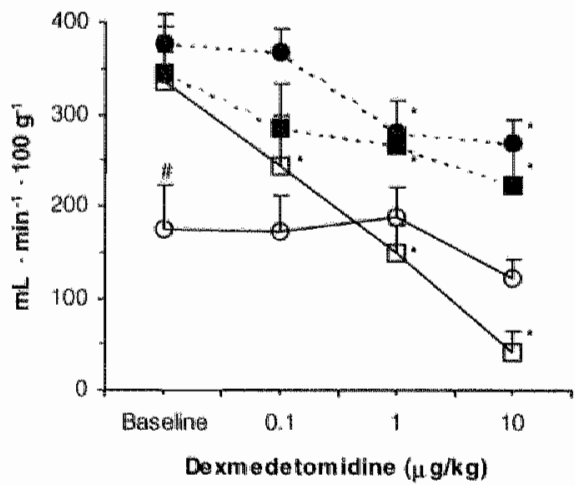

Left ventricular and cerebral blood flow

... LVOU — brain CU

-.. LVFH brain FH

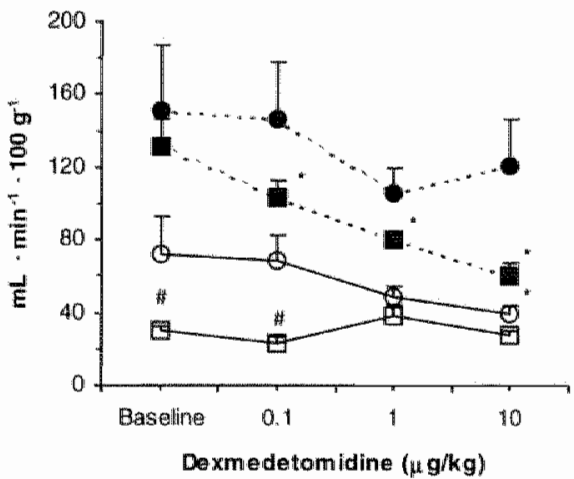

Figure 6-1 Effect of dexmedetomidine on organ bload flow in dogs anesthetized with either choralose/urethane (CU) or fentanylhalothane (FH). Values are expressed as mean $\#$ SEN. LV $=$ left ventriculiar blood flow. * Significantly different from baseline. Significant difference bewwen the two groups. 
for repeated measures was first applied to detect statistical differences between groups: If the two-way analysis also indicated significant changes within groups, this was further evaluated using one-way analysis of variance for repeated measures and Fisher's protected least significant difference test as a post-hoc multiple comparison procedure. Baseline values between the two groups were compared using Student's ttest. $P$ values $<0.05$ were considered significant.

\section{Results}

Baseline hemodynamics of the two groups were different (Table 6-1). Mean heart rate and MAP values were $91 \mathrm{bpm}$ and $100 \mathrm{~mm} \mathrm{Hg}$ in the FH group and $154 \mathrm{bpm}$ and 126 $\mathrm{mm} \mathrm{Hg}$ in the CU group. Stroke volume was significantly larger in the FH group (Table 6-1).

In both groups, dexmedetomidine administration caused a dose-dependent decrease in heart rate. Whereas MAP increased significantly in the FH group (from 100 to 127 $\mathrm{mm} \mathrm{Hg}$ after the $10-\mu \mathrm{g} / \mathrm{kg}$ dose), it tended to decrease in the CU group (from 126 to $95 \mathrm{~mm} \mathrm{Hg}$ ) $\mathrm{CO}$ decreased and systemic vascular resistance increased significantly in both groups. Baseline $\mathrm{CO}$, as well as blood flow in most organs, did not differ between the two groups. However, baseline cerebral blood flow (CBF) was significantly higher in the FH group and splenic and muscular blood flow were higher in the CU group (Figures 6-1 and 6-2).
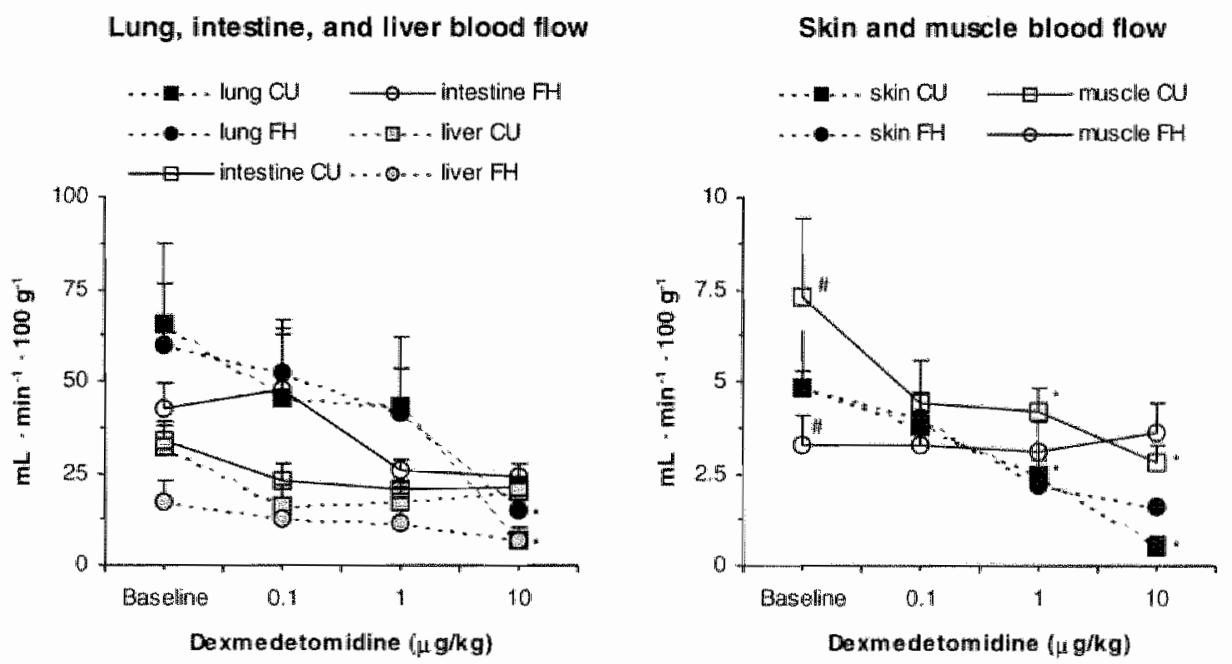

Figure 6-2 Effect of dexmedetomidine on organ blood flow in dogs anesthetized with either chloralose/urethane (CU) or fentany//halothane (FH). Values are expressed as mean \pm SEM. Lung $\mathrm{CU}$ and lung $\mathrm{FH}$ were significantly lower than baseline after $10 \mu \mathrm{g} / \mathrm{kg} .{ }^{*}$ Significantly different from baseline. \# Signiticant difference between the two groups. 
CBF decreased in one of six dogs in the CU group, but in five of eight experiments in the $\mathrm{FH}$ group. $\mathrm{CBF}$ mainly decreased in the experiments where baseline values were high, and in these cases dexmedetomidine decreased CBF to values similar to the baseline values of most of the experiments (Figure 6-1). The change in CBF was only significant in the $\mathrm{FH}$ dogs after $10 \mu \mathrm{g} / \mathrm{kg}$. The changes in LV blood flow were different between the two experimental groups. Total LV blood flow decreased dosedependently in the CU group. In contrast, no significant change of LV flow was found in the FH group (Figure 6-1).

There was also a marked difference in the effect of dexmedetomidine on the splenic flow between the two groups. Initially, flow was higher in the CU group (Figure 6-1) but this decreased significantly after $0.1,1$, and $10 \mu \mathrm{g} / \mathrm{kg}$, while the flow in the FH group did not change after dexmedetomidine. Dexmedetomidine $1 \mu \mathrm{g} / \mathrm{kg}$ decreased blood flow to the kidneys by $25 \%$ and in the skin by $50 \%$ in both groups, and the 10 $\mu \mathrm{g} / \mathrm{kg}$ dose caused slightly larger decreases (Figure 6-1). Blood flow through arteriovenous anastomoses ("lung flow") decreased by $90 \%$ (CU) and $75 \%(\mathrm{FH})$ after 10 $\mu \mathrm{g} / \mathrm{kg}$. Blood flow to the skeletal muscle was low and a further reduction was only observed in the $\mathrm{CU}$ group. Changes in blood flow in intestine and liver were not significant (Figure 6-2).

Dexmedetomidine increased mixed venous oxygen extraction dose-dependently, the increase becoming significant at a dose of $1 \mu \mathrm{g} / \mathrm{kg}$ in the CU dogs and $10 \mu \mathrm{g} / \mathrm{kg}$ in FH dogs (Table 6-2). Total body oxygen uptake was reduced in the CU dogs after 1 and $10 \mu \mathrm{g} / \mathrm{kg}$. Arterial lactate concentration was significantly reduced after I and $10 \mu \mathrm{g} / \mathrm{kg}$ in the CU group and did not change significantly in the FH group (Table 6-2).

Table 6-2 Effect of increasing doses of dexmedetomidine on oxygen consumption and lactate concentration

\begin{tabular}{|c|c|c|c|c|c|}
\hline \multirow[b]{2}{*}{ Variable } & \multirow[b]{2}{*}{ Group } & \multicolumn{4}{|c|}{ Dexmedetomidine $(\mu \mathrm{g} / \mathrm{kg})$} \\
\hline & & Baseline & 0.1 & 1.0 & 10.0 \\
\hline \multirow[t]{2}{*}{ Svor $(\%)$} & $\mathrm{CU}$ & $67.3 \pm 3.3$ & $65.8 \pm 3.3$ & $55.1 \pm 4.4^{*}$ & $39.4 \pm 4.8^{\circ}$ \\
\hline & $\mathrm{FH}$ & $65.4 \pm 2.1$ & $62.7 \pm 3.7$ & $64.6 \pm 3.8$ & $53.8 \pm 4.4$ \\
\hline$C(a-v) a_{2}$ & $\mathrm{Cu}$ & $5.05 \pm 0.25$ & $5.21 \pm 0.26$ & $6.84 \pm 0.44^{*}$ & $9.28 \pm 0.20^{\circ}$ \\
\hline$(\mathrm{mLO} / \mathrm{dL}$ blood) & $\mathrm{FH}$ & $4.54 \pm 0.77$ & $5.35 \pm 0.41$ & $5.40 \pm 0.50$ & $7.22 \pm 0.56^{\circ}$ \\
\hline \multirow[t]{2}{*}{ VOz (mLimin) } & $\mathrm{CU}$ & $197 \pm 18.9$ & $187 \pm 16.1$ & $160 \pm 114.3^{\text {th }}$ & $150 \pm 24.0^{\circ}$ \\
\hline & FHH & $142 \pm 15.3$ & $173 \pm 35.0$ & $141 \pm 20.4$ & $131 \pm 14.2$ \\
\hline Arterial lactate & $\mathrm{Cu}$ & $2.07 \pm 0.49$ & $1.88 \pm 0.48$ & $1.73 \pm 0.46^{\circ i}$ & $1.48 \pm 0.44$ \\
\hline (mmol/h) & $\mathrm{FHH}$ & $1.21 \pm 0.41$ & $1.13 \pm 0.32$ & $1.15 \div 0.35$ & $1.04 \pm 0.24$ \\
\hline
\end{tabular}

Values are expressed as mean \pm SEM. $\mathrm{CU}=$ dogs anesthetised with chloralose/urathane; $\mathrm{FH}=$ dogs anesthetised with fentany/halothane; $\mathrm{S} w_{2}=$ mixed venous oxygen saturation; $\mathrm{C}\left(\mathrm{a}-w_{2} \mathrm{O}_{2}=\right.$ mixed venous oxygen extracion; $V_{\mathrm{O}_{2}}=$ botall body oxygen consumaption. "Significanly different from baseline $(P<0.05)$. There were no significan differences between the wo groups. 


\section{Discussion}

The present study demonstrates that dexmedetomidine preserves flow to the most vital organs (brain, heart, liver, kidneys) at the expense of less vital organs and flow through arteriovenous shunts. Oxygen consumption of the body decreased only in the $\mathrm{CU}$ group. Baseline oxygen uptake was $39 \%$ higher in the CU group than in the FH group $(P=0.056)$. This difference may be due to a higher sympathetic activity, known to occur during $\mathrm{CU}$ anesthesia [10]. The finding that the decreased oxygen uptake in this group was accompanied by a lower arterial lactate concentration argues against the occurrence of major ischemia in any organ. Rather, it indicates that dexmedetomidine decreased the oxygen requirements of the body. Blood flow in the vital organs remained well above the levels known to induce underperfusion, supporting the idea that the redistribution of cardiac output induced by dexmedetomidine is appropriate. The decrease in blood flow in organs with low oxygen extraction appears an important contributor to the increase in mixed venous oxygen extraction.

The larger decrease in blood flow to the left ventricle in the $\mathrm{CU}$ than in the $\mathrm{FH}$ dogs can be explained by a greater myocardial energy-saving effect of dexmedetomidine in the former group [2]. In this earlier study little change in arteriocoronary oxygen saturation difference was observed after dexmedetomidine in either anesthesia group, indicating that most of the reduction in myocardial blood flow was due to metabolic regulation of the myocardium rather than adrenergic vasoconstriction [2].

The finding that CBF decreased only in the FH group (especially those with the high baseline values) may be explained by relative vasodilation in these experiments, a well-known side effect of halothane [11]. Of note, dexmedetomidine reduced CBF to a level similar to that observed in the CU group and to values usually found in conscious dogs [12]. In dog studies which have shown a decrease in sagittal sinus flow, either isoflurane [13] or halothane [14] was used as anesthetic. The larger decline in these studies might be explained by the fact that sagittal sinus outflow includes shunt flow. This idea is supported by the absence of changes in cerebral oxygen consumption $[13,14]$.

The decrease in renal blood flow is in accordance with the findings of de Leeuw et al. [15], who showed an increase of renal blood flow by administration of $\alpha_{2}$-adrenergic antagonists in the renal artery of hypertensive patients.

The decrease of cutaneous blood flow by dexmedetomidine is in agreement with findings on finger blood flow after administration of clonidine in human subjects, as measured by plethysmography [16]. This technique measures gross blood flow, including flow through arteriovenous anastomoses. In extremities, shunt flow accounts for a considerable part of total blood flow and the role of $\alpha_{2}$-adrenoceptors in regulation of shunt flow is well known |17].

Liver blood flow as measured with microspheres represents only flow through the hepatic artery [18] and does not take into account portal venous flow. Since intestinal 
flow did not change but shunt flow decreased considerably, dexmedetomidine may have decreased total blood flow through the liver to some extent.

The absolute contribution of each organ to the redistribution of $\mathrm{CO}$ requires knowledge of the size of these organs. With a body surface of approximately $1 \mathrm{~m}^{2}$, the weight of the skin is approximately $5 \mathrm{~kg}$, so that the reduction of cutaneous flow of $4 \mathrm{~mL} \cdot \mathrm{min}^{-4} \cdot 100 \mathrm{gg}^{-1}$ amounts to a total reduction of $200 \mathrm{~mL} / \mathrm{min}$. Similarly, with lung and kidney weights of 300 and $200 \mathrm{~g}$, respectively, total "lung" flow, representing arteriovenous shunt flow, and renal flow amount to decreases of about 150 and 200 $\mathrm{mL} / \mathrm{min}$, respectively. While blood flow to these three organs can explain a decrease of about one third of the decrease in $\mathrm{CO}$, all remaining organs make up the rest of the decrease.

We used dogs for this study, since the microsphere method is not applicable in man. Because animals have different sensitivity to anesthetics than man, the anesthetic regimen used is of limited clinical importance. Anesthesia was initially induced with thiopental, a barbiturate with a half-life of approximately $20 \mathrm{~min}$ in dogs. This was used to tracheally intubate the animals and subsequently start the two anesthetic regimens. The actual measurements occurred two to three hours after induction of anesthesia, so that the effect of this anesthetic had expired, and only the effects of the FH or CU anesthesia prevailed.

Chloralose and urethane (ethyl carbamate) are used as anesthetics for acute animal experiments especially because they have few effects on cardiac function [19] and cardiovascular reflexes [20]. Urethane activates the sympathetic outflow from the central nervous system [10]. Halothane depresses baroreflex activity [21] and reduces contractility [22], heart rate, and blood pressure [23]. Fentanyl increases vagal tone [24] and reduces sympathetic tone [25]. Using these two anesthetic regimens we obtained two groups of animals with considerably different baseline conditions, which allowed us to study the extent that differences in such conditions could affect the influence of dexmedetomidine on organ flow. Although the CU regimen is not directly applicable clinically, this study shows that dexmedetomidine's effect on organ flow is not much affected by the type of anesthesia, a conclusion with clinical relevance. The present study only focused on the effects of dexmedetomidine on organ flow under near optimal baseline conditions. Further studies are required to determine the effects of dexmedetomidine administration when the circulation is already compromised.

Summarizing, dexmedetomidine decreased blood flow to most organs, but the largest decrease occurred in skin, spleen, and in arteriovenous shunts. Mixed venous oxygen extraction increased and oxygen uptake remained constant (FH) or decreased to a limited extent (CU). Perfusion of vital organs such as the heart, brain, and kidneys was only moderately reduced, which could also be explained by functional alterations in these organs. Overall adequacy of oxygen supply to the body was indicated by unchanged $(\mathrm{FH})$ or lowered $(\mathrm{CU})$ arterial plasma lactate concentrations, even at the highest $(10 \mu \mathrm{g} / \mathrm{kg}$, supraclinical) dose of dexmedetomidine. 
The results in the present study were obtained in healthy dogs with a well maintained anesthesia, cardiac function, and preload. Dexmedetomidine's effect on organ tow has not been assessed under less optimal conditions.

\section{Acknowledgments}

Dexmedetomidine was supplied by Orion Corporation, Farmos, Turku, Finland. The technical assistance of Mr. R. Kruger, Mr. T. vd Nagel, and Mr.. J. Habets is gratefully acknowledged.

\section{References}

1 Maze M, Tranquilli W. Alpha-2 adrenoceptor agonists: defining the role in clinical anesthesia. Anesthesiology 1991; 74:581-605.

2 Lawrence CJ, Prinzen FW, de Lange $\mathrm{S}$. The Effect of dexmedetomidine on the balance of myocardial energy requirement and oxygen supply and demand. Anesth Analg 1996; 82:544-50.

3 Roekaerts PM, Willigers HMM, Prinzen FW, Lange S. The effects of alpha -adrenergic stimulation with mivazerol on myocardial blood flow and function during cononary artery stenosis in anesthetized dogs. Anesth Analg 1996;82(4): 702-11.

4 Roekaerts PMHJ, Prinzen FW, de Lange S. Coronary vascular effects of dexrnedetomidine during reactive hyperemia in the anesthetized dog. I Cardiothorac Vasc Anesth 1996; 10: 619-26.

5 Flacke WE, Flacke JW, Bloor BC, et al. Effects of dex medetomidine on systemic and coronary hemodynamics in the anesthetized dog $J$ Cardiothorac Vasc Anesth 1993; 7(1):41-9.

6 Proctor LT, Schmeling WT, Roerig D, et al. Oral dexmedetomidine attenuates hemodynamic responses during emergence from general anesthesia in chronically instrumented dogs. Anesthesiology $1991 ; 74(1): 108-14$.

7 Bloor BC, Ward DS, Belleville JP, Maze M. Effects of intravenous dexmedetomidine in humans. 1I. Hemodynamic changes. Anesthesiology 1992; 77(6): 1134-42.

8 Heymann MA, Payne BD, Hoffman JIE, Rudolph AM. Blood flow measurements with radionuclide-labeled microspheres. Prog Cardiovase Dis 1977: 20: 55-79.

9 Primzen FW, Van der Vusse GJ, Reneman RS. Blood flow distribution in the left ventricular frec wall in open chest dogs. Basic Res Cardiol 1981:76:431-7.

10 Maggi CA, Meli A. Suitability of urethane anesthesia for physiopharmacological investigations in warious systems. Part 1: General considerations. Experiemia 1986; 42(2): $109-14$.

11 Wollman H. Alexander SC, Cohen PJ, ef ai. Cerebral circulation of man during halothane anesthesiat effects of hypocarbia and $\delta$-tubocurarine. Anesthesiology 1964; 25 ; $180-4$.

12 Haberer IP, Audibert G, Saunier CG, et al. Effect of propofol and thiopentone on regional blood flow in brain and peripheral tissues during normoxia and hypoxia in the dog. Clin Physiol 1993; 13(2): 197-207.

13 Zonow MH, Fleischer JE, Scheller MS, et al. Dexmedetomidine, an alpha 2-adrenergic agonist, decreases cerebral blood flow in the isoflurane-anesthetized dog. Anesth Analg 1990; 70(6): $624-30$.

14 Karlsson BR, Forsman $M_{4}$ Raald $O K$, et al. Effect of dexmedetomidine, a selective and potent aipha 2-agonist, on cerebral blood flow and oxygen consumption during halothane anesthesia in dogs [see comments]. Anesth Analg 1990; 71(2): 125-9.

15 de Leew PW, van Es PN, de Bos R, Birkenhager WH. Role of alpha 1-and alpha 2-adrenergic receptors in the human hypertensive kidney. Hypertension 1987; 9: 1210-2. 
16 Coffman ID, Cohen RA. Role of alpha-adrenoceptor subtypes mediating sympathetic wasoconstriction in human digits. Eur J Clin Jnvest 1988; 18(3): 309-13.

17 Baker CH, Davis DL, Sutton ET. Blood flow distribution with adrenergic and histaminergic antagonists. Proc Soc Exp Bioi Med 1989, 190(3): 260-7.

18 Daemen MJP. Thijssen HHW, Essen Hv, el al. Liver blood flow measurement in the tat. The electromagnetic versus the microsphere and the clearance methods. J Pharmacal Methods 1989; 21: $287-97$.

19 Lang RM, Marcus RH, Neumann A, et al. A time-course study of the effects of pentobarbital, fentanyl, and morphine chloralose on myocardial mechanics. I Appl Physiol 1992; 73(1): $143-50$.

20 Maggi $\mathrm{CA}$, Meli A. Suitability of urethane anesthesia for physiopharmacological investigations in various systems. Part 2: Cardiovascular system. Experientia 1986; 42(3): 292-7.

21 Seagard JL, Hopp FA, Donegan JH, et al. Halothane and the carotid sinus reflex: evidence for multiple sites of action. Anesthesiology 1982; 57 : 19!-202.

22 Trigt $\times \mathbb{P}$, Christian $\mathrm{CC}_{4}$. Fagraeus $\mathrm{L}$, et al. Myocardial depression by anesthetic agents (halothane, enflurane and nitrous oxide): quantitation based on end-systolic pressure-dimension relations. Am J Cardial 1984; 53(1): $243-7$.

23 Wilkunson PL, Tyberg JV. Moyers JR, White AE. Correlates of myocardial oxygen consumption when afterload changes during halothane anesthesia in dogs. Anesth Analg 1980; 59: 233-9.

24 Inoue $K$, Samodelor $L F$, Arndt JO. Fentanyl activates a particular population of vagal efferentes which are cardioinhibitory. Nawyn-Schmiedebergs Arch Phannacol 1980; 312(1): 57-61.

25 Laubie M, Sctmitt $H$, Drouillat M. Centrall sites and mechanisms of the hypotensive and bradycardic elfects of the narcotic analgesic agent fentanyl. Naunyn-Schmiedebergs Arch Pharmacol 1977; 296: 255-61. 


\title{
CHAPTER 7
}

\section{Hemodynamic and coronary vascular effects of dexmedetomidine in the anesthetized goatt}

\author{
C. J. Lawrence, F. W. Prinzen, and S. de Lange
}

In phase III trials, the hemodynamic stabilising effect of the $\alpha_{2}$-adrenergic agonist dexmedetomidine is being investigated in patients with coronary artery disease. Coronary wascular effects of $\alpha_{2}$-agonists have been studied in dogs and pigs, but both species have at different hemodynamic response to dexmedetomidine than man. The aim of this study was to investigate the hemodynamic and coronary vascular effects in goats. In six openchest goats anesthetized with halothane, central and coronary hemodynamics and oxygen supply and demand were measured before and following IV bolus infusion of dexmedetomidine in doses ranging from 0.1 to $10 \mu \mathrm{g} / \mathrm{kg}$. With dexmedetomidine doses of $1 \mu \mathrm{g} / \mathrm{kg}$ or higher, mean arterial pressure (MAP), systemic vascular tesistance, coronary vascular resistance, and arterio-mixed venous oxygen content increased within 2 min, but returned to baseline within $15 \mathrm{~min}$. In contrast, there was a progressive and cumulative decrease in cardiac output $(\mathrm{CO})$, heart rate, and the first positive derivative of left ventricular pressure ( $\mathrm{dP} / \mathrm{dt} \mathrm{t}_{\text {insix }}$ ). Regional coronary venous oxygen extraction $\left(\mathrm{C}(\mathrm{a}-\mathrm{cv}) \mathrm{O}_{2}\right)$ transiently increased after $3 \mu \mathrm{g} / \mathrm{kg}$ dexmedetomidine and decreased 15 min after $10 \mu \mathrm{g} / \mathrm{kg}$ dexmedetomidine. Left ventricular end-diastolic pressure transiently increased after 3 and $10 \mu \mathrm{g} / \mathrm{kg}$ dexmedetomidline. The changes after dexnedetomidine $10 \mu \mathrm{g} / \mathrm{kg}$ differed from those after lower doses: MAP $(35 \%), \mathrm{CO}(50 \%)$, stroke volume $(33 \%), \mathrm{C}(\mathrm{a} \cdot \mathrm{c} w) 0_{2}(15 \%)$. and myocardial oxygen extraction (33\%) were all decreased. Myocardial oxygen supply and demand decreased in parallel. We conclude that (1) the cardiovascular response to IV dexmedetomidine in goats is similar to man, (2) in goats after dexmedetomidine, systemic and coronary vasoconstriction are short lived, and (3) the balance between myocardial oxygen supply and demend is maintained.

\footnotetext{
Published in Acta Anaesthesiol Scand 1997; 41: 830-6. Reproduced with permission of the pulblisher (presented in part at the European Association of Cardiothoracic Anaesthesiologists." sixuh Anmual Meeting. Milan, Italy. June 4-7, 1991, and published in abstract form in J Cardiowhorac Vasc Anesth 1992; 6 (Suppl 1): 76)
} 


\section{Introduction}

$\alpha_{2}$-Adrenergic agonists have been shown to produce sedation, analgesia, and reduction of anesthetic requirements together with increased hemodynamic stability in animals and man [1]. The selective $\alpha_{2}$-adrenergic agonists like dexmedetomidine seem to be more promising than clonidine in this respect $[2,3]$. In man, the hemodynamic effects of dexmedewmidine are biphasic: a rapid transient increase in mean arterial pressure (MAP) and systemic vascular resistance (SVR), accompanied by a reduction in heart rate (HR), followed within $15 \mathrm{~min}$ by a decrease in contractility and MAP [4]. The former is caused by stimulation of postsynaptic vascular receptors, whereas central $\alpha_{2}$ adrenergic receptors, by decreasing sympathetic activity and stimulating parasympathetic activity, are involved in the latter changes [5]. In contrast, studies in anesthetized dogs showed a sustained increase in blood pressure with systemic and coronary vasoconstriction after IV administration of dexmedetomidine [6,7], and it has been suggested that the coronary vasoconstriction may lead to myocardial ischemia [7]. Similar species differences may be present for the degree of $\alpha_{2}$-adrenergic coronary vasoconstriction. Dexmedetomidine IV increased coronary vascular resistance by up to $45 \%$ in dogs [8]. In man, Indolfi et al. demonstrated an $\alpha_{2}$ adrenergic -agonist-induced decrease in cononary artery diameter and flow velocity of approximately $28 \%$ [9]. On the other hand, Schulz et al. demonstrated that there are no $\alpha_{1}$ - and relatively little $\alpha_{2}$-adrenoceptor mediated coronary constrictive effects in pigs [10]. Better understanding of the coronary vascular effects of $\alpha_{2}$-adrenergic agonists is required because phase III trials are being carried out in patients with coronary artery disease. Since studies on coronary flow and oxygen consumption can be performed in more detail in experimental animals, we looked for a species whose response to $\alpha_{2}-$ adrenergic agonists was more similar to that observed in man.

Pilot experiments in anesthetized goats in our laboratory showed that the hypertensive phase after dexmedetomidine was shorter than in anesthetized dogs, and more like that seen in man. Therefore, we studied the effects of dexmedetomidine on systemic and coronary hemodynamics in goats, paying special attention to the balance between myocardial oxygen supplly and demand. For this purpose a range of IV doses of dexmedetomidine were administered to anesthetized open-chest goats.

\section{Methods}

Approval for the study was obtained from the local animal ethical committee prior to commencing the experiments. Six goats weighing $25-50 \mathrm{~kg}$ were used for the study. The goats were anesthetized with sodium thiopental $20 \mathrm{mg} / \mathrm{kg} \mathrm{IV}$. After intubation, the animals were ventilated with a mixture of oxygen $40 \%$ and nitrous oxide $60 \%$ to maintain end-expired carbon dioxide concentration between 3.5 and $4.5 \mathrm{kPa}$. Anesthesia was maintained by adding halothane $1-2 \%$ to the nitrous oxide anesthesia. 
Oxygen saturation was monitored by pulse oximetry and arterial blood gases were frequently analyzed during the study (ABL 3, Radiometer, Copenhagen, Denmark). The temperature was recorded and maintained as close as possible to $38^{\circ} \mathrm{C}$ by means of a heating pad under the animal. A venous cannula was inserted in a leg vein for infusion of fluids and medication. A femoral artery was surgically exposed and a long catheter for arterial blood sampling and measurement of arterial pressure (catheter-tip transducer, Millar Instruments Inc, Houston, Texas, U.S.A.) introduced into the aorta. The thorax was opened via the 5th lateral intercostal space and the pericardium opened to expose the heart. The left circumflex coronary artery was prepared and a flow probe (Skalar, Delft, The Netherlands) placed around it near its origen. A small polyethelene catheter (PE 60) was inserted into the coronary vein accompanying the artery in order to obtain regional venous blood samples. A catheter-tip transducer (Millar) was inserted into the left ventricle (LV) via the left common carotid artery or the right femoral artery. The first positive derivative of left ventricular pressure $\left(\mathrm{dP} / \mathrm{dt}_{\text {nax }}\right)$ and heart rate were derived from the left ventricular pressure signal. A thermodillution pulmonary artery catheter was used to obtain mixed venous blood samples from the pulmonary artery and to measure cardiac output by the thermodilution technique. Left ventricular pressure, aortic pressure, coronary flow, and ECG (lead II) were continuously displayed (Knott GS-8 Monitor, Knott Electronik, Hohen Schäftlarn, Germany). All pressures and flows were recorded continuously using a pen-recorder (Schwarzer RE 412 recorder, München, Germany) at $0.25 \mathrm{~cm} \cdot \mathrm{s}^{-1}$ with the speed increased to $5 \mathrm{~cm} \cdot \mathrm{s}^{-1}$ during data aquisition.

Dexmedetomidine was supplied by Orion Corp., Farmos, Turku, Finland as a crystalline powder. This was dissolved in saline to produce a solution containing 100 $\mu \mathrm{g} / \mathrm{mL}$. The calculated dose was taken from this solution using a $1-\mathrm{mL}$ syringe, transferred to a $20-\mathrm{mL}$ syringe, and diluted to $20 \mathrm{~mL}$ with $0.9 \%$ sodium chloride solution before injection. All test medications were given (over 2 min using a perfusor) into the right atrium through the right atrium port of the pulmonary artery catheter.

After completion of instrumentation and a stabilisation period of $15 \mathrm{~min}$ baseline measurements were taken. Following this, incremental doses of dexmedetomidine $(0.1,0.3,1,3$, and $10 \mu \mathrm{g} / \mathrm{kg})$ were given and measurements repeated at peak mean blood pressure effect (within $1-2 \mathrm{~min}$ ), and $15 \mathrm{~min}$ later. At each measurement point the following data were obtained: heart rate (HR), mean arterial pressure (MAP), left ventricular end-diastolic pressure (LVEDP), circumflex coronary artery blood flow (CF), $\mathrm{dP} / \mathrm{dt}_{\max }$, and thermodilution cardiac output (CO). Arterial, mixed venous (pulmonary artery), and coronary venous blood was collected for measurement of hemoglobin and blood gases (ABL 3, blood gas analyzer, OSM 2 hemoximeter saturation analyzer, Radiometer, Copenhagen, Denmark). After completion of the 15 min measurements, the next dose of dexmedetomidine was given. 
Systemic vascular resistance (SVR) and coronary vascular resistance (CVR) were calculated using the formulae below:

$$
\begin{aligned}
& S V R=M A P \times 80 / C O\left(\text { dynes } \cdot s \cdot \mathrm{cm}^{-5}\right) \\
& C V R=M A P / C F\left(m n H g \cdot m L^{-1} \cdot m^{-1}\right)
\end{aligned}
$$

Stroke Work (SW) was calculated as:

$$
S W=M A P \times S V(m L \cdot m m H g)
$$

where $\mathrm{SV}$ is stroke volume. Mixed venous oxygen extraction (mL/dL blood) was calculated as:

$$
\mathrm{Hb} \times 1.34 \times\left(\mathrm{SaO}_{2}-\mathrm{Svo}_{2}\right)
$$

where

$$
\begin{aligned}
\mathrm{Hb} & =\text { hemoglobin }(\mathrm{g} / \mathrm{dL}) \\
\mathrm{SaO}_{2} & =\text { arterial oxygen saturation } \\
\mathrm{SvO}_{2} & =\text { mixed venous oxygen saturation. }
\end{aligned}
$$

Total body oxygen uptake $(\mathrm{mL} / \mathrm{min})$ was calculated as:

$$
\mathrm{CO} \times \mathrm{Hb} \times 1.34 \times\left(\mathrm{SaO}_{2}-\mathrm{Svo}_{2}\right)
$$

where $\mathrm{CO}$ is cardiac output. Regional coronary venous oxygen extraction ( $\mathrm{mL} / \mathrm{dL}$. blood) as:

$$
\mathrm{Hb} \times 1.34 \times\left(\mathrm{SaO}_{2}-\mathrm{S}_{\mathrm{Cvo}}\right)
$$

where $\mathrm{ScrO}_{2}$ is regional coronary venous oxygen saturation. Myocardial oxygen uptake $\left(\mathrm{MVO}_{2}, \mathrm{~mL} / \mathrm{min}\right)$ in the region supplied by the left circumflex artery was calculated as:

$$
\mathrm{CF} \times \mathrm{Hb} \times 1.34 \times\left(\mathrm{SaO}_{2}-\mathrm{Scvo}_{2}\right)
$$

where $C F$ is coronary flow (left circumflex artery).

Analysis of variance for repeated measures (RM ANOVA) was used for statistical comparison. If the response over all data points showed a significant difference then each post-dexmedetomidine value was separately compared with baseline, and each peak value with preceding "recovery" value. $P<0.05$ was considered significant. 
Table 7-1 Effects of dexmedetomidine on hemodynamics and oxygen extraction in goats.

\begin{tabular}{|c|c|c|c|c|c|c|}
\hline \multirow[b]{3}{*}{ Variable } & \multirow[b]{3}{*}{ Baseline } & \multicolumn{5}{|c|}{ Dexmedetomidine dose (ug/kg) } \\
\hline & & \multicolumn{2}{|c|}{0.1} & \multicolumn{2}{|c|}{0.3} & \multirow{2}{*}{$\frac{1.0}{\text { peak }}$} \\
\hline & & peak & $15 \min$ & perak & 15 min & \\
\hline $\mathrm{CO}(\mathrm{Lmmin})$ & $2.95 \pm 0.43$ & $2.76 \pm 0.44$ & $2.83 \pm 0.45$ & $260 \div 0.44$ & $292 \pm 0.47$ & $2.35+0.43+$ \\
\hline LVEDP (mm Hg) & $7.50 \pm 0.58$ & $7.42 \pm 0.87$ & $6.67 \pm 0.58$ & $8.73 \pm 1.27$ & $8.37 \pm 0.57$ & $10.21 \pm 2.23$ \\
\hline$S V(m L)$ & $31.34 \pm 5.19$ & $30.78 \pm 5.41$ & $32.02 \pm 5.44$ & $31.63 \pm 5.25$ & $34.24 \pm 5.92$ & $29.49 \pm 4.72$ \\
\hline $\mathrm{SW}(\mathrm{mL} \cdot \mathrm{mm} \mathrm{Hg})$ & $2987 \pm 446$ & $2946 \pm 626$ & $2555 \pm 459$ & $3256 \pm 793$ & $2893 \pm 642$ & $3508 \pm 642$ \\
\hline QP/dtmax $(\mathrm{mm} \mathrm{Hg} / \mathrm{s})$ & $1628 \div 208$ & $1472 \pm 173$ & $1496 \pm 193$ & $1439+183^{\circ}$ & $1492 \pm 168$ & $9402 \pm 180^{*}$ \\
\hline $\mathrm{C}(\mathrm{a} \cdot \mathrm{v}) \mathrm{O}_{2}(\mathrm{~mL} / \mathrm{dL})$ & $4.69+0.38$ & $4.59 \pm 0.48$ & $4.51 \pm 0.52$ & $5.00 \pm 0.30$ & $4.06 \pm 0.42$ & $6.35 \pm 0.93^{\circ}$ \\
\hline $\mathrm{VO}_{2}(\mathrm{~mL} / \mathrm{min})$ & $137.80 \pm 22.38$ & $123,17 \pm .23$ & $125.68 \pm 25.45$ & $130.57 \pm 22.21$ & $118.64 \pm 24.41$ & $147.96 \pm 36.33$ \\
\hline \multirow[t]{3}{*}{$\mathrm{MVO}_{2}$ (mL/min) } & $2.88 \pm 0.87$ & $2.56 \pm 0.58$ & $2.41 \pm 0.70$ & $2.94 \pm 0.89$ & $2.26 \pm 0.68$ & $2.65 \pm 0.67$ \\
\hline & & 1.0 & \multicolumn{2}{|c|}{3.0} & \multicolumn{2}{|c|}{10.0} \\
\hline & & $15 \mathrm{~min}$ & peak & $15 \mathrm{~min}$ & peak & $15 \mathrm{~min}$ \\
\hline $\mathrm{CO}(\mathrm{L} / \mathrm{min})$ & & $2.43 \pm 0.44^{*}$ & $1.84 \pm 0.34^{*} \dagger$ & $2.1440 .41^{*}$ & $1.43 \pm 0.26^{*} \dagger$ & $1.41 \pm 0.31^{*}$ \\
\hline LVEOP $(\mathrm{mm} \mathrm{Hg})$ & & $8.08 \pm 0.88$ & $1262 \pm 1.37^{k} t$ & $9.68 \pm 1.31+$ & $13.88 \pm 1.50^{\circ}+$ & $8.83 \pm 1.43+$ \\
\hline $\mathrm{SW}(\mathrm{mL})$ & & $30.30 \pm 5.02$ & $25.42 \pm 4.55^{*}$ & $29.40 \pm 5.01$ & $21.81+4.22^{*}$ & $22.02 \pm 5.21 \%$ \\
\hline $\mathrm{SW}(\mathrm{mL} \cdot \mathrm{mm} \mathrm{Hg})$ & & $2414 \pm 481 \dagger$ & $3013 \pm 558$ & $2180 \pm 551$ & $2512 \pm 710$ & $4522 \pm 484^{\omega} \dagger$ \\
\hline DP/dtmax (mm Hg/s) & & $1287 \pm 160^{\circ}$ & $1310 \pm 174$ & $1104 \pm 171^{*}+$ & $1034 \pm 185^{*}$ & $746 \pm 142^{w_{4}} 4$ \\
\hline $\mathrm{C}\left(\mathrm{a}-\mathrm{V} / \mathrm{O}_{2}(\mathrm{~mL} / \mathrm{d} L)\right.$ & & $5.21+0.93$ & $6.38 \pm 0.66^{*}$ & $4.99 \pm 0.55$ & $7.05 \pm 0.48^{\text {m. }}$ & $6.60+0.43^{*}$ \\
\hline VOs (mL/miry) & & $132.03 \pm 39.84$ & $109.68 \pm 16.42$ & $102.41 \pm 22.15$ & $99.91+19.70$ & $90.22 \pm 18.98$ \\
\hline $\mathrm{MVO}_{2}(\mathrm{~mL} / \mathrm{min})$ & & $2.06 \pm 0.60^{\mathrm{k}}$ & $2.45 \pm 0.67$ & $2.45 \pm 0.84$ & $2.32 \pm 0.64$ & $1.91 \pm 0.56^{*}$ \\
\hline
\end{tabular}

Values are expressed as mean \pm SEM and are measured at baseline and after dexmedetomidine in the doses shown. peak = at the time of peak effect on mean arterial pressure: 15 min = 15 min after "peak" effect; $C O=$ cardiac output; $L V E D P=$ left ventricular end-cliastolic pressure; $S V=$ stroke volume", $S W=$ stroke work; $\mathrm{dP} / \mathrm{dt}_{\mathrm{max}}=$ first positive derivative of left ventuicular pressire; $\mathrm{C}(\mathrm{a}-v) \mathrm{o}_{2}=$ arteriomixed venous oxygen content difference; $\mathrm{VO}_{2}=$ total body oxygen consumption; $\mathrm{MVO}_{2}=$ myocadial oxygen uptake in the region supplied by the left circumflex coronary artery. ${ }^{*}=$ Significantly different $(P<0,05)$ from baseline, $t=$ Significanily different $(P<0.05)$ from previous value. (Repented Measures ANOVA - see Methods).

\section{Results}

MAP increased after each dose of dexmedetomidine except the lowest, this rise being significant when compared to the preceding "recovery" value. However, only after the 1 and $3 \mu \mathrm{g} / \mathrm{kg}$ dose was MAP significantly increased with respect to baseline. Fifteen minutes later, MAP had fallen below baseline, this decrease being significant after 10 $\mu \mathrm{g} / \mathrm{kg}$ (Figure 7-1). The acute MAP rise following each dose ( $\delta \mathrm{MAP}$ ) increased until 1 $\mu \mathrm{g} / \mathrm{kg}$ and then remained constant. SVR increased significantly from the previous "recovery" value following dexmedetomidine 1,3 , and $10 \mu \mathrm{g} / \mathrm{kg}$, and these "peak" values were significantly different from baseline. Fifteen minutes after each of these doses, SVR had decreased to values which were not significantly different from baseline (Figure 7-2). As with $\delta$ MAP, the maximum acute rise in SVR ( $\delta$ SVR) occurred after $1 \mu \mathrm{g} / \mathrm{kg}$ of dexmedetomidine whereafter it remained constant. HR (Figure 7-1) and $\mathrm{CO}$ (Table 7-1) declined dose-dependently reaching significance after 0.1 and $1 \mu \mathrm{g} / \mathrm{kg}$, respectively, and showing no recovery $15 \mathrm{~min}$ later. SV was reduced 
2 min following 3 and $10 \mu \mathrm{g} / \mathrm{kg}$ dexmedetomidine but recovered within 15 min except at the highest dose (Table 7-1).
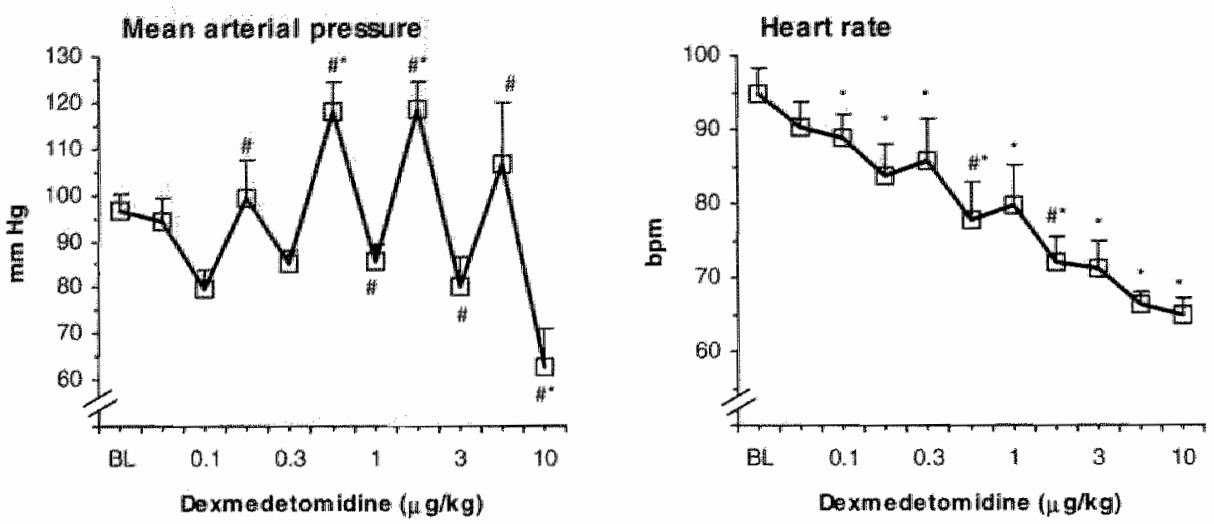

Figure 7-1 Effects of incremental doses of dexmedetomidine injected intravenously over $2 \mathrm{~min}$ in the doses shown on mean arterial blood pressure (left panel) and heart rate (right panel) in anesthetized goats. $\mathrm{BL}=$ Baseline. For each dose of dexmedetomidine the value at peak blood pressure effect (within $2 \mathrm{~min}$ ) and the effect after 15 min are shown. Values are mean $\pm S E M$ - Significanily different $(P<0.05)$ from baseline. H Significantly different $(P<0.05)$ from previous value. (Repeated Measures ANOVA - see Methods).
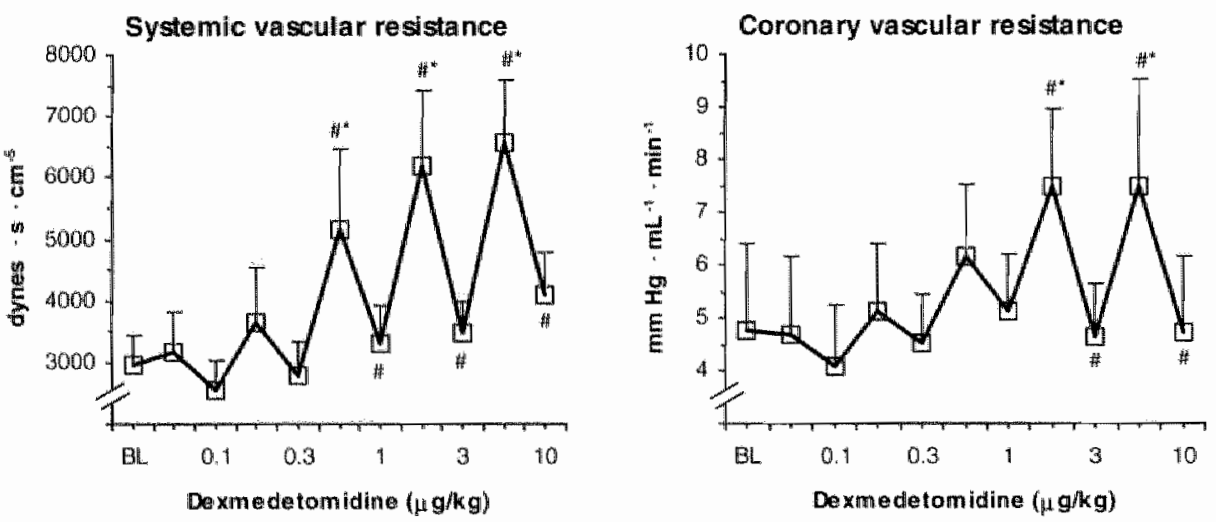

Figure 7-2 Effects of incremental doses of dexmedetomidine injected intravenously over 2 min in the doses shown on systemic vascular resistance (left panel) and coronary vascular resistance (right panel) in anesthetized goats. $\mathrm{BL}=$ Baseline. For each dose of dexmedetomidine the value at peak blood pressure effect (within 2 min) and the effect after 15 min are shown. Values are mean 1 SEM. " Significantly different $(P<0.05)$ from baseline. Significantly different $(P<0.05)$ from previous value. (Repeated Measures ANOVA - see Methods). 
LVEDP increased significantly following 3 and $10 \mu \mathrm{g} / \mathrm{kg}$ dexmedetomidine but recovered within 15 min (Table $7-1$ ). SW was significantly reduced 15 min after 10 $\mu \mathrm{g} / \mathrm{kg}$ dexmedetomidine (Table 7-1). LVdP/dt $t_{\max }$ declined dose-dependently; following 1,3 , and $10 \mu \mathrm{g} / \mathrm{kg}$ dexmedetomidine the $15 \mathrm{~min}$ value was lower than the "peak" effect (Table 7-1). Mixed venous oxygen extraction increased dosedependently (significant after dexmedetomidine 1,3 , and $10 \mu \mathrm{g} / \mathrm{kg}$ ) showing recovery except after dexmedetomidine $10 \mu \mathrm{g} / \mathrm{kg}$ (Table 7-1). In spite of this increase in extraction, oxygen consumption $\left(\mathrm{VO}_{2}\right)$ declined, though this was not significant ( $P=$ 0.058 , Table 7-1).

CVR increased immediately after dexmedetomidine 3 and $10 \mu \mathrm{g} / \mathrm{kg}$ but returned to baseline within $15 \mathrm{~min}$ (Figure 7-2). The acute rise in CVR following each dose of dexmedetomidine ( $\delta \mathrm{CVR}$ ) increased until $3 \mu \mathrm{g} / \mathrm{kg}$ and then remained constant. Coronary flow showed a gradual decrease, which did not reach the level of significance (Figure 7-3). Regional coronary venous oxygen extraction increased immediately following dexmedetomidine only after the $3 \mu \mathrm{g} / \mathrm{kg}$ dose but fell to below baseline $15 \mathrm{~min}$ after the $10 \mu \mathrm{g} / \mathrm{kg}$ dose (Figure 7-3). Fifteen minutes following dexmedetomidine 1 and $10 \mu \mathrm{g} / \mathrm{kg}$, regional myocardial oxygen consumption was significantly reduced.
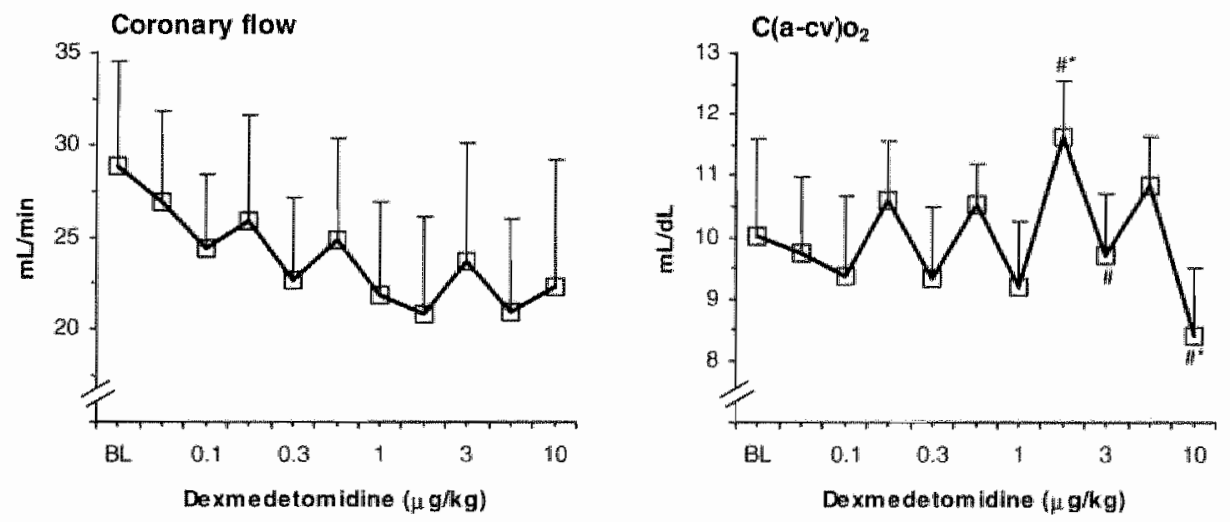

Figure 7-3. Effects of incremental doses of dexmedetomidine injected intravenously over 2 min in the doses shown on coronary blood flow (left panel) and arterio-regional coronary venous oxygen content difference (right panel) in anesthetized goats. BL = Baseline. For each dose of clexmedetomidine the value at peak blood pressure effect (within 2 min) and the effect after $15 \mathrm{~min}$ are shown. Values are mean \pm SEM. "Significantly different $(P<0.05)$ from baseline. \#ignificantly different $(P<0.05)$ from previous value. (Repeated Measures ANOVA - see Methods). 


\section{Discussion}

The main conclusions of this study are:

1. In goats, IN administration of dexmedetomidine causes a rapid short-lived increase in blood pressure and SVR, followed within 15 min by a decrease in blood pressure and accompanied by progressively decreasing $\mathrm{HR}$ and $\mathrm{CO}$, similar to the hemodynamic effects seen in man.

2. Systemic and coronary vasoconstriction are short-lived, even at the relatively high dose of $10 \mu \mathrm{g} / \mathrm{kg}$.

3. The balance between myocardial oxygen supply and demand may be better maintained in goats than in dogs.

\section{Hemodynamic effects}

In studies of the hemodynamic effects of dexmedetomidine in man, the subjects have all received dexmedetomidine while still awake. In conscious human volunteers, following a $2 \mu \mathrm{g} / \mathrm{kg}$ IV dose of dexmedetomidine, MAP increased initially (max at 3 min) and then decreased, remaining significantly lower $( \pm 17 \%)$ during the 330 min of the experiment; $C O$ and HR were also decreased [4]. In anesthetized dogs, however, a long-lasting increase in SVR is observed resulting in sustained hypertension in spite of reductions in $\mathrm{HR}$ and $\mathrm{CO}[6-8]$.

A difference between anesthetics in the modulation of dexmedetomidine-responses has been suggested [11], and we have previously shown that the hemodynamic response to dexmedetomidine is influenced by anesthetic technique in a dog model [8]. Specifically, halothane has been shown to reduce the pressor effect following dexmedetomidine in dogs [12] while fentanyl augments the bradycardic but not the pressor effects of dexmedetomidine [13]. Although the anesthetic may influence an animal's response to dexmedetomidine, in this goat study we used halothane, the same as was used in our previous dog investigation $[81$. The present study shows that the hemodynamic response of goats to IV administration of dexmedetomidine is more similar to that seen in conscious man.

In the present study, peak values of SVR at the various doses were similar to those of dogs under enflurane [7| or halothane anesthesia [8]. This suggests that the different response in goats is not due to a different number of (active) vascular $\alpha_{2}$-adrenergic receptors. Moreover, the decrease in $\mathrm{HR}$ and $\mathrm{CO}$ was similar in these studies, indicating that the stimulation of the central $\alpha_{2}$-adrenergic receptors was similar and that there was no major difference in clearance of the drug. The more rapid disappearance of the pressor effect in goats could then be caused by a more rapid distribution of dexmedetomidine in the body of the goats which might affect the peripheral more than the central actions. 
In studies by Jalonen et al. in anesthetized young domestic pigs, MAP increased by $45 \%$ within $2 \mathrm{~min}$ of a rapid (5 s) IV injection of dexmedetomidine $10 \mu \mathrm{g} / \mathrm{kg}$ but returned to baseline within 15 min. There was no decrease in $\mathrm{CO}$ and only a transient slight (11\%) decrease in HR [14]. Therefore, the pig seems to behave completely differently from other species with respect to its hemodynamic response to $\alpha_{2}$ agonists.

It should be mentioned that beside species differences and anesthetic technique other factors may influence the hemodynamic response to $\alpha_{2}$-agonists. A slower rate of infusion [15], oral administration [16,17], or intramuscular administration [18] reduces or avoids the pressor effect.

The small number of animals studied (6) may be the reason that some effects did not reach significance, for example, $\mathrm{CF}$ and $\mathrm{VO}_{2}$. However, most parameters changed quite reproducably from animal to animal. We did not include a control group because in previous dog studies, using similar preparation and anesthesia, the preparation was stable for several hours [19]. Since the protocol started some hours after the onset of anesthesia and ventilation, a steady state situation had been reached so that we primarily measured the effects of the drug. Throughout the surgical preparation and study protocol we paid special attention to maintaining constant temperature, respiratory and metabolic status as well as correcting blood and fluid losses.

The highest dose of dexmedetomidine was followed by effects not seen at lower doses: MAP decreased to about $60 \mathrm{~mm} \mathrm{Hg}$, myocardial oxygen extraction was $15 \%$ below baseline (Figure 7-3), $\mathrm{CO}$ was $50 \%$ and $\mathrm{SV} 33 \%$ below baseline, while $\mathrm{MVO}_{2}$ was $30 \%$ reduced (Table $7-1$ ). This indicates a marked inhibition of sympathetic outflow, which is probably favorable in view of the reduced vascular resistance, myocardial contractility, and oxygen extraction. The transiently increased LVEDP following 3 and $10 \mu \mathrm{g} / \mathrm{kg}$ dexmedetomidine does suggest some impairment of cardiac function probably due to the acute increase in afterload, but this is short-lived. This is in contrast to the effects seen in dogs where both MAP and SVR remain significantly ellevated above baseline, thereby increasing the work of the heart.

\section{Coronary vascular effects}

In the only study on the human coronary circulation, intracoronary infusion of azepexole decreased coronary artery diameter and blood fow velocity by $28 \% 191$.

Swine have been shown to exhibit hardly any $\alpha_{2}$ or $\alpha_{1}$-adrenoceptor-mediated coronary vasoconstriction [10]. Accordingly, Bloor and Fonarow did not observe any significant increase in coronary vascular resistance after intracoronary infusion of dexmedetomidine at a rate of up to $40 \mu \mathrm{g} / \mathrm{min}$ in anesthetized minipigs [20]. Also, Jalonen et al. found only a moderate $(15 \%)$ increase in regional coronary resistance in anesthetized young pigs after rapid IV injection of $30 \mu \mathrm{g} / \mathrm{kg}$ dex medetomidine 1141 . 
In contrast, sustained $\alpha_{2}$-adrenergic coronary vascular vasoconstriction has been shown in dogs $[2], 22]$. Our previous dog study demonstrated a transient increase in coronary vascular resistance by up to $45 \%$. A sustained increase in CVR as well as myocardial oxygen consumption occurred only at a dose of $10 \mu \mathrm{g} / \mathrm{kg}$ and this effect was independent of the anesthesia used. [8]. Moreover, no change in lactate extraction

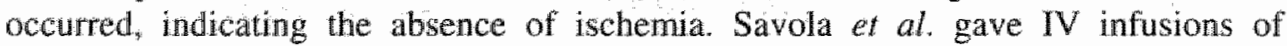
dexmedetomidine to enflurane-anesthetized dogs and found marked increases in systemic arterial pressure but no effect on coronary blood flow, as measured by positron emission tomography [23]. Also, in conscious, chronically-instrumented dogs $5 \mu \mathrm{g} / \mathrm{kg}$ dexmedetomidine IV over 10 min did not change coronary flow velocity, but: increased coronary resistance [24].

In the present study in goats, CVR increased by up to $57 \%$. In contrast to dogs [8], CVR and myocardial oxygen extraction rapidly returned to baseline and, after dexmedetomidine $10 \mu \mathrm{g} / \mathrm{kg}$, even decreased. This indicates that regulation of myocardial blood flow occurs through metabolic regulation rather than adrenergic stimulation [25]. The reduction in myocardial oxygen demand is most likely related to the central autonomic effects of dexmedetomidine, causing decreases in HR, contractility and MAP.

In conclusion, the present study shows that the systemic vascular effect of dexmedetomidine in man resembles that of goats better than dogs and that the balance between myocardial oxygen supply and demand may be better maintained in goats than in dogs. It is interesting that in dogs beneficial effects of clonidine, dexmedetomidine, and mivazero on ischemic myocardium have been observed $[19,26,27]$. This indicates that further investigation of the anti-ischemic effects of $\alpha_{2}$-adrenergic agonists in goats as well as in man is worthwhile.

\section{Acknowledgments}

The authors thank Orion Corporation Farmos, Turku, Finland for their support and providing dexmedetomidine. The technical assistance of Mr. R. Kruger, Mr. T. vd Nagel, and Mr. J. Habets is gratefully acknowledged.

\section{References}

1 Maze $M$, Tranquilli W. $\alpha_{2}$-adrenoceptor agonists: defining the role in clinical anesthesia. Antesthesiology 1991; 74: 581-605.

2 Aantat R, Kanto J. Scheinin M, Kallio A, Scheinin $H$. Dexmedetomidine, an $\alpha_{2}$-adrenoceptor agonist, reduces anesthetic requirements for patients undergoing minor gynecologic surgery. Anesthesology 1990; $73: 230-5$

3 Aho M. Erkola O. Katlio A, Scheinin H, Korttila K. Dexmedetomidine infusion for maintenance of anesthesia in patients undergoing abdominal hysterectony. Anesth Analg 1992; 75: 940-6.

4 Bloon BC. Ward DS, Belleville JP, Maze M. Effects of intravenous dexmedetomidine in humans. II. Hemodynamic changes. Aneshesiology 1992; 77: 1134-42. 
5 Bloor BC, Schmeling WT. Cardiovascular effects of $\alpha_{2}$-adrenoceptors. Anesh Pham Rev 1993: 1: $246-62$.

6 Bloor BC, Frankland M, Aper G, Raybould D, Weitz J, Shurtliff M. Hemodynamic and sedative effects of dexmedetomidine in dog. J Pharmacol Exp Ther 1992; $263: 690-7$.

7 Flacke WE, Flacke JW, Bloor BC, Mclntee DF, Sagan M. Effects of dexmedetomidine on systemic and coronary hemodynamics in the anesthetized dog. J Cardiothorac Vaso Anest 1993; 7: $41-9$.

8 Lawrence $\mathrm{CJ}$, Prinzen FW, de Lange S. The effect of dexmedetomidine on the balance of myocardial energy requirement and oxygen supply and demand. Anesth Anolg 1996; 82:544-50.

9 Indolfi C, Piscioni F, Villari B, Russolillo E, Rendina V, Golino P, et al. Role of a $x_{2}$ adrenoceptors in normal and atherosclerotic humaru coronary circulation. Circulation 1992; 86: $1116-24$.

10 Schulz. R, Oudiz RJ, Guth BD, Heusch G. Minimal AAI- and AA2-adrenoceptor-mediated coronary vasoconstriction in the anaesthetized swine. Naunyn-Schmiedebergs Anch Pharmacol 1990; 342: 422-8.

11 Scheller MS, Zonow MH. Are the hemodynamic effects of dexmedetomidine influenced by the background anesthetic? (letter; comment). Anesri Analg 1991; 72: 408-9.

12 Kenny D, Pelc LR, Brooks HL, Kampine JP, Schmeling WT, Warltier DC. Calcium channel

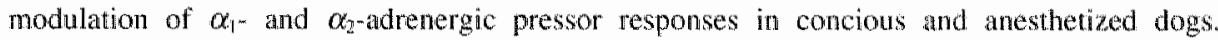
Anesthesiology 1990; 72: 874-81.

13 Salmenperä MT, Szlam F, Hug CJ. Anesthetic and hemodynamic intermetions of dexmedetomidine and fentanyl in dogs. Aresthesiology 1994; 80: 837-46.

14 Jalonen J, Halkola L, Kuttila K, Pertila J, Rajalin A, Savunen T, ef al. Effects of dexmedetomidine on coronary hemodynamics and myocardial oxygen balance. I Cardiorhorac: Vasc Anesth 1995; 9: 519-24.

15 Talke P, Li J, Jain U, Leung J, Drasner K. Hollenberg M, et al. Effects of perioperative dexmedetomidine infusion in patients undergoing vascular surgery. The Study of Perioperative Ischemia Research Group. Anesthesiology 1995;82:620-33.

16 Proctor LT, Schmeling WT, Roerig D, Kampine JP. Warltier DC. Oral dexmedetomidine attenuates hemodynamic responses during emergence from general anesthesia in chronically instrumented dogs. Anesthesiology 1991; 74: 108-14.

17 Proctor LT, Schmeling WT, Warltier DC. Premedication with oral dexmederomidine alters hemodynamic actions of intravenous anesthetic agents in chronically instrumented clogs. Anesthestology 1992:77: 554-62.

18 Dyck JB, Maze M, Hack C, Vuorilehto L, Shater SL. The pharmacokinetics and hemodynamic effects of intravenous and intramuscular dexmedetomidine bydrochloride in sidult thuman volunteers. Anesthesiology $1993 ; 78: 813-20$.

19 Roekaerts PM, Prinzen FW, Willigers HM, De Lange S. The effects of a-adrenergic stimulation with mivazerol on myocardial blood flow and function during coronary artery stenosis in anesthetized dogs. Anesth Analg 1996; 82: 702-111.

20 Bloor B, Fonarow G. Intracoronary dexmedetomidine does not produce coronary vasoconstriction at therapeutic blood levels in chronically instrumented anaesthetized swine. $f$ Cardiohorac Vasc: Anesth 1994; 8 (5, Suppl 3): 4.

21 Holtz. J, Saeed M, Sommer O. Norepinephrine constricts the canine coronary bed via postsynaptic $\alpha_{2}$-adrenoceprors. Eur J Pharmacol 1982; 82: 199-202.

22 Deussen A, Heusch G, Thämer $V$. $\alpha_{2}$-adrenoceptor-mediated cononary vatsoconstriction persists after exhaustion of coronary vasodilator reserve. Eur J Pharmacol $1985 ; 115: 147-53$

23 Savola J, Brennan K. Maze M, Stalnaker C, Budinger T. No decrease in myocardial blood flow during infusion of dexmedetomidine as assessed using positron emission tomography in anaesthetized dogs. Eur I Pharmacol 1990; 183: 360-1. 
24 Schmeling WT, Kampine JP, Roerig DL, Warltier DC. The effects of the stereoisomers af the $\alpha_{2}$. adrenergic agonist medetomidine on systemic and coronary hemodynamics in conscious dogs. Anesthesiology $1991 ; 75: 499-511$.

25 Mohrman DE, Feigl EO. Competition between sympathetic vasoconstriction and metabolic vasodilation in the canine coronary circulation. Circ Res 1978, 42: 79-86.

26. Heusch $G$, Schipke I, Thamer $V$. Clonidine prevents the sympathetic initiation and aggravation of poststenotic myocardial ischemia. $J$ Cardiovasc Pharmacol 1985; 7: 1176-82.

27 Roekaerts PMHJ, Prinzen FW, de Lange S. Coronary vascular effects of dexmedetomidine during reactive hyperemia in the anesthetized dog. J Cardiothorac Vasc Anesth 1996; 10: 619-26. 


\title{
CHAPTER 8
}

\section{Effects of a single pre-operative dexmedetomidine dose on isoflurane requirements and peri-operative hemodynamic stabilityt}

\author{
C. J. Lawrence and S. de Lange
}

\begin{abstract}
In a double-blind, placebo-controlled study we investigated the effect of a single preinduction intravenous dose of dexmedetomidine $2 \mu \mathrm{g} / \mathrm{kg}$ on anesthetic requirements and peri-operative hemodynamic stability in 50 patients undergoing minor orthopedic and general surgery. Patients were anesthetised with nitrous oxide/oxygen/fentanyl, supplemented if necessary with isoflurane. The mean ( \pm SD) intra-operative isoflurane concentration was lower in dexmedetomidine-treated patients than controls $(0.01 \pm 0.03 \%$ compared to $0.1 \pm 0.1 \% ; P=0.001$ ) although six of the 25 treated patients required isoflurane at some stage. The hemodynamic response to tracheal intubation and extubation was reduced in the dexmedetomidine group as was intra-operative heart rate variability; postoperative analgesic and anti-emetic requirements and peri-operative serum catecholamine concentrations were lower in the dexmedetomidine group. Hypotension and bradycardia occurred more frequently after dexmedetomidine.
\end{abstract}

\section{Introduction}

$\alpha_{2}$-Adrenergic agonists are of interest to anesthetists because of their ability to produce sedation, anxiolysis and analgesia. They have also been reported to reduce anesthetic requirements and afford hemodynamic and sympathetic stability during the intraoperative period $[1,2]$. Clonidine has been shown to increase hemodynamic stability $[3,4]$ and reduce anesthetic requirements in a variety of clinical situations $[5,6]$.

Dexmedetomidine, an imidazole derivative, is a full adrenoceptor agonist with high selectivity for $\alpha_{2}$-compared with $\alpha_{1}$-adrenergic receptors (selectivity ratio 1620:1 compared with 220:1 for clonidine) [7]. It causes a dose-dependent decrease in arterial

${ }^{7}$ Published in Anaeshesia 1997; 52: 736 -44. Reproduced with permission of the publisher. 
blood pressure and heart rate associated with a decrease in serum noradrenaline concentrations [8]. Dexmedetomidine, in a single pre-anesthetic intravenous dose of up to $0.6 \mu \mathrm{g} / \mathrm{kg}$, has been shown to reduce the requirements for supplementary isoflurane administration during nitrous oxide/oxygen/fentanyl anesthesia and to lessen the hemodynamic reaction to stressful intra-operative events, while causing few side-effects [9]. The purpose of this study was to investigate whether the higher intravenous dose of dexmedetomidine, $2 \mu \mathrm{g} / \mathrm{kg}$, would eliminate the need for isoflurane supplementation of nitrous oxide/oxygen/fentanyl anesthesia and provide hemodynamic stability during tracheal intubation, emergence and the early postoperative period. Previous studies in healthy volunteers have indicated that this dose is well tolerated $[10-12]$.

\section{Methods}

The study was double-blind, randomized and placebo controlled with two groups, dexmedetomidine and placebo. Power analysis before the study indicated that 25 patients in each of the two groups would give an $80 \%$ chance of detecting a $30 \%$ difference in anesthetic-sparing effect. The study was approved by the Medical Ethical Committee of the hospital and written informed consent was obtained from all patients. Patients with childbearing potential, a known allergy or who weighed more than $100 \mathrm{~kg}$ were not studied.

We investigated 50 patients, ASA 1 or 2, aged between 18 and 65 years, who were scheduled for elective minor surgery (general, urological or orthopaedic). All patients were interviewed the evening before and the morning after surgery.

\section{Study procedure and measurements}

Systolic blood pressure, diastolic blood pressure and heart rate were measured noninvasively using an automated sphygmomanometer (Datex Cardiocap) and ECG monitor. Peripheral oxygen saturation was measured by pulse oximetry.

On the evening before surgery the arterial blood pressure was measured by the Korotkoff method. The measurements were taken on the same arm throughout the study at the following times: the evening before surgery; on arrival in the anesthetic room; 5 min before and at $1-$ min intervals during trial medication administration; 1 and 5 min after completion of trial medication administration; just before induction of anesthesia; immediately after induction; 1 min after tracheal intubation; every $3 \mathrm{~min}$ during the operative period; every $5 \mathrm{~min}$ in the postanesthesia care unit for the first 60 min; thereafter, every 15 min until discharge from the unit.

Blood samples for catecholamine measurements were obtained at the following times: $5 \mathrm{~min}$ before trial medication; $1 \mathrm{~min}$ before anesthetic induction; 1 min after first skin incision; 30 min into surgery; immediatelly after arrival in the recovery room; $3 \mathrm{~h}$ after arrival in the recovery room. Blood for catecholamine assay was collected into chilled 
polypropylene tubes containing potassium-ethylene diamine tetra-acetate; these tubes were stored in ice until centrifuged within $2 \mathrm{~h}$ at $0-4^{\circ} \mathrm{C}$. The plasma samples were stored at $-80^{\circ} \mathrm{C}$ until assayed. Samples were transported in carbon dioxide tce to the Department of Pharmacology, University of Turku, Finland, for assay. Concentrations of endogenous catecholamines in venous plasma were determined using highperformance liquid chromatography with coulometric electrochemical detection as described by Scheinin et al. [13]. The assay has been shown to be linear at least over a concentration range of $0.25-50 \mathrm{nM}$ for noradrenaline and $0.25-5 \mathrm{nM}$ for adrenaline. The reproducibility of the assay was tested using pooled plasma samples from previous clinical studies, and the resulting intra-assay coefficients of variation were $1.55 \%$ for noradrenaline and approximately $3 \%$ for adrenaline in the relevant concentration ranges.

\section{Anesthesia}

Patients were premedicated with atropine $0.5 \mathrm{mg}$ intramuscularly $30 \mathrm{~min}$ before scheduled arrival on the anesthetic room. Monitoring was initiated with ECG (lead II), automated noninvasive blood pressure measurement and pulse oximetry (Datex Cardiocap ${ }^{(B)}$ ) and these were recorded continuously (Datex Cardiocap ${ }^{(*)}$ Recorder). A venous cannula was inserted in the forearm and a glucose/salt solution ( $3.3 \%$ glucose and $0.3 \%$ sodium chloride) was commenced at a rate of $6-8 \mathrm{~mL} \cdot \mathrm{kg}^{-1} \cdot \mathrm{h}^{-1}$. The patient was allowed to rest for 5-10 min after which the first blood samples were obtained. Balanced randomization was carnied out using block design (block size 10 patients, five in each group) and random permutations. Patients were allocated randomly to receive, in a double-blind manner, either dexmedetomidine $(n=25)$ or saline $(n=25)$. The required amount $(2 \mu \mathrm{g} / \mathrm{kg}$ ) was transferred to a $20-\mathrm{mL}$ syringe, diluted to $20 \mathrm{~mL}$ with physiological saline and given over 5 min through the intravenous cannula. The patients were observed for $15 \mathrm{~min}$, during which period depth of sedation (Ramsey scale [14]) was assessed every 5 min. Following this, induction of anesthesia was initiated.

Fentanyl, $2 \mu \mathrm{g} / \mathrm{kg}$ was given intravenously and the patient was pre-oxygenated for 3 $\min$. Thiopental $3 \mathrm{mg} / \mathrm{kg}$ was given intravenously, supplemented, if necessary, with I $\mathrm{mg} / \mathrm{kg}$ aliquots to produce loss of eyelid reflex. After calibration of a Datex Relaxograph ${ }^{\text {(2) }}$, vecuronium $0.1 \mathrm{mg} / \mathrm{kg}$ was given intravenously to provide neuromuscular block. The trachea was intubated and the lungs ventilated with nitrous oxide $67 \%$ in oxygen (end-tidal carbon dioxide tension between 3.5 and $4.5 \mathrm{kPa}$; Datex, Capnomac ${ }^{(Q)}$. Isoflurane was added, if necessary, and adjusted in steps of $0.25 \%$ every 3 min when systolic blood pressure exceeded pre-anesthetic values by $20 \%$ or more. When systolic blood pressure decreased below this value, isoflurane was reduced in $0.25 \%$ steps every $3 \mathrm{~min}$. End-tidal concentrations of isoflurane were measured continuously using a Datex, Capnomac ${ }^{\text {(i) }}$ monitor. If the heart rate exceeded $100 \mathrm{bpm}$ the patient was given fentanyl in increments of $1 \mu \mathrm{g} / \mathrm{kg}$ intravenously. In addition to the hemodynamic signs of anesthetic depth, we looked for other clinical 
signs of 'lightness' such as sweating, lacrimation, swallowing and movement. If necessary, anesthesia was deepened with isoflurane in $0.25 \%$ steps untill judged adequate. Neuromuscular block was maintained with vecuronium $0.025 \mathrm{mg} / \mathrm{kg}$ when the T1 (Relaxograph) exceeded 10\%. Isoflurane was discontinued, if possible, $10 \mathrm{~min}$ before the end of surgery. Residual neuromuscular block was antagonised with neostigmine $2.5 \mathrm{mg}$ intravenously preceded by atropine $1 \mathrm{mg}$.

The interval from discontinuation of inhalation of nitrous oxide at the end of surgery to the time when the patient spontaneously opened his/her eyes (the emergence period) was recorded together with the time to perform simple commands (grip hand) and the time to fitness for discharge from the postanesthesia care unit. All patients were monitored in this unit for at least $3 \mathrm{~h}$ after surgery. Piritramide $20 \mathrm{mg}$ intramuscularly was given if the patient complained of moderate or severe pain and alizapride $100 \mathrm{mg}$ intravenously was used to treat emetic complications.

The anesthetist assessed the quality of induction and recovery using a visual analogue scale (marking on an ungraded $100-\mathrm{mm}$-long horizontal line with $0=$ extremely poor and $100=$ excellent at opposite ends $)$. The following morning all patients evaluated their experience of the period from administration of trial drug until discharge from the unit using at similar scale.

Hypotension (systolic blood pressure $<90 \mathrm{~mm} \mathrm{Hg}$ ) was treated with a rapid infusion of $250 \mathrm{~mL}$ of glucose-salt solution, followed by ephedrine $2.5 \mathrm{mg}$ in repeated doses if systolic blood pressure did not increase above $90 \mathrm{~mm} \mathrm{Hg}$ within 2 min. Bradycardia (heart rate $<45 \mathrm{bpm}$ ) was treated with atropine in $0.5 \mathrm{mg}$ intravenously.

\section{Blinding}

Because of the sedative and hemodynamic effects seen in the dexmedetomidine group special attention was given to the blinding procedure. An anesthetist not present during administration of trial drug and induction of anesthesia independently assessed the hemodynamic and clinical signs of anesthetic depth in the operating room. In addition. a print-out of all monitored variables was obtained and checked against the clinical record form by an independent observer.

\section{Statistical analysis}

The mean expiratory concentration of isoflurane was calculated as the sum of the products of expiratory concentrations and times (area under the curve - AUC) divided by total anesthesia time. Patient characteristics, operation and recovery times, anesthetic requirements and patient and anesthetist's evaluations were analysed using Student's $t$-test; hemodynamic and plasma catecholamine data were analysed using unbalanced two-way analysis of variance for repeated measurements (RM ANOVA). Hemodynamic variability was evaluated by assessing the AUC of systolic blood pressure and heart rate deviations from time-averaged mean. Mann-Whitney testing 
Was used to analyse the differences between the treatment groups for pirtramide and alizapride requirements. Results are presented as mean \pm SD unless otherwise stated and $P<0.05$ was considered statistically significant.

\section{Results}

All patients were included in the statistical analysis. The physical characteristics and operation times of the two groups of patients were similar (Table 8- 1 ) with 49 men and one women studied. Patients underwent a variety of surgical procedures (Table 8-2), mainly superficial surgical and minor orthopedic; the distribution of operative procedures was similar in the two groups.

Table 8-1 Pallent detaills and operation times

\begin{tabular}{lcc}
\hline & $\begin{array}{l}\text { Dexmedetomidine } \\
(n=25)\end{array}$ & $\begin{array}{l}\text { Placebo } \\
(n=25)\end{array}$ \\
\hline Weight $(\mathrm{kg})$ & $76.8 \pm 9.3$ & $74.48 \pm 10.4$ \\
Height $(\mathrm{cm})$ & $77.2 \pm 7.1$ & $178.2 \pm 7.0$ \\
Age (years) & $42.4 \pm 12.7$ & $38.9 \pm 14.2$ \\
Induction to last suture (min) & $68.6 \pm 23.4$ & $75.0 \pm 26$ \\
Incision to last suture (min) & $44.0 \pm 21.6$ & $48.5 \pm 24.3$ \\
\hline
\end{tabular}

Vallues are expressed as mean \pm SD.

Table 8-2 Number of patients undergoing the operative procedures shown

\begin{tabular}{lcc}
\hline & $\begin{array}{l}\text { Dexmedetomidine } \\
(n=25)\end{array}$ & $\begin{array}{l}\text { Placebo } \\
(n=25)\end{array}$ \\
\hline Superficial surgical & 14 & 14 \\
Minor orthopasdic & 2 & 5 \\
Joint surgery & 9 & 6
\end{tabular}

Superfictal surgical procedures included inguinal and incisional hernia repair. operations for vaticose veins, hydrocoele, pilonidal sinus. Minor orthopaedic procedures incladed removil of exostoses, plates and/or screws. osteotomy of a digit, arthrodesis of the foot. Joint surgery included non-feptacement surgeny of the shoudder or kniee.

\section{Anesthetic requirements}

Six out of the 25 patients receiving dexmedetomidine required isoflurane compared with 18 of the 25 patients in the placebo group. The mean intra-operative isoflurane concentration in the dexmedetomidine group was significantly less than in the placebo group (Table 8-3). 
More thiopental was required for induction and more fentanyl during operation in the placebo group (Table 8-3). The doses of muscle relaxant required during operation was simillar in the two groups (Table 8-3).

Table 8-3. Mean 4 so doses of the drugs showm

\begin{tabular}{|c|c|c|c|}
\hline & $\begin{array}{l}\text { Dexmedeltomidine } \\
(n=25)\end{array}$ & $\begin{array}{l}\text { Placebo } \\
(n=25)\end{array}$ & $P$ \\
\hline \multicolumn{4}{|l|}{ Mean intra operative isoflurane } \\
\hline concentration $(\%)$ & $0.01 \pm 0.03$ & $0.1 \pm 0.1$ & $P<0.001$ \\
\hline Thiopental for induction (mg) & $230.6 \pm 28$ & $268.0 \pm 48.4$ & $P=0,002$ \\
\hline Fentanyl during operation (ug) & $156.6 \pm 237$ & $233.4 \pm 72.5$ & $P<0.001$ \\
\hline Vecuronium (mg) & $10.9 \pm 28$ & $14.9 \pm 3.6$ & $P=0.3$ \\
\hline Piritramice dose (mg) & $5.60 \pm 10.83$ & $13.60 \pm 12.54$ & $P=0.01$ \\
\hline Alzapride dose (ning) & $0.00 \pm 0.00$ & $32.00 \pm 61.03$ & $P=0.005$ \\
\hline
\end{tabular}

The nean expiratory concentation of isoflurane was calculated as the sum of the products of expiratory concentrations and times (area under the ctrve - AUC) divided by total anesthesia time.

\section{Cardiovascular effects}

Initial systolic blood pressure was similar in the two groups. Administration of the study drug had no significant effect on systolic or diastolic blood pressure (Figure 81). There was a statistically significant difference in initial heart rate $(P=0.003)$ between the two groups. During drug administration this difference increased (drug*time effect; $P<0.001$ ).

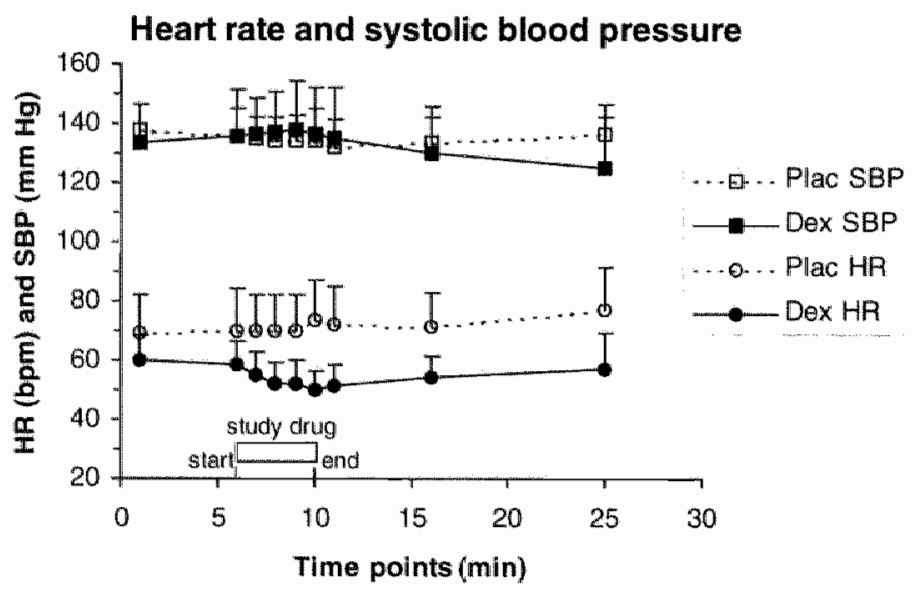

Figure 8-1 Heart rate (HR) and systolic blood pressure (SBP) from $5 \mathrm{~min}$ before starting administering the trial drug until $15 \mathrm{~min}$ after completion of administration. Dex = dexmedetomidine; Plac = placebo. Values are mean \pm SO. There was a significant difference in HR between the two groups during this period $(P<0.001)$. 
Laryngoscopy and tracheal intubation resulted in 0 and 31 mm $\mathrm{Hg}$ mean increases in systolic blood pressure in the dexmedetomidine and placebo groups, respectively. Increases for diastolic blood pressure were 1 and $26 \mathrm{~mm} \mathrm{Hg}$ and for heart rate 13 and $29 \mathrm{bpm}$ in the dexmedetomidine and placebo groups, respectively. These differences were significant. The two groups were compared during the first 51 min after tracheal intubation (intra-operative period). The systolic blood pressure, diastolic blood pressure and heart rate were significantly lower in the dexmedetomidine group during this period ( $P<0.001$; drug elfect, two-way ANOVA), as were maximum and minimum values for systolic blood pressure and heart rate (Table $8-4$ ).

Table 8-4 Mean \pm SD and range minimum and maximum systolic blood pressure (SBP) and heart rate (HR) during and after anaesthesia as indicated

\begin{tabular}{|c|c|c|c|}
\hline & $\begin{array}{l}\text { Dexmedetomidine } \\
(n=25)\end{array}$ & $\begin{array}{l}\text { Placebo } \\
(n=25)\end{array}$ & $P$ \\
\hline \multicolumn{4}{|c|}{ (a) From just after induction of anesthesia until end of operation } \\
\hline Minimal SBP $(\mathrm{mm} \mathrm{Hg})$ & $\begin{array}{c}97.0 \pm 12.1 \\
79-120\end{array}$ & $\begin{array}{r}110.2 \pm 12.7 \\
85-133\end{array}$ & $P<0.001$ \\
\hline Maximal SBP $(\mathrm{mm} \mathrm{Hg})$ & $\begin{array}{c}138.6 \pm 13.9 \\
110-168\end{array}$ & $\begin{array}{c}166.6 \pm 18.0 \\
140-201\end{array}$ & $P<0.001$ \\
\hline Minimal HR (bpm) & $\begin{array}{c}48.2 \pm 4.5 \\
39-58\end{array}$ & $\begin{array}{c}52.0 \pm 6.6 \\
41-66\end{array}$ & $P=0.02$ \\
\hline Maximal HR (bpm) & $\begin{array}{c}78.8 \pm 13.2 \\
55-105\end{array}$ & $\begin{array}{r}114.2 \pm 15.1 \\
83-150\end{array}$ & $P<0.001$ \\
\hline \multicolumn{4}{|l|}{ (b) Postoperative } \\
\hline Minimal SBP $(\mathrm{mm} \mathrm{Hg})$ & $\begin{array}{c}97.3 \pm 10.2 \\
71-11.4\end{array}$ & $\begin{array}{c}122.6 \pm 14.9 \\
84-157\end{array}$ & $P<0.001$ \\
\hline Maximal SBP (mm Hg) & $\begin{array}{c}123.7 \pm 12.3 \\
106-156\end{array}$ & $\begin{array}{c}150.4 \pm 15.1 \\
117-189\end{array}$ & $P<0.001$ \\
\hline Minimal HR (bpm) & $\begin{array}{c}43.3 \pm 3.5 \\
33-50\end{array}$ & $\begin{array}{c}55.9 \pm 10.1 \\
45-82\end{array}$ & $P<0.001$ \\
\hline Maximal HR (bprn) & $\begin{array}{c}59.2 \pm 7.7 \\
48-74\end{array}$ & $\begin{array}{c}83.0 \pm 20.2 \\
55-137\end{array}$ & $P<0.001$ \\
\hline
\end{tabular}

There was a significant difference in heart rate variability between the two groups during the intra-operative period but not in systolic blood pressure variability (Table 8 $5)$.

One minute post-extubation the mean ( \pm SD) systolic blood pressure ( $\mathrm{mm} \mathrm{Hg}$ ) was significantly lower in the dexmedetomidine group compared to the placebo group (128 \pm 19.0 compared to $153 \pm 18.8 ; P<0.001)$. There was a similar change in heart rate (bpm) $(70 \pm 17.8$ compared to $87 \pm 23.9 ; P<0.001)$. 


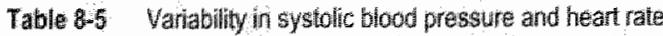

\begin{tabular}{llll}
\hline Variable & $\begin{array}{l}\text { Dexmedetomidine } \\
(n=25)\end{array}$ & $\begin{array}{l}\text { Placebo } \\
(n=25)\end{array}$ & $P$ \\
\hline $\begin{array}{l}\text { Systolic blood pressure (mm Hg) } \\
\text { Hean rate }(\mathrm{bpm})\end{array}$ & $\begin{array}{l}4.8 \pm 1.6 \\
3.8 \pm 1.4\end{array}$ & $\begin{array}{l}6.0 \pm 2.7 \\
0.9 \pm 2.1\end{array}$ & $P=0.06$ \\
\hline
\end{tabular}

These parameters were calculated by measuring the areas under the curves (AUC) of systolic blood pressure and heart rate dewiations from time-averaged means over the intritoperative period. The AUCs were calculated as deviations both above and below the mean. Becuse of the differences in the duration of surgery the AUCs were divided by the dutation of surgery.

Over a 3-h period in the postanesthesia care unit, the mean systolic blood pressure, diastolic blood pressure and heart rate were significantly lower in the dexmedetomidine group ( $P<0.001$; drug effect, two-way ANOva) as were the maximum and minimum systolic blood pressure and heart rate (Table 8-4).

\section{Oxygen saturation}

Oxygen saturation remained above $95 \%$ throughout the monitored period and there was no difference between groups.

\section{Sedative effects}

Approximately 5 min after completion of the administration of trial drug in the dexmedetomidine group the patients were deeply sedated (Ramsey level $4-5$ ). Their
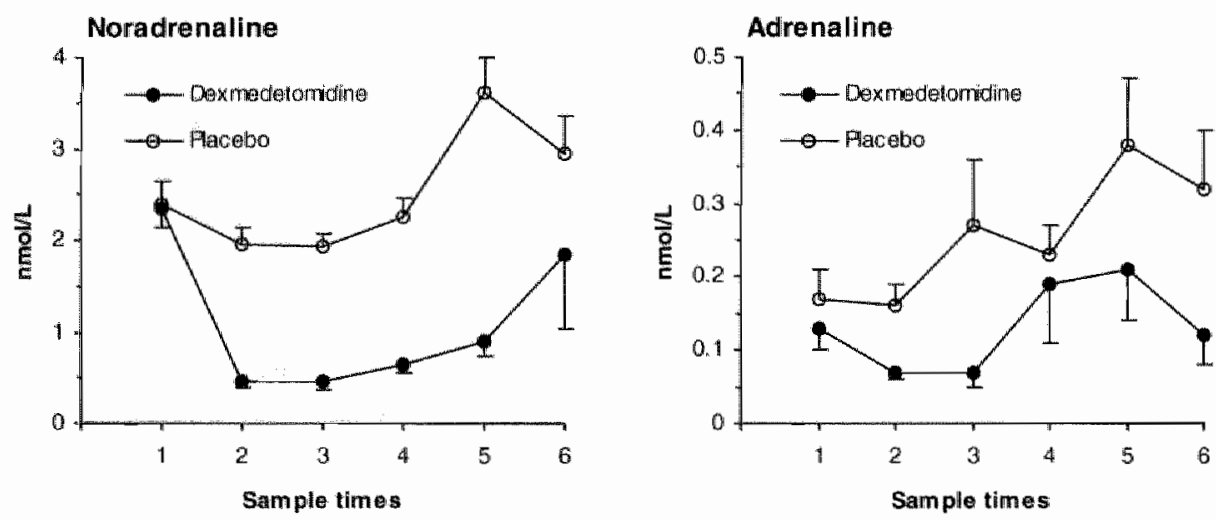

Figure 8-2 Plasma catecholamine concentrations: noradrenaline (left pane) and adrenaline (right panel). Sample times: $1,5 \mathrm{~min}$ before trial drug; $2,1 \mathrm{~min}$ before induction; $3,1 \mathrm{~min}$ after first skin incision; 4, 30 min into surgery; 5, immediately on arrival in postanesthesia care unit (PACU); $6,3 \mathrm{~h}$ after arrival on PACU. Values are mean \pm SEM. There was a significant difference between the two groups (adrenaline, $P=0.01$; notadrenaline, $P<0.001$ ). 
reaction to painful stimuli was reduced, pin-prick producing little or no response. No sedation was seen in the placebo group.

The respiratory rate was unchanged, but three patients $(12 \%)$ in the dexmedetomidine group developed a partial respiratory obstruction which disappeared if they were roused.

\section{Catecholamines}

The plasma noradrenaline concentration was reduced by $75 \%$ following dexmedetomidine (Figure 8-2) and the increase seen in the placebo group after anesthesia and surgery did not occur. The plasma adrenaline concentrations followed a similar pattern.

\section{Postoperative recovery}

Times to spontaneous eye opening and ability to obey simple commands were similar in the two groups (Table 8-6) and both groups of patients were allert and cooperative on the postanesthesia care unit. However, the time to fitness for discharge was significantly longer in the dexmedetomidine group (Table 8-6) largely due to persistent hypotension (systolic blood pressure $<100 \mathrm{~mm} \mathrm{Hg}$ ) or bradycardia (heart rate $<50 \mathrm{bpm})$.

Table 8-6 Mean \pm SD recovery times

\begin{tabular}{lccl}
\hline & $\begin{array}{c}\text { Dexmedetomidine } \\
(n=25)\end{array}$ & $\begin{array}{c}\text { Placabo } \\
(n=25)\end{array}$ & $P$ \\
\hline Times to awakening (min) & $3.5 \pm 2.5$ & $3.2 \pm 2.9$ & $P>0.05$ \\
Obey commands (min) & $5.6 \pm 3.2$ & $5.1 \pm 3.3$ & $P>0.05$ \\
Fitness for discharge (min) & $133.8 \pm 41.3$ & $97.0 \pm 37.3$ & $P=0.0018$ \\
\hline
\end{tabular}

Times 10 awakening = lime from termination of nitrous oxide until spondaneous eye openima: Obey commands $=$

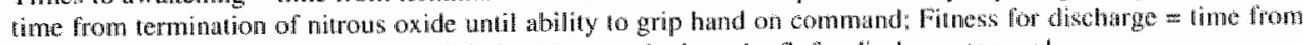
arrival on postanesthesia care unt until judged by anesthetist to be fit for dischange to wark.

Patients in the dexmedetomidine group required less analgesia (piritramide) and antiemetic (alizapride) postoperatively than those who were given the placebo treatment (Table 8-3). The visual analogue scale assessment of quality of induction scored by the anesthetist was better for dexmedetomidine than placebo but that for recovery showed no difference (Table 8-7). The patient evaluation visual analogue scale showed no difference between dexmedetomidine and placebo (Table 8-7). No patient complained of intra-operative recall when interviewed on the morning of the first postoperative day. 


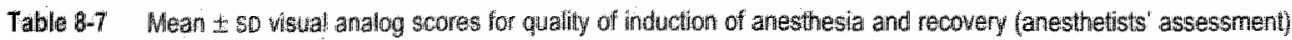
and overall palient assessiment

\begin{tabular}{llll}
\hline & Dexmedetomidine & Placebo & $P$ \\
\hline Anaestheic induction & $86.3 \pm 11.8$ & $60.2 \pm 15.5$ & $P<0.001$ \\
Recovery & $80.6 \pm 14.2$ & $75.4 \pm 15.9$ & N.S. \\
Patient assessment & $B 1.8 \pm 11.8$ & $74.3 \pm 17.8$ & N.S. \\
\hline
\end{tabular}

The scald was 100 mm and marked $0=$ extremely poor and $100=$ excellent at oppositte ends.

\section{Side-effects}

No allergic phenomena were observed. Following administration of trial drug and during anesthesia ephedrine was required to treat hypotension in five patients in the dexmedetomidine group compared with none in the placebo group; atropine was required to treat bradycardia in six patients in the dexmedetomidine group compared with two in the placebo group. When given shortly after administration of dexmedetomidine, atropine $0.5 \mathrm{mg}$ intravenously increased heart rate but also caused systolic and especially diastolic hypertension which lasted for several minutes. This could be prevented by titrating atropine in $0.05-0.1 \mathrm{mg}$ aliquots until the desired effect was obtained.

In the postanesthesia care unit, bradycardia (heart rate $<45$ bpm) occurred in 14 patients in the dexmedetomidine group compared with none in the placebo group. One dexmedetomidine-treated patient developed sudden reductions in heart rate (33 bpm) and systolic blood pressure $(71 \mathrm{~mm} \mathrm{Hg}) 2 \mathrm{~h}$ after arrival in the unit. This was accompanied by symptoms of feeling unwell and dizziness. Atropine $0.5 \mathrm{mg}$ and 250 $\mathrm{mL}$ glucose-salt solution ( $3.3 \%$ glucose and $0.3 \%$ sodium chloride) were given with immediate improvement. Two minutes later heart rate was $66 \mathrm{bpm}$ and blood pressure $119 / 76 \mathrm{~mm} \mathrm{Hg}$. Further recovery was uneventful.

\section{Discussion}

The most likely site of the hypnotic/anesthetic action of dexmedetomidine is a postsynaptic $\alpha_{2}$-adrenoceptor [15] located in the locus coeruleus [16] which involves an inhibitory pertussis-toxin-sensitive $\mathrm{G}$ protein and increased conductance through a potassium channell [17]. In dogs treated with dexmedetomidine, the MAC for halothane was decreased by $>90 \%$ following $10 \mu \mathrm{g} / \mathrm{kg}$ intravenously [18], and in rats treated with dexmedetomidine $100 \mu \mathrm{g} / \mathrm{kg}$ intraperitoneally, halothane could be discontinued for up to $30 \mathrm{~min}$ without eliciting a purposeful response to tail-clamping [19].

Various studies in humans have demonstrated the anesthetic-sparing effects of dexmedetomidine for both thiopental [20] and isoflurane $[9,21]$. The relatively high intravenous dose of $2 \mu \mathrm{g} / \mathrm{kg}$ dexmedetomidine used here has not previously been 
investigated in a clinical anesthetic study. In our study we achieved a reduction in isoflurane requirements of $90 \%$, similar to that found by Aho et al. using a two-stage infusion technique in patients undergoing cholecystectomy [21], but it was not possible to avoid the use of isoflurane entirely, six patients requiring it at some stage. The decrease in anesthetic requirements does not lead to more rapid recovery of consciousness, since there was no difference in the recovery times measured.

A biphasic effect on hemodynamics is seen after intravenously dexmedetomidine [12]; an immediate increase in systemic arterial pressure (mediated by stimulation of peripheral $\alpha_{2}$-adrenoceptors [22]) followed by a longer lasting reduction in pressure caused by stimulation of $\alpha_{2}$-adrenoceptors in the central nervous system. The initial pressor effect is influenced by the rate of intravenous infusion. In healthy volunteers, a maximum increase in systolic blood pressure of $24 \pm 10 \mathrm{~mm} \mathrm{Hg}$ occurred 3 min after dexmedetomidine $2 \mu \mathrm{g} / \mathrm{kg}$ given over $2 \mathrm{~min}$ intravenously [12]. By infusing dexmedetomidine over 5 min we saw no increase in systolic blood pressure (Figure 8-1).

Increases in systolic blood pressure and heart rate have been shown to be causally related to peri-operative ischaemia in patients with cardiovascular disease [23]. Laryngoscopy and tracheal intubation as well as emergence from anesthesia and extubation are known to be particularly dangerous periods for patients with ischaemic heart disease. The almost complete suppression of the pressor response to intubation seen in the dexmedetomidine patients together with the lesser increase in heart rate led to a lower rate pressure product. Moreover, the decreased intra-operative heart rate variability despite a reduction in anesthetic requirement may also be beneficial in these patients.

The continuation of a stabilising effect on blood pressure and heart rate throughout the recovery period may be important in patients with coronary artery disease [24].

All patients were sedated (Ramsey 4-5) following dexmedetomidine $2 \mu \mathrm{g} / \mathrm{kg}$ intravenously. This sedation is associated with a diminished response to painful stimuli. Unfortunately, the partial respiratory obstruction seen in a number of patients means that patients cannot be left unattended following intravenous dexmedetomidine in this dose. Irregular breathing and short episodes of apnoea have been described immediately following an intravenous infusion of dexmedetomidine $2 \mu \mathrm{g} / \mathrm{kg}$ in human volunteers [11]. Clonidine has also been associated with an obstructive pattern of respiration, probably due to the sedative effect, and requiring treatment with oxygen [25].

It is known that $\alpha_{2}$-adrenergic agonists diminish salivary flow [26] and reduce galstrointestinal motility [27]. This study suggests that dexmedetomidine reduces postoperative nausea and vomiting, although larger studies will be necessary to confirm this.

$\alpha_{2}$-Adrenergic agonists have been shown to produce analgesia by action at the $\alpha_{2}$ adrenoceptor independent of opioid receptors [28] and their analgesic effects have 
been demonstrated in animals $[29,30]$ and in man [31]. The analgesia produced by $\alpha_{2}$ agonists is of interest as it has been shown not to be associated with respiratory depression $[32,33]$. In this study the reduction in postoperative analgesic requirements was not accompanied by a reduction in oxygen saturation.

Deximedetomidine, like other $\alpha_{2}$-adrenergic agonists, exerts sympatholytic effects by activating inhibitory $\alpha_{2}$-receptors both in the central nervous system and on peripheral sympathetic nerve endings, resulting in inhibition of noradrenaline release [34]. The inhibition of sympathetic transmitter release can be measured in humans as a decline in the concentration of noradrenaline in plasma. [35]. In our study, the plasma noradrenaline concentration was markedly decreased following dexmedetomidine while the increase in plasma noradrenaline and adrenaline concentrations seen in the placebo group after anesthesia and surgery were attenuated in the dexmedetomidine group. The prevention of the catecholamine reaction to stress by dexmedetomidine may be of clinical importance, since there is a clear relationship between surgical events known to produce intense sympathetic stimulation and perioperative myocardial infarction [23].

Our study has demonstrated that a single pre-induction intravenous dose of dexmedetomidine $2 \mu \mathrm{g} / \mathrm{kg}$ increased hemodynamic stability intra-operatively, during emergence and in the early postoperative period. However, there was a higher incidence of bradycardia and hypotension, as has been described following intramuscular dexmedetomidine [36,37]. In the future dexmedetomidine will probably be administered by continuous infusion in order to reduce the incidence of hemodynamic side-effects [21].

It is important to improve hemodynamic stability in the postoperative period when the highest incidence of cardiovascular complications occurs, especially in high-risk patients [24]. Future research should concentrate on increasing hemodynamic stability intra-operatively, on emergence and in the postoperative period by means of a continuous infusion of dexmedetomidine aiming to achieve a constant plasma concentration [38]. Preliminary results in small patient groups suggest that a plasma dexmedetomidine concentration of $4.5 \mathrm{ng} / \mathrm{mL}$ results in a low incidence of tachycardia in the postoperative period in patients undergoing vascular surgery [39]. Larger studies in high-risk cardiovascular patients will be required to confirm these findings.

\section{Acknowledgments}

We thank the Post Anesthesia Care Unit and anesthesia nursing staff of the University Hospital of Maastricht for their assistance. We thank Dr. M Scheinin of the University of Turku, Finland, for performing the catecholamine assays and Orion-Farmos Pharmaceuticals for supplying the dexmedetomidine. 


\section{References}

1. Aho M, Erkola O, Korttila K. Alpha2-adrenergic agonists in anesthesia. Current Opinion in Anaesthesiology 1992; 5: 481-7.

2. Maze M, Tranquilli W. Alpha-2 adrenoceptor agonists: defining the role in clinical anesthesia. Anesthesiology 1991; 74: 581-605.

3 Ghignone M, Calvillo O, Quintin $L$. Anesthesia and hypertension: the effect of clonidine on perioperative hemodynamics and isoflurane requirements. Anesthesiology 1987: 67: 3-10.

4 Ghignone M, Quintin L, Duke P, Kehler C, Calvillo O. Effects of clonidine on marcotic requirements and hemodynamic response during induction of fentanyl anesthesia and endotracheal intubation. Anesthesiology 1986; 64: 36-42.

5 Flacke J, Bloor B, Flacke W, et al. Reduced narcotic requirement by clonidine with improved hemodynamic and adrenergic stability in patients undergoing coronary bypass surgery. Anesthesiology 1987; 67: 11-9.

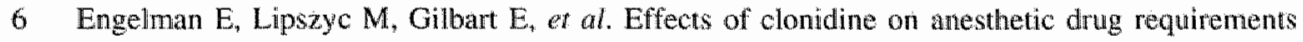
and hemodynamic response during aortic surgery. Anesthesiology 1989; 71: 178-87.

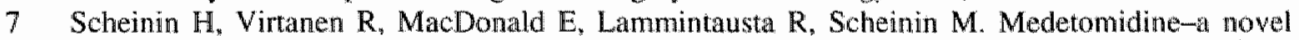
alpha 2-adrenoceptor agonist: a review of its pharmacodynamic effects. Prog Neuropsychopharmacol Biol Psychiatry 1989; 13: 635-51.

8 Kallio $A_{\text {. }}$ Scheinin $M$, Koulu M, et al. Effects of dexmedetomidine, a selective alpha 2adrenoceptor agonist, on hemodynamic control mechanisms. Clin Pharmacol Ther 1989; 46: $33-42$.

9 Aho M, Lehtinen AM, Erkola O, Kallio A. Kontila K. The effect of intravenously administered dexmedetomidine on perioperative hemodynamics and isoflurane requirements in patients undergoing abdominal hysterectomy. Anesthesiology 1991; 74: 997-1002.

10 Dyck JB, Maze M, Haack C, Vuorilehto L, Shafer SL. The pharmacokinetics and hemodynamic effects of intravenous and intramuscular dexmedetomidine hydrochloride in adult human volunteers. Anesthesiology 1993; 78: 813-20.

11 Belleville JP, Ward DS, Bloor BC, Maze M. Effects of intravenous dexmedetonidine in humans. I. Sedation, ventilation, and metabolic rate. Anesthesiology 1992; 77: 1125-33.

12 Bloor BC, Ward DS, Belleville JP, Maze M. Effects of intravenous dexmedetomidine in humans. II. Hemodynamic changes. Anesthesiology 1992; 77: 1134-42.

13 Scheinin M, Koulu M, Laurikainen E. Allonen H. Hypokalaemia and other non-bronchial effects of inhaled fenoterol and salbutamol: A placebo-controlled dose-response study in human. volunteers. Br J Cin Pharmacol 1987; 24: 645-53.

14 Ramsey MAE, Savage TM, Simpson BRJ, Goodwin R. Controlled sedation with alphaxalonealphadolone. Brirish Medical Journal 1974; 2 :656-9.

15 Doze VA, Chen BX. Maze M. Dexmedetomidine produces a hypnotic-anesthetic action in rats via activation of central alpha-2 adrenoceptors. Anesthesiology 1989; $71: 75-9$.

16 Correa-Sales C. Rabin BC, Maze M. A hypnotic response to dexmedetomidine, an alpha 2 agonist, is mediated in the locus coeruleus in rats [see comments]. Anesthesiology 1992: 76 : 948-52.

17 Doze VA, Chen BX. Tinklenberg JA, Segal IS, Maze M. Pertussis toxin and 4-aminopyridine differentially affect the hypnotic-anesthetic action of dexmedetomidine and pentobarbital. Anesthesiology $1990 ; 73: 304-7$.

18 Vickery RG, Sheridan BC, Segal $\llbracket S$, Maze M. Anesthetic and hemodynamic effects of the stereoisomers of medetomidine, an alpha 2 adrenergic agonist, in halothane-anesthetized dogs. Anesth Analg 1988; 67: 611-5.

19 Segal IS Vickery RG, Walton JK, Doze VA, Maze M. Dexmedetomidine diminishes halothane anesthetic requirements in rats through a postsynaptic alpha 2 adrenergic receptor. Anesthesiology 1988; 69: 818-23. 
20 Aautaa $R$, Kanto J, Scheinin $M$, Kallio $A$, Scheinin $H$. Dexmedetomidine, an alpha 2 adrenoceptor agonist, reduces anesthetic requirements for patients undergoing minor gynecologic surgery. Anewthesiology $1990 ; 73: 230-5$.

21 Aho M, Erkola $O$, Kallio A, Scheinin $H$, Kortila $K$. Dexmedetomidine infusion for maintenance of anesthesia in patients undergoing abdominal hysterectomy. Anesth Analg 1992; 75: 940-6.

22 Nichols A. Hieble J, Rulfolo R. The pharmacology of peripheral alpha 1- and alpha 2adrenoceptors. Rev Clin Basic Pharm 1988; 7: 129-205.

23 Slogoff S. Perioperatiwe ischemia. Sernin Anesth 1990; 9: 1-7.

24 Mangano D, Browner W, Hollenberg M, Li J, Tateo I. SPI Research Group. Peri-operative myocardial ischemia in patients undergoing non-cardiac surgery. I. Incidence and severity during the 4 day peri-operative period. J Am Coll Cardiol 1991; 7: 843-50.

25 Benhamou D, Veillette $Y$, Narchi P, Ecoffey C. Ventilatory effects of premedication with clonidine: Anesth Analg 1991; 73: 799-803.

26 Karthwyara $S$, Kallio $A$, Salonen $M$, Tuoninen $J$, Scheinin $M$. Rapid reversal of alpha 2 adrenoceptor agonist effects by atipamezole in human volunteers. Br J Chin Pharnacol 1991; 31: $160-5$.

27 Wikberg J. Localization of adrenergic receptors in guinea pig ileum and rabbit jejunum to cholinergic neurons and to smooth muscle cells. Acta Physiol Scand 1977; 99: 190-207.

28 Spaulding TC, Fielding $\mathrm{S}$, Venafro JJ, Lal H. Antinocioceptive activity of clonidine and its potentiation of morphine analgesia. Eur J Pharmacol 1979; 58: 19-25.

29 Puke MJ, Wiesenfeld HZ. The differential effects of morphine and the alpha 2-adrenoceptor agonists clonidine and dexmedetomidine on the prevention and treatment of experimental neuropathic pain. Anesth Analg 1993; 77: 104-9.

30 Ylisela $\mathbb{E}$, Vainio $O$. Effects of medetomidine on the experimental auricular pain in dogs. Acta Vet Scand Supp/ 1989; 85: 187-91.

3) Aho MS, Erkola OA. Scheinin H, Lehtinen AM, Korttila KT. Effect of intravenously administered dexmedetomidine on pain after laparoscopic tubal ligation. Anesth Analg 1991; 73: $112-8$.

32 Furst SR, Weinger MB. Dexmedetomidine, a selective alpha 2-agonist, does not potentiate the cardiorespiratory depression of alfentanil in the rat. Anesthesiology 1990; 72: 882-8.

33 Bailey PL, Sperry RJ, Johnson GK, et al. Respiratory effects of clonidine alone and combined with morphine, in humans. Anesthesiology $1991 ; 74: 43-8$.

34 Langer S. Presynaptic regulation of the release of catecholamines. Pharmacol Rev 1981; 32: $337-62$.

35 Scheinin M, Kallio A, Koulu M, Viikari J, Scheinin H. Sedative and cardiovascular effects of medetomidine, at novel selective alpha 2 -adrenoceptor agonist, in healthy volunteers. Br J Clin Phamacol 1987; 24: 443-51.

36 Levanen J, Makela ML, Scheinin H. Dexmedetomidine premedication attenuates ketanineinduced cardiostimulatory effects and postanesthetic delirim. Anesthesiology 1.995; 82: $1117-25$.

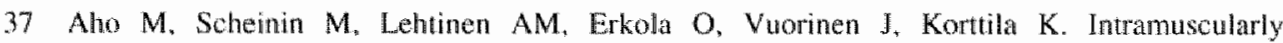
administered dexmedetomidine attenuates hemodynamic and stress hormone responses to gynecalogic laparoscopy. Anesh Analg 1992: 75:932-9.

38 Dyck JB, Maze M, Haack C. Azarnoff DL, Vuorilehto L. Shafer SL. Computer-controlled infusion of intravenous dexmedetomidine hydrochloride in adult human volunteers. Anesthesiology 1993; 78: 821-8.

39 Talke P. Li J, Jain U, et al. Effects of perioperative dexmedtetomidine infusion in patients undergoing vascular surgery. The Study of Perioperative Ischemia Research Group. Anesthesiology 1995; 82: 620-33. 


\section{CHAPTER 9}

\section{General discussion}

\subsection{Cardiovascular effects}

The first major aim of this study was to investigate whether the initial peripheral $\alpha_{2}$ adrenergic vasoconstriction could be a concern for the use of selective $\alpha_{2}$-adrenergic agonists like dexmedetomidine. The present studies demonstrated a reduction in heart rate and redistribution of coronary blood flow which are potentially beneficial to the more vulnerable endocardium, together with maintainance of the balance of myocardial oxygen supply and demand (Chapters 5 and 7). Reduction in cardiac output was associated with a relative sparing of nutrient perfusion of vital organs (Chapter 6).

\subsection{Vascular effects}

We found that the cardiovascular effects of dexmedetomidine and clonidine were qualitatively similar, but that dexmedetomidine is 3 to 10 times more potent than clonidine in causing bradycardic and vasoconstrictive effects. The systemic and coronary vasoconstriction, but not the bradycardic effect, are shorter lived after dexmedetomidine than after clonidine. At high doses (10 and $30 \mu \mathrm{g} / \mathrm{kg}$ ) clonidine has persistent negative inotropic and coronary vasoconstrictive effects not shown by high dose dexmedetomidine (Chapter 4).

The immediate reaction after a 2 -min intravenous dose of dexmedetomidine is an increase in arterial blood pressure and systemic vascular resistance and this is seen in dogs (Chapter 5), goats (Chapter 7) and in humans [1]. This blood pressure effect is dose-dependent and is significant with doses $\geq 0.3 \mu \mathrm{g} / \mathrm{kg}$ dexmedetomidine in the dog (Figure 4-1), $\geq 1 \mu \mathrm{gg} / \mathrm{kg}$ in the goat (Figure $7-1$ ), and $\geq 1 \mu \mathrm{g} / \mathrm{kg}$ in humans $[1]$. In the clinical study using $2 \mu \mathrm{g} / \mathrm{kg}$ (Chapter 8 ), we were able to avoid the pressor effect by giving dexmedetomidine over $5 \mathrm{~min}$. More recently, studies of $\alpha_{2}$-adrenergic agonists have used a continuous infusion to achieve a constant plasma level $\mid 2-4]$.

Our studies also suggest a species difference in the initial vasoconstrictor effect, dogs showing a more persistent increase in blood pressure and systemic vascular resistance 
than goats (Figures 4-1, 4-2,7-1 and 7-2). In this, goats appear to behave less like dogs and more like humans, where the most commonly seen response is a short-lived hypertension followed within minutes by a reduction in blood pressure [5].

\subsection{Coronary vasoconstriction}

We demonstrated that in dogs, especially under chloralose/urethane anesthesia, dexmedetomidine reduces myocardial blood flow. At doses $\leq 3 \mu \mathrm{g} / \mathrm{kg}$, this is primarily due to a decrease in myocardial oxygen requirement. Moderate adrenergic coronary vasoconstriction (as shown by increased oxygen extraction) occurs after $10 \mu \mathrm{g} / \mathrm{kg}$ (Table 5-3). Therefore, the oxygen sparing effect occurs at a lower dose than vasoconstriction. Increased oxygen extraction occurred with unchanged lactate production, an indication that aerobic metabolism was maintained.

In the goat we found unchanged oxygen extraction even after $10 \mu \mathrm{g} / \mathrm{kg}$ dexmedetomidine (Figure 7-3). Thus goats may possess a lesser tendency for coronary vasoconstriction at high doses of dexmedetomidine. Since the peripheral vasoconstrictor (pressor) effect was less in goats than in dogs and more like that in humans (see above), it is probable that $\alpha_{2}$-coronary vasoconstriction is not as severe in humans as in dogs. The latter species has most commonly been used for experiments demonstrating increased coronary vasoconstriction after $\alpha_{2}$-adrenergic agonists [6]. Indolfi has shown in humans with normal coronary arteries that coronary artery blood velocity decreased by a maximum of $28 \%$ after intracoronary administration of an $\alpha_{2}$ adrenergic agonist [7], supporting the idea that the coronary vasoconstrictive effect of $\alpha_{2}$-agonists is moderate in humans. It is important to note that at the dose of dexmedetomidine used till now in clinical anesthesia (between 0.5 and $2 \mu \mathrm{g} / \mathrm{kg}$ ), the myocardial energy sparing effect prevails even in dogs and vasoconstrictive effects are negligible.

The data from our study appear to contradict that from other studies in dogs. Flacke et al. suggested that the coronary vasoconstriction seen after dexmedetomidine might lead to myocardial ischemia [8]. However, the present studies showed that reduction in coronary blood flow and increase in coronary vascular resistance occur in parallel with reduced myocardial energy demands. Heusch's group showed that cardiac sympathetic nerve stimulation [9] and exercise [10], both combined with $\alpha_{1}$-receptor blockade, elicited myocardial ischemia in dogs with coronary artery stenosis. However, their experimental conditions are quite different from those in our studies, where the central sympatholytic effects of the $\alpha_{2}$-receptor agonist were more important.

Therefore, it may be concluded that with slow intravenous administration $\alpha_{2}$ adrenergic agonists have no untoward myocardial effects. Furthermore, the finding that dexmedetomidine increases endocardial/epicardial blood flow ratio in dogs with normal coronary perfusion indicates support for the perfusion of the myocardial layer which is most vulnerable to a reduction in coronary blood flow. 


\subsection{Contractility}

In both dogs and goats we observed an increase in left ventricular end-diastolic pressure (LVEDP) immediately following infusion of dexmedetomidine (Tables 4-1 and 7-1), but this was short-lived, LVEDP returning to baseline within $15 \mathrm{~min}$. $\mathrm{LVdP} / \mathrm{dt}_{\max }$ was decreased 15 minutes following dexmedetomidine in dogs (Table 5-1) and in goats (Table 7-1). This indicates a reduction in myocardial contractility, which may be due to one of a number of possible mechanisms; a direct effect on the myocardium is unlikely, since dexmedetomidine has no direct effect upon myocardial cells $[11,12]$; a reduction in contractility due to myocardial ischemia is unlikely as we have shown that myocardial oxygen balance is maintained in dogs and goats (Chapters 5 and 7) and complete reversal of the peripheral and coronary vatsoconstriction with ATP only partially reversed the reduction in cardiac function induced by dexmedetomidine [13]. Therefore, the reduction in myocardial contractility is most likely due to dexmedetomidine's sympatholytic effect as evidenced by reduced plasma catecholamines (Chapter 8). The reduction in myocardial contractility and heart rate contributes to the decrease in myocardial oxygen consumption.

\subsection{Nutrient organ flow}

In most species, except for the pig [14], $\alpha_{2}$-adrenergic agonists cause a reduction in cardiac output. We saw a reduction of $50 \%$ in cardiac output after dexmedetomidine $10 \mu \mathrm{g} / \mathrm{kg}$ in both dogs (Figure 4-2) and goats (Table 7-1), and after clonidine $30 \mu \mathrm{g} / \mathrm{kg}$ in dogs (Figure 4-2). In human volunteers, dexmedetomidine $2 \mu \mathrm{g} / \mathrm{kg}$ intravenously (the dose used in our clinical study) decreased cardiac output by $17 \%$ [1]. In the dog, dexmedetomidine decreased blood flow to most organs, but the largest decrease $(70 \%-90 \%)$ occurred in skin and in flow through arterio-venous anastomoses. Renal blood flow decreased by $30 \%$, cerebral blood flow only when baseline blood flow was high (in the fentanyl/halothane group), and left ventricular blood flow only in the chloralose/urethane group, where the largest decrease in hemodynamic variables occurred (Chapter 6). Overall adequacy of oxygen supply to the body was indicated by unchanged or even lowered arterial plasma lactate concentrations, even at the highest $(10 \mu \mathrm{g} / \mathrm{kg}$ ) dose of dexmedetomidine (Table 5-3). In our clinical study we observed a marked pallor of the skin of patients immediately following the intravenous infusion of dexmedetomidine, strongly suggesting that marked cutaneous vasoconstriction occurred in man, which has earlier been shown for clonidine [15]. The adequacy of myocardial oxygen supply has been discussed above. Other investigators have shown that cerebral metabolic rate for oxygen does not decrease when cerebral blood flow is reduced following dexmedetomidine in dogs receiving halothane or isoflurane anesthesia $[16,17]$. Therefore, the reduction in cardiac output caused by dexmedetomidine appears to be due to a combination of redistribution of flow away from less vital organs and decreased energy demands of the vital organs. 


\subsection{Advantages as an anesthetic adjuvant in humans}

The second main aim of this thesis was to investigate the effects of dexmedetomidine in humans. In a study of healthy patients undergoing minor surgery, we showed that a single intravenous dose of dexmedetomidine $2 \mu \mathrm{g} / \mathrm{kg}$ given prior to anesthesia resulted. in a reduction in anesthetic requirements and improved peri-operative hemodynamic stability accompanied by lower plasma catecholamine levels. Post-operatively, less analgesic and anti-emetic medication was required. Dexmedetomidine was well tolerated in this group of healthy patients.

\subsection{Anesthetic reduction}

Some of the initial studies of $\alpha_{2}$-adrenergic agonists in anesthesia were carried out using intravenous clonidine. These studies were performed mainly in Europe because in the U.S.A. only the use of an oral preparation was officially approved by the FDA. With the development of the more selective $\alpha_{2}$-adrenergic agonist dexmedetomidine, research into the anesthetic sparing and hemodynamic stabilizing effects of $\alpha_{2}$ adrenergic agonists continued using this agent administered by a variety of routes, oral, intramuscular and intravenous. Our study (Chapter 8) and that of Aho et al. have shown that dexmedetomidine is capable of greater reductions in anesthetic requirement of up to $90 \%$ [18] compared to $50 \%$ for clonidine $[19,20]$.

Both these dexmedetomidine studies can be criticised on the grounds that hemodynamic criteria (systolic blood pressure and heart rate) were used as a measure of anesthetic depth. There is always a danger of awareness when using anesthetic agents possessing hemodynamic effects in addition to their anesthetic properties. However, for clonidine it has been shown that similar reductions in anesthetic requirements occurred in experiments using either hemodynamic criteria [21] or continuous electro-encephalogram (EEG) $[19,20]$ as indicator of anesthetic depth. In our elinical study no patient in either group reported awareness when interviewed on the day following surgery (Chapter 8 ).

\subsection{Analgesia and anti-emetic effect}

Our patients showed a decrease in postoperative analgetic requirements. A reduction in postoperative pain after $\alpha_{2}$-adrenergic agonists has been demonstrated for dexmedetomidine [22] and for clonidine [23]. In addition, we demonstrated a reduction in the incidence of nausea and vomiting in the dexmedetomidine group. Clonidine has also been shown to be effective in reducing postoperative vomiting when given prophylactically in children [24]. Since nausea and vomiting is common in the post-operative period, and is responsible for much patient discomfort, such an antiemetic effect is of considerable benefit to patient comfort. 


\subsection{Sympatholysis}

Whereas the sympathetic nervous system is important in helping to mobilize energy stores and in optimizing the "fight and flight" response, such reactions are not useful in humans undergoing anesthesia and surgery. Increases in plasma levels of cortisol, glucagon and catecholamines and other hormones lead to major metabolic changes which are often harmful to the surgical patient and anesthesiologists have recently shown increased interest in modifying these responses [25]. Epidural anesthesia can markedly suppress the increase in many of the stress hormones during lower abdominal surgery [26], but are less effective for upper abdominal surgery [27]. Inhalational agents do not seem to suppress the response to stress [28,29]. Higli doses of opioids, e.g. $4 \mathrm{mg} / \mathrm{kg}$ of morphine and $100 \mu \mathrm{g} / \mathrm{kg}$ of fentanyl, markedly reduce the hormonal response to surgery $[30]$, but are only suitable for operations where postoperative ventilation is a standard part of the anesthetic technique $(e . g$. cardiac surgery).

$\alpha_{2}$-Adrenergic receptor stimulation seems to provide ideal control during anesthesia and surgery, limiting the increases seen in catecholamines and vasopressin [31]. cortisol 132], and other hormones. We have shown in our clinical study in healthy patients that a single pre-induction dose of dexmedetomidine depresses the normal post-operative increase in circulating catecholamines (Figure 8-2) and stabilises perioperative blood pressure and heart rate (Table 8-4). Stress may also be diminished post-operatively by improved amalgesia with a reduced tendency for nausea and vomiting.

\subsection{Effects on ischemic myocardium}

Since we completed the experiments described here, further studies have been performed in our laboratory specifically aimed at potentially beneficial effects of $\alpha_{2-}$ adrenergic agonists on the ischemic myocardium. It was found that the $\alpha_{2}$-adrenergic agonists dexmedetomidine and mivazerol improved endocardial/epicardial blood flow ratio and reduced myocardial oxygen deficit in dogs with coronary artery stenosis $[33,34]$. A large multi-center study has shown that a continuous intravenous infusion of mivazerol reduced the incidence of myocardial ischemia in the perioperative period in patients undergoing peripheral vascular surgery 127. Thus, in addition to the favourable effects of the newer selective $\alpha_{2}$-adrenergic agonists as anesthetic adjuvants demonstrated in patients with a normal cardiovascular system (this thesis), they may also prove to be beneficial in patients with coronary vascular diseatse. 


\subsection{Conclusions}

We can conclude the following:

1. Dexmedetomidine is 3-10 times more potent for hemodynamic effects than clonidine; slow infusion is more important for a selective $\alpha_{2}$-adrenergic agonist like dexmedetomidine than for clonidine (Chapter 4).

2. Dexmedetomidine reduces myocardial oxygen requirements in parallel with oxygen consumption (Chapter 5).

3. In dogs with normall coronary arteries, dexmedetomidine increases the endocardial/epicardial blood flow ratio (Chapter 5).

4. In goats, dexmedetomidine caused less vasoconstriction than in dogs while the systemic hemodynamic effects were similar to those seen in humans. This suggests that humans are less susceptible to $\alpha_{2}$-adrenergic coronary vasoconsitriction than dogs (Chapters 5 and 7 ).

5. Dexmedetomidine redistributes cardiac output, with preferentiall reduction in flow to the skin as well as through arterio-venous anastomoses, while flow to vital organs is relatively better preserved (Chapter 6 ).

6. Dexmedetomidine premedication in healthy patients causes sedation and a reduction in anesthetic requirements and improves hemodynamic stability while reducing analgesic and anti-emetic requirements post-operatively. Although hypotension and bradycardia occur more commonly after dexmedetomidine, no harmful effects were seen (Chapter 8).

\section{References}

1 Bloor BC, Ward DS, Belleville JP, Maze M. Effects of intravenous dexmedetomidine in humans. II. Hemodynamic changes. Anesthesiology 1992; 77: 1134-42.

2 McSpi- Europe RG. Perioperative sympatholysis: Beneficial effects of the $\alpha_{2}$-adrenergic agonist miwazerol on hemodynamic stability and myocardial ischemia. Anesthesiology 1997; 86: 346-63.

3 Talke P. Li J, Jain U, et al. Effects of perioperative dexmedetomidine infusion in patients undergoing vascular surgery. The Study of Perioperative Ischemia Research Group. Anesthesiology 1995; 82: 620-33.

4 Jalonen I, Hynynen M. Kuitunen A, et al. Dexmedetomidine as an anesthetic adjunct in coronary artery bypass grafting. Anesthesiology $1997 ; 86: 33 \rrbracket-45$.

5 Bloor BC. Schmeling WT. Cardiovascular effects of $\alpha_{2}$-adrenoceptors. Anaesth Pharm Rev 1993; II: $246-62$.

6 Heusch G. Alpha-adrenergic mechanisms in myocardial ischemia. Circulation 1990; 81: 1-13.

7 Indolfï C, Piscioni F, Villari B, et at. Role of alphay-adrenoceptors in normal and atherosclerotic human coronary circulation. Circulation 1992; 86: 1116-24.

8 Flacke WE, Flacke JW, Bloor BC, Mclntee DF, Sagan M. Effects of dexmedetomidine on systemic and coronary hemodynamics in the anesthetized dog. J Cardiothorac Vasc Anesth 1993; 7: $41-9$

9 Heusch $\mathrm{G}_{\text {, Deussen }} \mathrm{A}$. The effects of cardiac sympathetic nerve stimulation on the perfusion of stenotic coronary arteries in the dog. Circ Res $1983 ; 53: 8-15$. 
10 Seitelberger R, Guth B, Heusch G, Lee J, Katayama K, Ross JJ. Intracoronary alpha 2-adrencrgic receptor blockade attemuates ischemia in conscious dogs during exercise. Circ Res 1988; 62: $436-42$.

11 Flacke WE. Flacke JW, Blow KD, McIntee DF, Bloor BC. Etfecr of dexmedetomidine, an alpha 2-adrenergic agonist, in the isolated heart. J Cardiowhorac Vasc Anesh 1992; 6: 418-23.

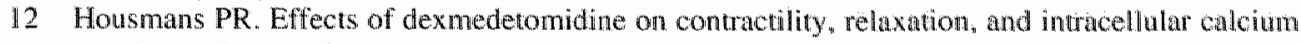
transients of isolated ventricular myocardium. Anesthesiology 1990; 73: 919-22.

13 Roekaerts P. Alpharadrenergic receptor agonists in myocardial ischemia. University of Maastricht, 1997.

14 Jalonen J, Halkola L, Kuttila $\mathrm{K}$, et al. Effects of dexmedetomidine on coronary hemodynamics and myocardial oxygen balance. $J$ Cardiothorac Vasc Anesth 1995; 9; 519-24.

15 Coffman JD, Cohen RA. Role of alpha-adrenoceptor subtypes mediating sympathetic vasoconstriction in human digits. Eur J Clin lowest 1988; 18: 309-13.

16 Zornow MH, Fleischer JE. Scheller MS, Nakakimura K, Drummond JC. Dexmedetomidine, an alpha 2-adrenergic agonist, decreases cerebral blood flow in the isoflurane-anesthetized dog. Anesth Analg 1990; 70: 624-30.

17 Karlsson BR. Forsman M, Roald OK. Heier MS, Steen PA. Effect of dexmedetomidine a selective and potent alpha 2-agonist, on cerebral blood flow and oxygen consumption during halothane anesthesia in dogs [see comments]. Anesth Analg 1990; 71: 125-9.

18 Aho M, Erkola O, Kallio A, Scheinin H, Korttila K. Dexmedetomidine infusion for maintenance of anesthesia in patients undergoing abdominal hysterectomy. Anesth Analg 1992; 75: 940-6.

19 Ghignone $M$, Calvillo $\mathrm{O}$, Quintin L. Anesthesia and hypertension: the effect of clonidine on perioperative hemodynamics and isoflurane requirements. Anesthesiology 1987; 67:3-10.

20 Ghignone $M$, Quintin L. Duke P, Kehler C. Calwillo O. Effects of clonidine on narcotic requirements and hemodynamic response during induction of fentanyl anesthesia and endotracheal intubation. Anesthesiology 1986; 64: 36-42.

2) Flacke J, Bloor B, Flacke $W$, et al. Reduced narcotic requirement by clonidine with improved hemodynamic and adrenergic stability in patients undergoing coronary bypass surgery. Anesthestology 1987; 67: $11-9$.

22 Aho MS, Erkola OA, Scheinin H, Lehtinen AM, Kortaila KT. Effect of intravenously administered dexmedetomidine on pain after laparoscopic tubal ligation. Anesth Analg 1991; 73: $112-8$.

23 Mikawa K, Nishina K, Maekawa N, Obara $H$. Oral clonidine premedication reduces postoperative pain in children. Anesth Anatg 1996:82:225-30.

24 Mikawa K. Nishina $\mathrm{K}$, Maekawa $\mathrm{N}$, Asano M, Obara $\mathrm{H}$. Oral clonidine premedication reduces vomiting in children after strabismus surgery. Can d Andesh 1995; 42: 977-81.

25 Biebuyck J. The metabolic response to stress: An owerview and update. Anesthesiology 1990: 73 : $308-27$.

26 Engquist A, Fog Moller F, Christiansen C. Thode J. Anderson T, Nistrup-Madsen S. Influence of epidural analgesia on the catecholamine and cyclic AMP response to surgery. Acta Anesthol Scand 1980; 24: 17-21.

27 Asoh T. Tsuji H, Shirasaka C. Takeuchi Y. Effect of epidural analgesia on metabolic response to major abdominal surgery. Acta Anesthesiol Scand 1983; 27: 233-7.

28 Oyama $T$. Taniguchi $K$, Ishihara $H$, et al. Effects of enflurane anaesthesia and surgery on endocrine function in man. Br J Arcesth 1979; $51: 14 \|-8$.

29 Lacoumenta $S$, Paterson J, Burrin J, Causon $R$. Brown M, Hall G. Effects of owo differing halothane concentrations on the metabolic and endocrine responses to surgery. Br J Araesth 1986; $58: 844-50$.

30 Walsh E. Paterson J, O'Riorden J, Hall G. Effect of high dose fenanyl anaesthesia on the metabolic and endocrine response to cardiac surgery. Br J Andesth $1981 ; 53: 1155-65$. 
31 Quntin $L$, Roudot $F$, Roux $C_{\text {e }}$ er al Effect of clonidine on the circulation and vasoactive homones after awrtic surgery. Br I Anaesh 1991:66: 108-15.

32 Kallio $A$, Koulu $M$, Scheinin $H$, Vuikari d, Scheinin $M$. Acute effects of medetomidine, a selective alpha 2-adrenoceptor agonist, on anterior pituitary hormone and cortisol secretion in man. Acta Endocinol Copenh 1988, 119: 11-5.

33 Roekaests PM, Prinzen FW, Willigers HM, De LS. The effects of alpha 2-adrenergic stimulation with mivazerol on myocardial blood flow and function during cononary artery stenosis in anesthetized dogs. Anesth Analy 1996; 82: 702-11.

34 Roekaerts $\mathrm{P}$, Primzen $\mathrm{F}$, de Lange $\mathrm{S}$. Beneficial effects of dexmedetomidine on ischaemic myocardium in anaesthetized dogs. Br J Anaesth 1996; 77: 427-9. 


\section{Summary}

Improvements in anesthesia and perioperative patient care have allowed patients to undergo surgery with a minimum of discomfort and complications. Although anesthesia can, during less stressful surgery, protect patients against the harmful effects of noxious stimuli, it is not always possible to provide optimal protection throughout all types of surgery without recourse to invasive techniques (like epidural analgesia) or large doses of anesthetic agents which may cause hemodynamic instability and prolong recovery. In order to provide stable anesthesia without recourse to high doses of anesthetics, other pharmacological agents which are not themselves anesthetics may be applied as anesthetic adjuvants. Recently, $\alpha_{2}$-adrenergic receptor agonists have been advocated as such anesthetic adjuvants since they provide sedation, and reduce anxiety, nausea and pain (Chapter 3 ). These effects are more apparent following the recently developed agents with a greater selectivity for the $\alpha_{2}$-receptors than the "classic" $\alpha_{2}$-adrenergic agonist clonidine.

The anesthetic effects of dexmedetomidine and other $\alpha_{2}$-adrenergic agonists are due to stimulation of $\alpha_{2}$-adrenergic receptors in centers such as the locus coeruleus in the brain.

$\alpha_{2}$-Receptors are found also in the walls of blood vessels where they cause vasoconstriction. Some animal studies raised concerns about the potential vasoconstrictive effects of $\alpha_{2}$-agonists on $\alpha_{2}$-receptors in peripheral and coronary arteries. Therefore, before exploring the use of dexmedetomidine in clinical anesthesia, we investigated its cardiovascular effects on the normal cardiovascular system in detail. Since more invasive studies on coronary blood flow and oxygen requirements of the heart can be performed in experimental animals, we studied the effects of dexmedetomidine on the cardiovascular system in anesthetized dogs and goats. Finally, we carried out a clinical study in humans to better evaluate the benefits and cardiovascular effects of a preanesthetic dose of dexmedetomidine on healthy patients undergoing minor surgery.

In Chapter 4, we compared the hemodynamic effects of clonidine with dexmedetomidine in dogs using a range of doses. Both agents caused a transient increase in arterial blood pressure and systemic vascular resistance and a longer-lasting decrease in heart rate and cardiac output, but dexmedetomidine was 3-10 times more potent than clonidine for the pressor effects. Within $15 \mathrm{~min}$ the pressor effect recovered considerably for doses $\leq 3 \mu \mathrm{g} / \mathrm{kg}$ of dexmedetomidine and clonidine. High dose 
clonidine $(10$ and $30 \mu \mathrm{g} / \mathrm{kg}$ ) induced prolonged coronary wasoconstriction and reduction in myocardial contractility. These results indicate that slow intravenous administration is more important for the potent and selective $\alpha_{2}$-adrenergic agonist dexmedetomidine than for clonidine, and that dexmedetomidine lacks the ontoward $\alpha_{1}$ adrenergic effects, occurring at high doses of clonidine.

In Chapters 5 and 6 we describe the hemodynamic effects of dexmedetomidine in dogs anesthetized with either chloralose/urethane or fentanyl/halothane. The rapid, transient increase in blood pressure, systemic vascular resistance and left ventricular enddiastolic pressure, and longer-lasting reduction in cardiac output and heart rate was similar in both dog groups. Fifteen minutes later the effect was dependent on anesthetic technique. In chloralose/urethane anesthetized dogs, blood pressure decreased, whereas in fentanyl/halothane anesthetized dogs blood pressure remained elevated. Thus, anesthetic technique influences the cardiovascular effects of dexmedetomidine in dogs. Since sympathetic tone is known to be greater in dogs anesthetized with chloralose/urethane it is likely that the stabilizing effect of dexmedetomidine on heart rate and blood pressure is greater in situations where the initial sympathetic tone is high.

This stabilizing effect in chloralose/urethane anesthetized dogs was also accompanied by decreased myocardial energy requirement, while myocardial oxygen supply decreased in parallel with demand. Myocardial oxygen extraction increased only after the highest dose of $10 \mu \mathrm{g} / \mathrm{kg}$ dexmedetomidine, but even at this dose the heart continued to extract lactate, indicating the absence of global myocardial ischemia. These data indicate that for dexmedetomidine $\leq 3 \mu \mathrm{g} / \mathrm{kg}$, the reduction in myocardial blood flow is functional; by metabolic vasoregulation rather than adrenergic vasoconstriction. Although total myocardial blood flow is reduced after dexmedetomidine, endocardial/epicardial blood flow ratio is increased, safeguarding the layer most vulnerable to ischemia (Chapter 5).

In Chapter 6, a study of the distribution of cardiac output using radioactive microspheres, we show that the reduction in cardiac output following dexmedetomidine is not the result of an equal reduction of blood flow to all organs. Blood flow to the vital organs (heart, brain, kidneys) is spared and greater reductions occur in the blood flow to less vital organs such as the skin, intestine and spleen and through arterio-venous anastomoses.

After studying the cardiovascular effects of dexmedetomidine in the dog, a species prone to $\alpha$-adrenergic vasoconstriction, we investigated the goat. We found that the pressor effect of dexmedetomidine in goats was shorter than in dogs, and therefore more like that seen in humans. In goats, dexmedetomidine $10 \mu \mathrm{g} / \mathrm{kg}$ reduced myocardial oxygen extraction (Chapter 7 ), whereas in the dog this dose increased it (Chapter 5). This indicates that the balance of myocardial oxygen supply and demand is maintained up to a higher dose of dexmedetomidine in goats. If similarity in pressor 
response is indicative of the coronary vasoconstrictive effect in goats and humans, humans may be less prone to cononary vasoconstriction following dexmedetomidine.

In the clinical study during minor surgery in healthy adults, we showed that a single intravenous dose of $2 \mu \mathrm{g} / \mathrm{kg}$ dexmedetomidine given over 5 min prior to anesthetic induction reduced the requirements for isoflurane by $90 \%$, for thiopental by $14 \%$ and for fentanyl by $33 \%$. Plasma catecholamine levels were lower in the dexmedetomidine patients, indicating a sympatholytic effect. Dexmedetomidine reduced the hemodynamic response to intubation and emergence from anesthesia and increased hemodynamic stability in the peri-operative period. Also, there was a reduced requirement for post-operative analgetic and anti-emetic medication. While the incidence of peri-operative bradycardia was high in these patients, this did not produce adverse hemodynamic effects (Chapter 8).

Therefore, we have demonstrated that the hemodynamic effects of dexmedetomidine do not represent a contraindication to its use during anesthesia. On the contrary whe central sympatholysis together with the many other beneficial effects demonstrated in this thesis suggest that dexmedetomidine is a an excellent agent for use as an anesthetic adjuvant in healthy patients. 


\section{Samenvatting}

Verbeteringen in anesthesie en peri-operatieve patiëntenzorg hebben ertoe geleid dat patiënten kunnen worden geopereerd met een minimum aan ongemak en complicaties. In de anesthesiologie wordt ook steeds meer ingezien dat anesthesie patiënten kan beschermen tegen de nadelige effecten van schadelijke prikkels. Het lukt echter niet altijd om optimale bescherming aan te bieden zonder gebruik te maken van invasieve technieken, zoals epidurale anesthesie, of hogere doseringen van anesthesiemiddelen. Dit laatste kan leiden tot hemodynamische instabiliteit en verlengde nawerking. Daarom worden ook wel farmaca, die zelf geen anesthetische werking hebben, gebruikt als anesthetisch adjuvans. $\alpha_{2}$-Adrenerge agonisten worden steeds meer genoemd als mogelijk anesthetisch adjuvans omdat zij kalmering veroorzaken, alsmede vermindering van angst, misselijkheid en pijn. (hoofdstuk 3). Deze effecten treden met name op bij recent ontwikkelde stoffen die een hogere selectiviteit hebben voor de $\alpha_{2}$-receptoren dan de "klassieke" $\alpha_{2}$-agonist clonidine.

De bovengenoemde effecten van dexmedetomidine en andere $\alpha_{2}$-adrenerge agonisten worden veroorzaakt door stimulatie van $\alpha_{2}$-adrenerge receptoren die zich bevinden in hersen centra zoals de locus coeruleus.

$\alpha_{2}$-Receptoren bevinden zich echter ook in de vaatwand, waar ze vaatvernauwing veroorzaken. Sommige dierexperimentele studies suggereerden dat $\alpha_{2}$-adrenerge stimulatie nadelige vasoconstrictie kan veroorzaken van perifere en coronaire bloedvaten. Daarom hebben wij, voordat wij dexmedetomidine wensten te gebruiken tijdens klinische anesthesie, eerst zijn hemodynamische effecten op het normale cardiovasculaire systeem onderzocht. Om meer gedetaillerde studies aangaande coronaire doorbloeding en zuurstofgebruik van het hart te kunnen verrichten hebben wij de effecten van dexmedetomidine op het cardiovasculaire systeem van honden en geiten onderzocht. Daarna hebben wij een klinische studie verricht met als doel cardiovasculaire effecten en de voordelen van dexmedetomidine te evalueren in gezonde patiënten die een kleine operatie moesten ondergaan.

In hoofdstuk 4 vergeleken wij de hemodynamische effecten van clonidine met dexmedetomidine in honden bij een aantal doseringen. Beide stoffen veroorzaakten een tijdelijke verhoging van de arteriële bloeddruk en de systemische valatweerstand, een langer durende verlaging van het hartminutvolume en de hartfrekwentie. Dexmedetomidine bleek 3 tot 10 keer potenter te zijn dan clonidine voor wat betreft de 
pressor effecten. Binnen 15 min na toediening verminderde het pressor effect van dexmedetomidine en clonidine aanzienlijk bij doseringen $\leq 3 \mu \mathrm{g} / \mathrm{kg}$. Hoge doses clonidine (10 en $30 \mu \mathrm{g} / \mathrm{kg}$ ) veroorzaakten langdurige coronaire vasoconstrictie alsmede verminderde myocardiale contractiliteit. Deze resultaten geven aan dat langzame intraveneuze toediening belangrijker is bij de potente en selectieve $\alpha_{2}$ adrenerge agonist dexmedetomidine dan bij clonidine, en dat dexmedetomidine de $\alpha_{1}$ adrenerge effecten mist die na hoge dosis clonidine voorkomen.

In hoofdstukken 5 en 6 beschrijven wij de hemodynamische effecten van dexmedetomidine in honden onder chloralose/urethane of fentanyl/halothane anesthesie. De snelle, tijdelijk verhoogde bloeddruk, systemische vasculaire weerstand en linker kamer eind-diastolische druk, alsmede de langer durende vermindering in hartminuutvolume en hart- frekwentie waren vergelijkbaar in de twee groepen. Vijftien minuten daarna was het effect afhankelijk van de gebruikte anesthesietechniek. In de chloralose/urethane groep daalde de bloeddruk, terwijl in de fentanyl/halothane groep de bloeddruk hoog bleef. De vorm van anesthesie beinvloedt dus de cardiovasculaire effecten van dexmedetomidine in honden. Omdat bekend is dat de sympathische tonus hoger is onder chloralose/urethane anesthesie, is het waarschijnlijk dat de stabiliserende effecten van dexmedetomidine op hartfrekwentie en bloeddruk groter zijn in situaties met een hogere initiële sympathische tonus.

Dit stabilizerende effect van dexmedetomidine in de chloralose/urethane groep ging gepaard met verminderde energie behoefte van het myocard, terwij] de myocardiale zuurstof toevoer verminderde parallel aan de zuurstofbehoefte. Myocardiale zuurstofextractie ging alleen omhoog na de hoogste dosis van $10 \mu \mathrm{g} / \mathrm{kg}$ dexmedetomidine, maar zelfs na deze dosering extraheerde het hart lactaat, wijzend op de afwezigheid van globale myocardiale ischemie. Deze gegevens wijzen erop, dat voor dexmedetomidine $\leq 3 \mu \mathrm{g} / \mathrm{kg}$ de vermindering van myocardiale doorbloeding functioneel is, dat wil zeggen veroorzaakt is door verminderde metabole behoeften en niet door adrenerge vasoconstrictie. Bovendien was de afname van de myocardiale doorbloeding het sterkst in de buitenste lagen van de linker kamerwand en minder uitgesproken in de binnenste lagen, de lagen die het meest gevoelig zijn voor ischemie (hoofdstuk 5).

Ook het effect van dexmedetomidine op de doorbloeding van veel andere organen is onderzocht (hoofdstuk 6). Het bleek dat de reductie in hartminutvolume door dexmedetomidine gepaard gaat met sterke verschillen in de veranderingen van doorbloeding van de verschillende organen. Doorbloeding van de vitale organen (hart, hersenen, nieren) wordt gespaard, terwijl de doorbloeding van minder vitale organen, zoals huid, ingewanden en milt, sterk afnemen, evenals de doorstroming van arterioveneuze anastomoses.

Nadat wij de cardiovasculaire effecten van dexmedetomidine bestudeerd hadden in honden, een species waarvan bekend is dat het erg gevoelig is voor $\alpha$-adrenerge vasoconstrictie, onderzochten wij de geit. Het pressor effect van dexmedetomidine in 
geiten bleek kortdurender dan in de hond, en daarmee meer vergelijkbaar was met dat in de mens. In geiten verminderde $10 \mu \mathrm{g} / \mathrm{kg}$ dexmedetomidine de myocardiale zuurstofextractie (hoofdstuk 7), terwijl in de hond deze dosis de extractie deed toenemen (hoofdstuk 5). Dit betekent dat de balans van zuurstofaanvoer en -behoefde in het myocard stabiell blijft, zelfs na een hogere dosis dexmedetomidine in geiten. Als de pressor respons (in de perifere circulatie) een maat is voor het effect in de coronair circulatie, is het mogelijk dat $\alpha_{2}$ adrenerge coronaire vasoconstrictie in mensen minder uitgesproken is dan in honden.

Hiema is een klinische studie verricht bij gezonde volwassenen tijdens kleine chirurgische ingrepen. Dexmedetomidine werd toegediend in een dosering van $2 \mu \mathrm{g} / \mathrm{kg}$ intraveneus gedurende 5 min voor de inleiding van anesthesie. Deze dosis verminderde de benodigde hoeveelheid isofluraan met $90 \%$, de benodigde hoeveelheid thiopental met $14 \%$ en die van fentanyl met $33 \%$. Plasma catecholamine spiegels waren lager in patiènten met dexmedetomidine, wat wijst op verlaging van de sympatholytische activiteit. Dexmedetomidine verminderde de hemodynamisch reacties op intubatie en ontwaken uit de anesthesie, en verhoogde de hemodynamische stabiliteit in de perioperatieve periode. Verder was er een verminderde behoefte aan post-operatieve analgetica en anti-emetica. Ondanks het feit dat peri-operatieve bradycardie vaker voorkwam in de dexmedetomidine patiënten, heeft dit niet geleid tot ongewenste hemodynamische effecten (hoofdstuk 8).

Wij concluderen uit de bovenstaande gegevens dat de hemodynamische effecten van dexmedetomidine geen contraindicatie vormen voor zijn gebruik tijdens anesthesie. De centrale sympatholyse tesamen met de reductie van anesthetica, analgetica en antiemetica geven aan dat dexmedetomidine een veel belovend middel is voor gebruik als anesthetisch adjuvans bij gezonde patienten. 


\section{Acknowledgments}

This thesis was made possible through the help and support of many people. My sincere thanks go to all those who, either directly or indirectly, have contributed to its completion.

The initial impetus for this work grew out of a sabbatical visit to our department by Professors Joan and Werner Flacke of the University of California, Los Angeles. I thank them not only for starting me on the path of $\alpha_{2}$-adrenergic receptor agonists, but for their continuing support and friendship.

My thanks are due to my promotor, Professor Simon de Lange, who realised the potential of $\alpha_{2}$-agonists in anesthesia, and whose advice and critical comments have helped to shape this thesis.

I am indebted to Frits Prinzen for his expert guidance in the laboratory, his help and criticism in preparing publications, but especially for his unbounded enthusiasm.

If thank the members of the evaluation committee for their contructive comments.

I am deeply grateful to my colleague, Paul Roekaerts, for his advice and help.

I wish to thank Ruud Kruger. Theo Van Der Nagel and Jo Habets for their technical assistance during the experimental studies.

The clinical study would not have been possible without the expert assistance of the anesthetic and recovery room nursing staff of the University Hospital of Maastricht.

The "Finnish Connection" was very important for the completion of this thesis. I am grateful to Orion Corporation, Farmos, Turku, Finland for their support. I am especially thankful to Risto Lammintausta, Antero Kallio and Riku Aantaa for their help and advice, and to Professor Mika Scheinin, Department of Pharmacology, University of Turku, Finland for the determination of the plasma concentrations of catecholamines in the clinical study.

None of this would have been possible without the time given me by my colleagues in the department of Anesthesiology at the University Hospital of Maastricht. 
Thanks are also due to the secretarial staff of the Anesthetic Department for all their help.

I owe a debt of gratitude to my late father and to my mother for their loving support throughout my career.

I thank my son, James, for making the lay-out for this book, and my daughter, Elizabeth, for the cover ullustration.

To my dear wife, Gordana: your belief in me has been so strong that I could not but succeed. To you, I dedicate this book. 


\title{
Curriculum Vitae
}

\author{
C.J. Lawrence, M.A., B.M., B.Ch., F.R.C.A.
}

Christopher John Lawrence was born on July 22nd, 1945 in Tunbridge Wells, England. He attended Chichester High School for Boys from 1956 to 1964, where he was School Captain from September 1963 till May 1964.

In 1964 he was awarded an Open Exhibition to study medicine at Christ Church Oxford, obtaining an honours degree in human physiology in June 1967. He continued his medical studies in Oxford and at University College Hospital Medical School in London. In January/February 1970 he visited University College Hospital, Ibadan, Nigeria on an exchange scholarship. He graduated in medicine at the University of Oxford in December, 1970, with the degrees of Batchelor of Medicine and Batchelor of Surgery (B.M., B.Ch., Oxon).

After appointments in surgery, internal medicine, obstetrics and Accident and Emergency, he commenced his training in anaesthesia at St. Richard's Hospital, Chichester in 1973, continuing in 1974 at the Shackelton Department of Anaesthesia at Southampton University Hospital (Professor John Norman), and becoming Fellow of the Faculty of Anaesthetists of the Royal College of Surgeons of England in February, 1977.

In 1978 he joined the anaesthetic staff of the St. Annadal Hospital in Maastricht and since 1983 has been a staff member of the Department of Anaesthesia at the University Hospital of Maastricht. 


\section{List of Publications}

Flacke JW, Lawrence CJ, Flacke WE, Prinzen FW, Scheinin M, de Lange S. Hemodynamic effects of dexmedetomidine in anesthetized dogs and their antagonism by ATP. J Cardiothorac Anesth 1990; 4 (6, Suppl 3): 97.

Flacke WE, Flacke JW, Lawrence CJ, Prinnzen FW, Floor E, de Lange S. Effects of dexmedetomidine and ATP on the coronary circulation and cardiac function in anesthetized dogs. J Cardiothorac Anesthesia 1990; 4 (6, Suppl 3): 47.

Lawrence CJ, Lestrade A, de Lange S. Isradlipine, a calcium antagonist, in the control of hypertension following coronary artery-bypass surgery. Am $J$ Hypertension 1991; 4 (2, Suppl 2): 207S-209S.

Prinzen FW, Lawrence CJ, de Lange S. Endo/epicardial blood flow ratio after infusion of specific alpha2-agonist dexmedetomidine in dogs. Pfluegers Archive 1991; 419: R9.

Prinzen FW, van Leeuwen CJ, de Lange S. Effect of the specific $\alpha_{2}$-adrenergic agonist dexmedetomidine on myocardial oxygen supply and demand in anesthetized dogs. Pftuegers Arch 1991; 420 (Suppl 1): R115.

Lawrence CJ, Prinzen FW, de Lange S. Effects of clonidine on the coronary circulation and cardiac function of anaesthetized dogs. I Cardiothorac Vasc Anesth 1992; 6 (1. Suppl 1): 75.

Lawrence CJ, Prinzen FW, de Lange S. Effects of the specific $\alpha_{2}$-adrenergic agonist dexmedetomidine on the systemic and coronary circulation of the anaesthetized goat. I Cardiothorac Vasc Anesth 1992; 6 (1 Suppl 1): 76.

Lawrence CJ, Lestrade A, Chan E, de Lange S. Comparative study of isradipine and sodium nitroprusside in the control of hypertension in patients following coronary artery-bypass surgery. Acta Anaesthesiol Scand 1993; 37 (Suppl 99): 48-52.

Lawrence CJ, Prinzen FW, de Lange S. Comparison of the haemodynamic effects of the $\alpha_{2}$-agonists clonidine and dexmedetomidine in the anaesthetized dog. $J$ Cardiothorac Vasc Anesth 1994; 8 (3, Suppl 2): 32.

Lawrence CI, Prinzen FW, van Leeuwen CJ, de Lange S. The haemodynamic effects of the $\alpha_{2}$-agonist dexmedetomidine depend on the animal species and the anaesthetic agent used. J Cardiothorac Vasc Anesth 1994;8 (3, Suppl 2): 83. 
Prinzen FW, Lawrence CJ, van Leeuwen CJ, de Lange S. Effect of the $\alpha_{2}$-adrenergic agonist dexmedetomidine on nutrient blood flow to various organs in anaesthetized dogs. J Cardiothorac Vasc Anesth 1994; 8 (3, Suppl 2): 82.

Prinzen FW, Lawrence CJ, van Leevwen CJ, de Lange S. Effect of the $\alpha_{2}$-adrenergic agonist dexmedetomidine on myocardial oxygen supply and demand in anaesthetized dogs. J Cardiothorac Vasc Anesth 1994; 8 (3, Suppl 2): 84.

Lawrence CJ, Prinzen FW, de Lange S. Effect of dexmedetomidine on the balance of myocardial energy requirement and oxygen supply and demand. Anesth Analg 1996; 82: 544-50.

Lawrence CJ, Prinzen FW, de Lange S. The effect of the $\alpha_{2}$-agonist dexmedetomidine on nutrient organ blood flow. Anesth Analg 1996; 83: 1160-5.

Roekaerts PMHJ, Lawrence CJ, Prinzen FW, de Lange S. Alleviation of the peripheral hemodynamic effects of dexmedetomidine by the calium channel blocker isradipine. Acta Anaesthesiol Scand 1997; 41: 364-70.

Lawrence CJ, Prinzen FW, de Lange S. Hemodynamic and coronary vascular effects of dexmedetomidine in the anesthetized goat. Acta Ancesthesiol Scand 1997; 41: $830-6$.

Lawrence $\mathrm{CJ}$, de Lange $\mathrm{S}$. Effects of a single pre-operative dexmedetomidine dose on isoflurane requirements and peri-operative haemodynamic stability. Anaesthesia 1997; 52: 736-44. 